\title{
Investigation of the red algal parasites Rhodophyllis parasitica sp. nov. and Pterocladiophila hemisphaerica from New Zealand
}

\author{
BY \\ MAREN PREUSS
}

\begin{abstract}
A thesis
submitted to the Victoria University of Wellington in fulfillment of the requirements for the degree of Master of Science
\end{abstract}

Victoria University of Wellington

(2014) 


\section{Acknowledgement}

I would like to express my gratitude to my supervisor Dr. Joe Zuccarello. I'm really thankful for the opportunity to work in his lab and I really appreciate it to have such a great supervisor, who worked hard to help and support me during my Master thesis. I would also like to thank our work group for their support. A special thanks to Narongrit Muangmai and Christian Boedecker for their efforts towards my Master thesis. I would also like to thank Dr. Wendy Nelson and Dr. Roberta D'Archino at NIWA for the possibility to use the microtome in their facilities and all their help from answering questions to teaching me how to use the microtome. Another thanks goes to Jenn Dalen from Te Papa for the possibility to use their facility to examine their herbarium collections. Another thanks goes to Dr. Peter Northcote, who provided me kindly with some Rhodophyllis samples. I would also like to thank Prof. Olivier DeClerck for providing his SSU alignment. I also would like to thank Ken Ryan for the use of his camera. All of you were an essential part of making my Master's thesis possible and I really appreciate everything that you have done.

I would also like to thank the DAAD (German Academic Exchange Service) for my scholarship, which was an incredible financial help for my studies and life in New Zealand. Another thanks goes to the Botanical Society in Wellington for a travel grant, which helped to collected samples from the east coast of the North Island for my thesis.

A special thanks to my family. I probably would have never had the opportunity to do my Master in New Zealand without the help and support of my boyfriend, aunt \& uncle, grandmother and my boyfriend's family. I would also like to thank all my friends who always helped me to focus on my goals. At the end I would like to express my gratitude to my boyfriend Sven Sondhauß, who supported and helped me in every moment of my Master's thesis. 


\section{Abstract}

Red algal parasites are common within red algae and most parasites are closely related to their host. Red algal parasites can switch hosts and their development is unique. Red algal parasites are poorly known in New Zealand. There are only four parasites described in New Zealand and those are based on morphological characteristics. This thesis focuses on the two red algal parasites Rhodophyllis parasitica sp. nov. and Pterocladiophila hemisphaerica from New Zealand. First, development and phylogeny and distribution of an undescribed red algal parasite growing on Rhodophyllis membranacea was investigated. Microscopy, molecular markers (ITS2, cox 1, cox2-3 spacer) and phylogenetic analysis, and herbarium sampling were used to address these questions. The parasite, described as Rhodophyllis parasitica sp. nov. shows a close relationship of all genomes to Rhodophyllis membranacea, which suggests that the parasite evolved from its hosts. The parasite is widely distributed throughout New Zealand. The second parasite, Pterocladiophila hemisphaerica was grouped taxonomically, based on morphology, in the order Gracilariales and parasitizes Pterocladia lucida in the order Gelidiales. Molecular marker were used to reveal the relationship of Pterocladiophila hemisphaerica to its host: if the parasite is grouped in the Gracilariales or the Gelidiales; if host switches might have occurred; and if atp 8 is present in the parasite. Nuclear DNA (SSU rRNA, LSU rRNA), mitochondrial ( $c o x 1)$ and plastid regions ( $r b c \mathrm{~L}-r b c \mathrm{~S}$ spacer) from the parasite were sequenced and phylogenetic analysis performed. New primer were designed to amplify atp 8 and genetic analysis performed. Pterocladiophila hemisphaerica evolved in the Florideophytes but neither in the Gracilariales or Gelidiales and the parasite possibly switched hosts at least two times, which was shown by three different origins of chloroplast, mitochondria and nuclear DNA. Atp8 in the parasite is present but probably a pseudogene. Rhodophyllis parasitica sp. nov. is the first described red algal parasite species in New Zealand in 55 years and Pterocladiophila hemisphaerica is the first parasite with organelles and nuclei with different histories of origin. 

Abbreviations
$1^{\circ} \mathrm{PC}$
$2^{\circ} \mathrm{PC}$
Atp8
BSA
Cox 1
CTAB
DAPI
DNA
dNTP
EDTA
ITS
$\mathrm{H}$
$\mathrm{HCl}$
LSU
ML
$\mathrm{N}$
$\mathrm{NaCl}$
ORF
$\mathrm{P}$
PCR
PVP
RFLP
Primary pit connections
Secondary pit connections
Adenosintriphosphate 8
Bovine serum albumin
Cytochrome c oxidase subunit I
Cetyltrimethylammoniumbromide
4',6-Diamidin-2-phenylindole
Deoxyribonucleic acid
Deoxyribonucleosidetriphosphate
Ethylenediaminetetraacetic acid
rRNA internal transcribed spacers
Host
Hydrogen chloride
Large subunit ribosomal RNA
Maximum likelihood
Number of samples / sequences
Sodium chloride
Open reading frame
Parasite
Polymerase chain reaction
Polyvinylpyrrolidone
Restriction fragment length polymorphism 
RNA

rRNA

$\mathrm{RuBisCO}$

Sdhc

SSU

$S p$.

Spp.

TE

Te Papa

Tris
Ribonucleic acid

ribosomal RNA

Ribulose-1,5-bisphospate carboxylase/oxygenase

Succinate dehydrogenase complex subunit C

Small subunit ribosomal RNA

Species (singular)

Species (plural)

Tris-EDTA solution / buffer

Museum of New Zealand Te Papa Tongarewa

Tris(hydroxymethyl)-aminomethane 
The two chapters of my Master's thesis are written as independent papers and therefore there may be some repetitions in the introduction and discussion. 


\section{Table of contents}

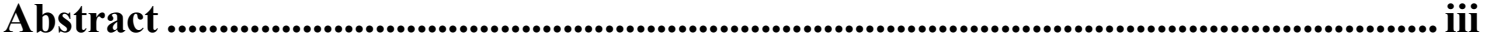

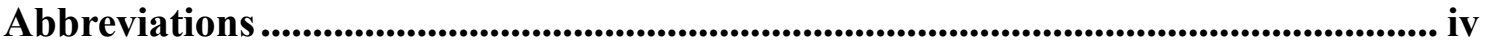

Table of contents ................................................................................................................ vii

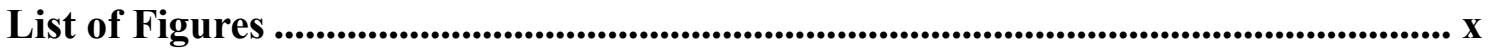

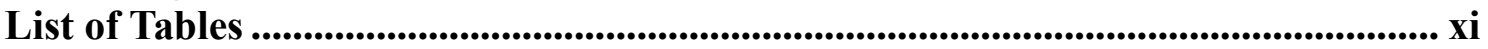

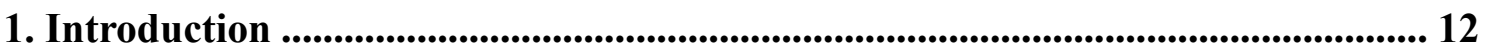

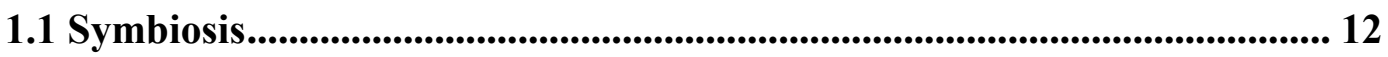

1.2 Origin of Rhodophytes.............................................................................................. 14

1.3 Rhodophyta (red algae) ............................................................................................. 14

1.4 Taxonomy and Systematic of Rhodophyta........................................................ 15

1.5 Importance of red algae.......................................................................................... 16

1.6 Primary and Secondary pit connections ...................................................... 17

1.7 Red algal parasites ........................................................................................ 17

1.8 Development of red algal parasites......................................................................... 18

1.9 Molecular markers ........................................................................................................ 20

1.10 Red algal parasites in New Zealand ................................................................. 21

1.11 General goals .............................................................................................................. 22

Chapter 2: Rhodophyllis parasitica (Cystocloniaceae, Gigartinales, Rhodophyta) sp. nov. from New Zealand ....................................................................................................... 23

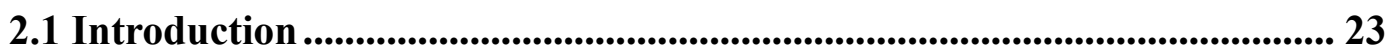

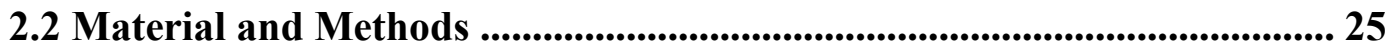

2.2.1 Sampling............................................................................................................... 25

2.2.2 Fixation \& Embedding............................................................................. 25

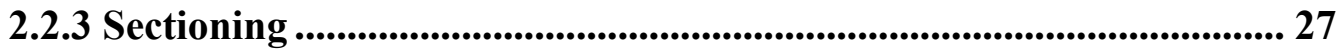

2.2.4 Staining and microscopy ........................................................................ 27

2.2.5 Permanent slides............................................................................................ 28

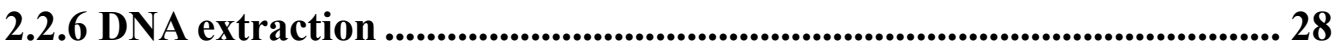

2.2.7 Primers ...................................................................................................................... 30

2.2.8 Primer Design for specific ITS2 primer ............................................... 31 
2.2.10 Alignment and haplotype networks .....................................................32

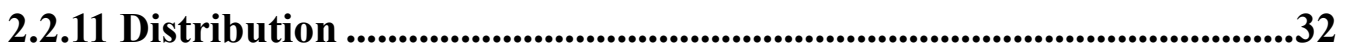

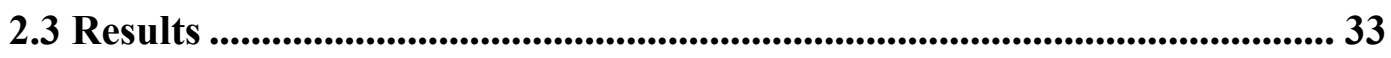

2.3.1 Morphology of the Rhodophyllis parasite.............................................33

2.3.2. Comparison of morphological characters between host

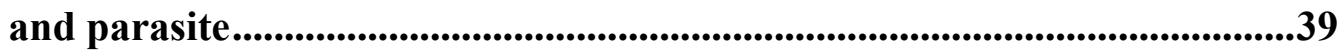

2.3.3 Phylogeny of Rhodophyllis parasite ......................................................40

2.3.4 Distribution of the Rhodophyllis parasite...................................................42

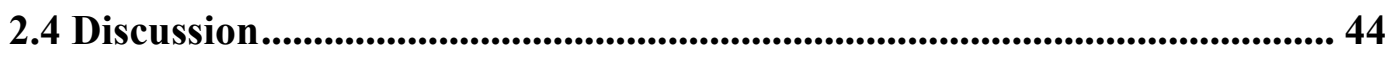

2.4.1 Morphology of Rhodophyllis parasite ...............................................44

2.4.2 Phylogeny of Rhodophyllis parasite ..........................................................48

2.4.3 Distribution of Rhodophyllis parasite .........................................................49

2.4.4 Placement and naming of the Rhodophyllis parasite..............................50

2.4.5 Future work on Rhodophyllis parasitica ...........................................53

Chapter 3: A phylogenetic study of the red algal parasite Pterocladiophila hemisphaerica ............................................................................................................ 55

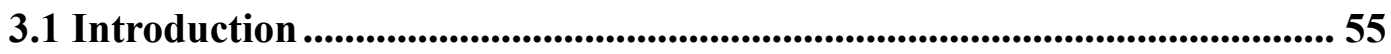

3.2 Material and Methods ...................................................................................58

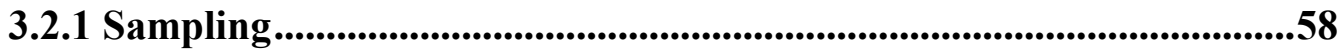

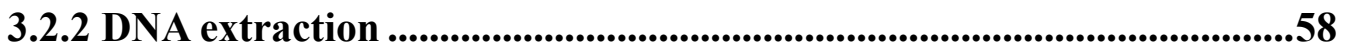

3.2.3 Primer.......................................................................................................59

3.2.4 Primer Design ........................................................................................60

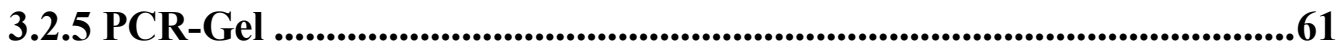

3.2.6 Assembly and alignment .........................................................................661

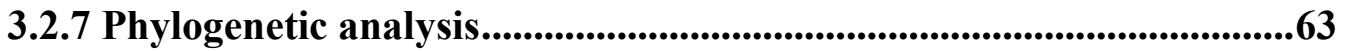

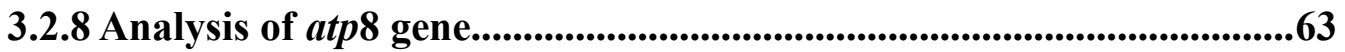

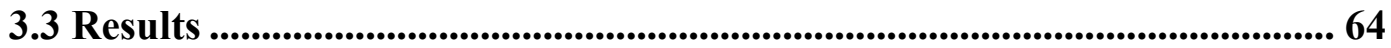

3.3.1 Chloroplast .............................................................................................64 64

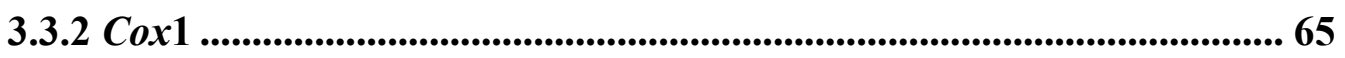




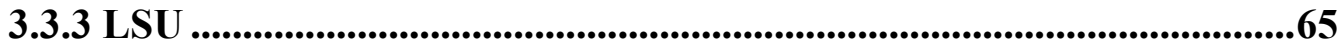

3.3.4 SSU

3.3.5 Atp8

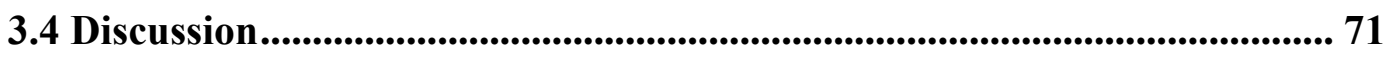

3.4.1 Chloroplast .......................................................................................................72

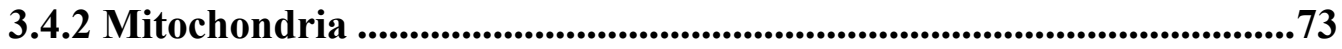

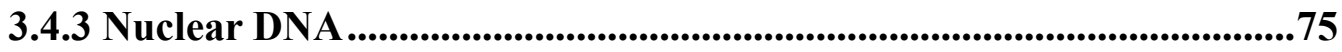

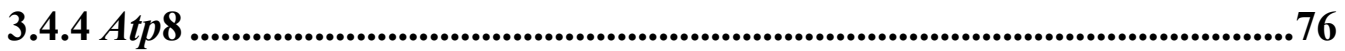

3.4.5 Phylogenetic studies in red algal parasites ................................................78

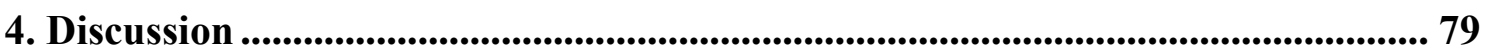

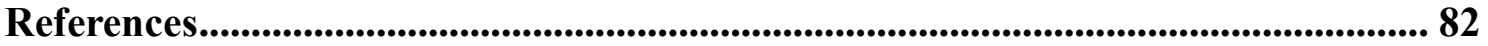

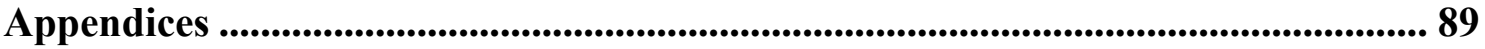

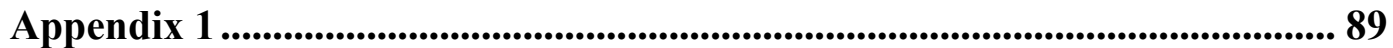

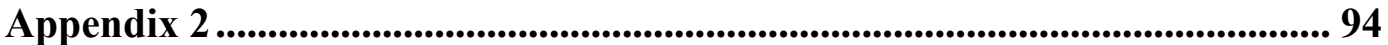

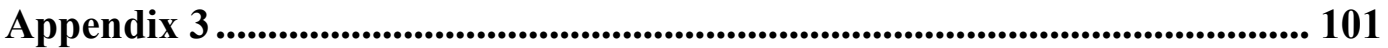

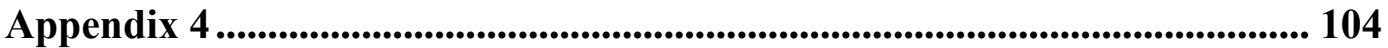

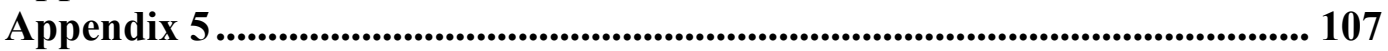

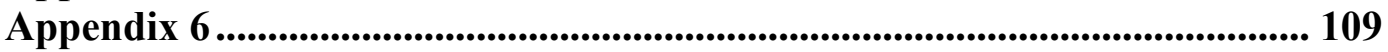

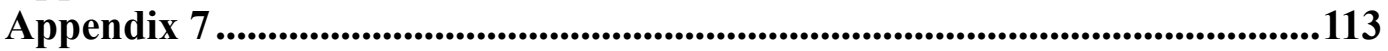

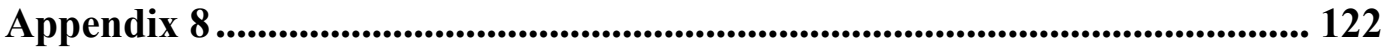

Appendix 9 .......................................................................................................................... 130

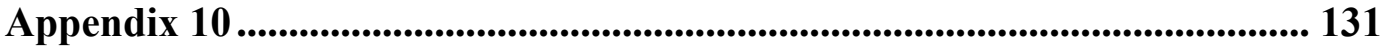




\section{List of Figures}

\section{Chapter 2}

Figure 2.1A-D. Rhodophyllis parasite thallus on its host

Rhodophyllis membranacea .............................................. 34

Figure 2.2A-F. Vegetative structure of Rhodophyllis parasite....................36

Figure 2.3A-F. Reproductive structure of the Rhodophyllis parasite.............38

Figure 2.4A-B. Networks of Rhodophyllis membranacea and its parasite sequence data................................................41

\section{Chapter 3}

Figure 3.1. RuBisCo spacer of two host-parasite combinations of

Pterocladia lucida and Pterocladiophila

hemisphaerica...

Figure 3.2. ML reconstruction of relationships based on cox 1 sequences

of Pterocladiophila hemisphaerica....

Figure 3.3. ML reconstruction of relationships based on LSU sequences

of Pterocladiophila hemisphaerica ...

Figure 3.4. ML reconstruction of relationships based on SSU sequences

of Pterocladiophila

hemisphaerica

Figure 3.5. Amino acid sequence of the atp 8 sequence of Pterocladiophila hemisphaerica.

Figure 3.6. Atp 8 amino acid alignment of Gelidum vagum, Pterocladia

lucida and Pterocladiophila

hemisphaerica 


\section{List of Tables}

\section{Chapter 2}

Table 2.1. Collected samples of Rhodophyllis membranacea and its parasites from different locations in New Zealand .26

Table 2.2. List of all samples of Rhodophyllis membranacea and its parasite used in molecular analysis .28

Table 2.3. Comparison of vegetative and reproductive structures between Rhodophyllis membranacea and its parasite. .40

Table 2.4. Te Papa vouchers of Rhodophyllis membranacea with red algal parasites on them.

\section{Chapter 3}

Table 3.1. All samples of Pterocladia lucida and its parasite Pterocladiophila hemisphaerica used in molecular analysis...

Table 3.2. List of top ten species from Blast search hits of the Pterocladiophila hemisphaerica LSU sequences....

Table 3.3. Pairwise distance between the atp 8 amino acid sequences of Gelidium vagum, Pterocladia lucida and Pterocladiophila hemisphaerica.....71

\section{Appendix 4}

Table A4.1. Downloaded sequences from Genbank used in all phylogenetic analysis 104 


\section{Introduction}

\subsection{Symbiosis}

Symbiosis is the general term for an intimate living together of dissimilar organisms, first described by De Bary in 1879 (Bary, 1879). Symbiosis can be characterize by, in most cases, the smaller organism being the symbiont and the larger organism the host (Graham \& Wilcox, 1999). Ectosymbiosis defines a symbiont growing outside of the host or within close proximity, and endosymbiosis defines a symbiont that is living inside of the host (Smith \& Douglas, 1987). Furthermore, endosymbionts can occur within host cells (intracellular) (Ball et al., 2011) or in the host tissue between host cells (extracellular) (Smith \& Douglas, 1987). An obligate symbiont depends on the host to survive and reproduce and a facultative symbiont can survive and reproduce without a host (Koga et al., 2003). Another feature is host specificity, which describes the degree of relationship between host and symbiont and therefore symbionts with high specificity occur only on one, or a few, species (Smith \& Douglas, 1987).

Symbiosis can also be divided into commensalism, mutualism and parasitism. Commensalism describes an interaction where one organism neither harms nor benefits another organism (Paracer \& Ahmadjian, 2000). It is presumed that some species of beetles, mites and moths gain shelter without harming or benefiting a sloth (Gilmore et al., 2001). Mutualism describes an interaction where both organisms benefit (Paracer \& Ahmadjian, 2000). There are several mutualistic relationships between bacteria and protozoa in human intestine and animal guts (Bäckhed et al., 2005). Another example are prokaryotic (bacteria) and eukaryotic (flagellates, yeasts) organism in termite guts 
(Konig et al., 2013). The enzymes to degrade lignocellulose are essential for the survival of termites and are provided by those symbionts, which depend on the termite gut as habit (Ohkuma, 2008). Parasitism defines a relationship where one organism benefit from another organism by harming it (Paracer \& Ahmadjian, 2000). There are several parasitic human pathogens which can cause infectious diseases (Daszak et al., 2000). Plasmodium sp., which causes malaria, is transferred by mosquitoes into blood (Gueirard et al., 2010) which causes nonspecific detrimental symptoms (Trampuz et al., 2003).

Many symbioses can't be strictly classified as commensalism, mutualism or parasitism (Roossinck, 2011) as the interaction can change over time due to changes in environment (Neuhauser \& Fargione, 2004). Normally, mycorrhizae are a mutualistic relationship between a host plant and a symbiotic fungus, but the interaction can change to a parasitic interaction with increasing soil fertility (Neuhauser \& Fargione, 2004).

The understanding of the diversity of parasites can help science in two main areas. First, parasites can be used to study host specificity and diversification rate and evolutionary processes because parasitism arisen several times independently. Second, they are also important for the understanding of medical and veterinary science as many parasites have switched their animal host to a human host (Poulin \& Morand, 2000). One example is the switch of the parasite Plasmodium falciparum Welch, 1897 from an avian host to a human host (Waters et al., 1991). The understanding of the host-switches in parasites could help to control infectious diseases and virulence (Poulin \& Morand, 2000). Symbiotic relationships also help organisms adapt in environment with poor nutrition (Muscatine \& Porter, 1977). For example, in corals the symbiotic 
dinoflagellates share their photosynthetic products with the host (Porter, 1976), which is essential because the surrounding waters have a low productivity (Stoddart, 1969).

Finally, mycorrhizae are an important symbiosis in plants, which could have been around since plants colonized land (Pirozynski \& Malloch, 1975). The arbuscular mycorrhizae formed between a plant and a fungi within the phylum Glomeromycota occurring in $70-90 \%$ of all land plants (Schussler et al., 2001). The fungi supplies the host with water and nutrients and receives up to $20 \%$ of the plant-fixed carbon (Parniske, 2008).

\subsection{Origin of Rhodophytes}

The superkingdom Archaeplastida contain three lineages: Rhodophyta (red algae), Chloroplastida (green algae, land plants) and Glaucophyta (Adl et al., 2005). All three lineages share a plastid which is derived from a primary endosymbiosis approximately 1.5 billion years ago (Yoon et al., 2004). The plastid originated from an up-take of a cyanobacterium by a heterotrophic eukaryote (Reyes-Prieto et al., 2007). This plastid gave the eukaryote the ability to convert light into chemical energy through photosynthesis (Ball et al., 2011).

\subsection{Rhodophyta (red algae)}

Rhodophyta contains over 6400 described species (http://www.algaebase.org/) among 834 genera (Schneider \& Wynne, 2007). Most Rhodophyta are marine but a few live in freshwater (Graham \& Wilcox, 1999). Rhodophyta lack centrioles and flagella in all life history stages (Yoon et al., 2006). The chloroplasts are surrounded by a double membrane and contain unstacked thylakoids (van den Hoek et al., 1996). Rhodophyta 
have chlorophyll $a$ but no chlorophyll $b$ or $c$ (Yoon et al., 2006). The unstacked thylakoids contain allophycocyanin, phycocyanin and phycoerythrin (van den Hoek et al., 1996) in phycobilisomes. Phycoerythrin is a red pigment and gives the algae their characteristic colour (Graham \& Wilcox, 1999). Floridean starch is the most important carbohydrate storage product and it is found in the cytoplasm (van den Hoek et al., 1996). Sexual reproduction is in most cases isomorphic or heteromorphic diplohaplontic and gametic fusion is always oogamous (van den Hoek et al., 1996).

Most Rhodophyta have three life-history stages: a carposporophyte, a tetrasporophyte and a gametophyte. The tetrasporophyte produces haploid tetraspores through meiosis, which can become female or male gametophytes or are bisexual. The male gametophyte produces spermatia (sperm) and the female gametophyte produces a carpogonium (egg). The released spermatia can fertilize the carpogonium, which stays attached to the female gametophyte (Flint et al., 1992). The fertilized carpogonium (zygote) is diploid and grows into a diploid carposporophyte on the female. The carposporophyte produces non-flagellate carpospores, which are released and develop into the free-living tetrasporophyte (Saunders \& Hommersand, 2004).

\subsection{Taxonomy and Systematic of Rhodophyta}

Traditionally, Rhodophyta were divided into two classes; the Florideophyceae and the Bangiophyceae (Saunders \& Hommersand, 2004). The Bangiophyceae contained the six orders: Bangiales, Cyanidiales, Compsopogonales, Erythropeltidales, Porphyridiales and Rhodochaetales (Freshwater et al., 1994). Recent studies showed that a monophyletic group is formed by the Florideophyceae and Bangiales (Oliveira \& Bhattacharya, 2000, Yoon et al., 2002). 
Yoon (2006) used a multigene analysis to show that the order Rhodophyta consists of seven lineages, which he decided to make into seven classes:

Cyanidiophyceae, Bangiophyceae, Compsopogonophyceae, Florideophyceae, Porphyridiophyceae, Rhodellophyceae and Stylonematophyceae. Cyanidiophyceae is the sister class to the six remaining lineages (Yoon et al., 2010).

\subsection{Importance of red algae}

Red algae are abundant and species-rich (Graham \& Wilcox, 1999). Their distribution is from the Arctic to Antarctic and includes temperate as well as tropical locations (van den Hoek et al., 1996). Red algae are also associated with mangroves and coral reef (Graham \& Wilcox, 1999). Coralline, calcareous, red algae consolidate and stabilize the reef structure because they form a hard crust over the soft limestone. This is especially important for areas with high wave exposure (Björk et al., 1995). Red algae are also commercially important. In 2010 the total value of farmed algae were estimated at 5.7 billion US\$ and the most common farmed red algae were Kappaphycus spp., Gracilaria spp. and Pyropia spp. (FAO, 2012). The use of red algae differ and especially in Asian countries red algae are used for direct human consumption like nori, made from Pyropia sp. (Wikfors \& Ohno, 2001).

The extracellular matrices of red algae contain sulfated polysaccharides, which are extracted and purified as agar, agarose and carrageenan. Red algal are the only source of these polysaccharides because the compounds are too complex for industrial synthesis. These carbohydrates are used for cell-culture media, nucleic acid research and food processing (Graham \& Wilcox, 1999). Another important area is medical research and treatment, where red algae are used for the development of new drugs, 
antiviral substances and antifouling compounds (Smit, 2004).

\subsection{Primary and Secondary pit connections}

Primary pit connections are formed during cytokinesis between daughter cells (Graham \& Wilcox, 1999) and are the result of incomplete septum formation (Blouin \& Lane, 2012).

The incomplete septum formation leaves a pore in the central region with a tubular membrane around it. Then a homogenously granular protein mass is deposited around the tubular membrane, which afterwards disappears. This leaves a structural linkage between adjacent mature cells (Graham \& Wilcox, 1999).

The primary pit $\left(1^{\circ} \mathrm{PC}\right)$ connection is not really an intercellular connection comparable to the plasmodesmata in certain brown algae, green algae and land plants (Pueschel, 1990). Secondary pit connections $\left(2^{\circ} \mathrm{PC}\right)$ are formed by cell fusion between non-daughter cells (Blouin \& Lane, 2012). $2^{\circ} \mathrm{PC}$ are produced when cells divide unequally (Graham \& Wilcox, 1999). The smaller cell, called a conjunctor cell, fuses with a non-daughter cell (Wetherbee \& Quirk, 1982). The nucleus, and other cell organelles, of the conjunctor cell moves into the non-daughter cell (Goff \& Coleman, 1985).

\subsection{Red algal parasites}

In the beginning of the $19^{\text {th }}$ century red algal parasites were first closer studied and red algae were characterized as parasites by Setchell (1918). The characteristics used to describe red algal parasites were: 1) the penetration of the parasite beyond the superficial cells of the host; 2) reduction of the thallus, and 3) the loss of color (Setchell, 
1918). Over 100 species in 50 genera are described as red algal parasites within the Florideophyceae but there are no descriptions of red algal parasites within the Bangiophyceae (Goff, 1982). The majority occur in the orders of Gigartinales, Cryptonemiales and Ceramiales (Evans et al., 1978). Red algal parasites can be divided into "adelphoparasites" and "alloparasites" (Goff, 1982). "Adelphoparasites" are taxonomically within in the same family or tribe as their host based on morphological characters (Blouin \& Lane, 2012) and include $80 \%$ of all described red algal parasites and are closely related to their host (Goff, 1982). "Adelphoparasites" have a high hostspecificity and in most cases they can only infect one species (Goff, 1982). One example is the red algal parasite Dawsoniocolax bostrychiae (Joly et YamaguishiTomita) Joly et Yamaguishi-Tomita, which can only grow on Bostrychia radicans (Montagne) Montagne (Zuccarello \& West, 1994a). "Alloparasites" include the remaining $20 \%$ of described red algal parasites and are not closely related to their host (Goff, 1982). “Alloparasites” grow on distantly related hosts (Blouin \& Lane, 2012).

The classification in "adelphoparasite" and "alloparasite" are still used even though it is suggest that there is a correlation between newly evolved parasites, which are closely related to their hosts and parasites not closely related to their hosts. It was proposed that all red algal parasites evolved from their host, which evolved further over time until they switched their host (Zuccarello et al., 2004).

\subsection{Development of red algal parasites}

All described red algal parasites where found to have secondary pit connections to their hosts (Evans et al., 1978) and these are essential for early development of the red algal parasites (Zuccarello et al., 2004). Secondary pit connections are used to 
connect the parasite cells with the host cells (Goff \& Zuccarello, 1994) and are used to transfer parasite nuclei and other organelles (mitochondria, plastids) into a host cell (Goff \& Coleman, 1995).

The development of red algal parasites is unique. Parasite spores attach to their host and germinate (Goff \& Coleman, 1984). This produces an infection peg and the infection peg fuses with an epidermal or subepidermal cell of the host (Goff \& Zuccarello, 1994). The nucleus of the parasite enters the cytoplasm of the host cell via a $2^{\text {nd }}$ PC and either divides (Goff \& Coleman, 1984) or not in the host cytoplasm (Goff \& Zuccarello, 1994). The replicated nuclei can be transferred by secondary pit connections to other host cells and spread the infection (Goff \& Coleman, 1995).

Host cellular transformation describes the process of the red algal parasites controlling their hosts (Goff \& Coleman, 1987). There are two examples of host cellular transformation (Graham \& Wilcox, 1999). The red algal parasite Leachiella pacifica Kugrens transfers its nucleus through secondary pit connection into the host cells of Polysiphonia confusa Hollenberg (Goff \& Zuccarello, 1994). The parasite nuclei does not divide or undergo DNA synthesis in the host cytoplasm (Goff \& Coleman, 1984). The red algal parasite Gracilariophila oryzoides Setchell et Wilson transfers its nucleus into the host cells of Gracilariopsis andersonii (Grunow) Dawson (Goff \& Zuccarello, 1994). The nuclei of the parasite undergoes DNA synthesis and divides in the host cells (Goff \& Coleman, 1984). Those host cells, which received parasite DNA through $2^{\circ} \mathrm{PC}$ are called infected cells and they undergo unusual developmental processes (Goff \& Coleman, 1995). The infection can spread either by $2^{\circ} \mathrm{PC}$ or by dissolution of primary pit connection of the host until a tumor like mass of "transformed" host cells is formed, 
which contain parasite DNA (Goff \& Coleman, 1995).

\subsection{Molecular markers}

Molecular markers are used in phylogenetic studies to study interspecific or intraspecific evolutionary relationships (Chenuil, 2006). There are five molecular markers used in the phylogeny of red algal parasites: cytochrome c oxidase subunit I (coxI) (Kurihara et al., 2010), rRNA internal transcribed spacers (ITS) (Goff et al., 1997), restriction fragment length polymorphism (RFLP) (Goff \& Coleman, 1995), small subunit ribosomal RNA (SSU) (Kurihara et al., 2010, Zuccarello et al., 2004) and large subunit ribosomal RNA (LSU) (Kurihara et al., 2010).

Gene sequences of the plastid between host and parasite are identical and suggest that the parasite retained the chloroplast of its host (Goff \& Coleman, 1995). Mitochondrial and nuclear DNA are different between host and parasite which suggest that the parasite keeps its own mitochondria and nucleus (Goff et al., 1996). RFLP pattern of mitochondrial and nuclear DNA showed those differences between host and parasite (Goff \& Coleman, 1995). Mitochondrial and nuclear DNA can show the phylogenetic relationship between host and parasite (Goff \& Coleman, 1995).

Goff (1997) used ITS to show that the red algal parasite species within the genus Asterocolax are polyphyletic. Furthermore ITS is a useful molecular marker to study the evolutionary relationships between host and parasite because it is highly variable and it is assumed that the nucleus of the parasite doesn't recombine with the host during cellular transformations (Goff et al., 1997).

SSU was used to study the relationship between host and parasite within the Choreocolacaceae and showed that all studied red algal parasite are in the same family 
as their hosts (Zuccarello et al., 2004).

Kurihara (2010) used cox1, SSU and LSU to show that Benzaitenia yenoshimensis Yendo and Janczewskia morimotoi Tokida are closely related to their hosts. In addition, Ululania stellata Apt et Schlech and Janczewskia hawaiiana Apt are not sister-species to their host and probably arose from other species (Kurihara et al., 2010).

Hancock (2010) sequenced the mitochondrial genome of the red algal parasite Gracilariophila oryzoides and its host Gracilariopsis andersonii, both genomes are similar to each other but atp 8 and $s d h c$ are pseudogenes in the parasite (Hancock et al., 2010).

\subsection{Red algal parasites in New Zealand}

There are four described red algal parasites in New Zealand. The alloparasite Pterocladiophila hemisphaerica Fan et Papenfuss was found on the North Island in Wellington and on the South Island in Kaikoura parasitizing Pterocladia lucida (R. Brown ex Turner) J. Agardh. The adelphoparasite Gloiocolax novae-zelandiae Sparling grows on Gloioderma saccatum (J. Agardh) Kylin. The adelphoparasite Gonimophyllum buffhamii Batters grows on Hymenena semicostata (J. Agardh) Kylin. The adelphoparasite Microcolax botryocarpa (Hooker et Harvey) Schmitz et Falkenberg was found on the North Island in Auckland grown on Streblocladia glomerulata (Montagne) Papenfuss (Goff, 1982). 


\subsection{General goals}

Red algal parasite diversity is poorly known. There are still many undescribed species and most studies focused only on a few morphological characteristics. As mentioned previously only a few red algal parasites are taxonomically described in New Zealand. There are no current studies on the phylogeny of red algal parasites in New Zealand, plus the development of red algal parasitism had only been described in a few species. Further studies are important to get a better understanding and insight into the evolution of parasites. Therefore this study focuses on one undescribed species and one described species from New Zealand. This study will describe the morphology and developmental processes on their host of the undescribed red algal parasites and the evolutionary relationships between parasite and host of both red algal parasites. 


\section{Chapter 2: Rhodophyllis parasitica (Cystocloniaceae, Gigartinales,}

\section{Rhodophyta) sp. nov. from New Zealand}

\subsection{Introduction}

Red algal parasites are common on other red algae and the majority of species descriptions are based on morphology (Goff, 1982). The molecular diversity of red algal parasite has been studied in only a few species, and new species are still being described (Ng et al., 2013). Red algal parasites are described in several orders within the Florideophyceae (Kurihara et al., 2010). One of the orders, where red algal parasites are well-represented, is the Gigartinales (Evans et al., 1978), which contains several parasitic genera: Coccotylus (Kützing, 1843), Callocolax (Batters, 1895), Hypneocolax (Børgesen, 1920), Gardneriella (Kylin, 1941).

The morphological characteristics used to describe red algal parasites are: 1) the penetration of the parasite beyond the superficial cells of the host; 2) reduction of the thallus; and 3) the loss of colour (Setchell, 1918). Another important character are the presence of secondary pit connections ( $\left.2^{\circ} \mathrm{PC}\right)$ formed between host and parasite (Goff, 1982). $2^{\circ} \mathrm{PC}$ were observed in all described red algal parasites studied (Goff \& Coleman, 1995, Goff \& Zuccarello, 1994, Kim \& Cho, 2010, Zuccarello \& West, 1994b).

The taxonomy of red algal parasites is mostly based on morphology, and this is true for the few described red algal parasites from New Zealand (Goff, 1982). There have been very few molecular studies of red algal parasites but these are helpful to determine the evolutionary relationship between host and parasite (Zuccarello et al., 
2004). Gene sequences of plastid DNA showed that they are identical between host and parasite, which suggests that red algal parasite retain the host chloroplast (Goff \& Coleman, 1995). Comparison of mitochondria and nuclear sequences showed differences between the red algal parasite Plocamiocolax pulvinata Setchell, Gracilariophila oryzoides Setchell et Wilson, Gardneriella tubifera Kylin and their respective hosts Plocamium cartilagineum (Linnaeus) Dixon, Gracilariopsis lemaneiformis (Bory de Saint-Vincent) Dawson, Acleto et Foldvik and Sarcodiotheca gaudichaudii (Montagne) Gabrielson, which suggest that the red algal parasite retains its own mitochondria und nucleus (Goff \& Coleman, 1995).

The distribution of red algal parasites are unknown and incomplete. There are no studies in which the distribution of parasites has been carefully documented. Distribution patterns could be useful to better understand parasite range (is parasitic distribution the same as the host?), tolerances (can the parasite tolerate the same water temperatures of its host?) and host switching (do parasite switch host if the host is rare?).

This study will combine morphological and phylogenetic data to study an undescribed red algal parasites from New Zealand growing on Rhodophyllis membranacea (Harvey) Hooker et Harvey. This study will address the following research questions: Does the suspected parasite fulfill the characters of a red algal parasite? What are the differences and similarities in morphological characters between host and parasite? What is the distribution of the parasite in New Zealand? What is the phylogenetic relationship between host and parasite? 


\subsection{Material and Methods}

\subsubsection{Sampling}

Rhodophyllis membranacea and its parasite were collected from 2012 to 2013 at different locations in New Zealand. A list of all collected samples and locations is shown in Table 2.1. All host and parasite tissue was collected as drift on the beach. Only tissue without any sign of degradation was collected. All tissue was collected and transported in plastic bags to the lab.

\subsubsection{Fixation \& Embedding}

Parasite tissue with surrounding host tissue were cut out under a dissecting microscope (Olympus SZ61) using a scalpel blade and transferred in containers with sterile sea water. The tissue samples were fixed overnight in $2 \%$ glutaraldehyde in phosphate buffer $(0.1 \mathrm{M}, \mathrm{pH} 6.8)$ in $50 \%$ sea water. Then the tissue was washed three times at intervals of 10 minutes with phosphate buffer $(0.1 \mathrm{M}, \mathrm{pH} 6.8)$ in $50 \%$ sea water. The tissue was dehydrated in an ascending ethanol-water-series of $20 \%, 40 \%$ and $60 \%$ ethanol and three times with $70 \%$ ethanol for 15 minutes each. The fixed samples were stored in $70 \%$ ethanol at $4{ }^{\circ} \mathrm{C}$ until embedding in JB-4. The tissue was transferred in a mixed series of ascending infiltration solution (JB-4 Solution A-Monomer, Benzoyl Peroxide) and descending ethanol series. The tissue was transferred once every 15 minutes to a solution of $75 \%$ ethanol and $25 \%$ infiltration solution, $50 \%$ ethanol and $50 \%$ infiltration solution, $25 \%$ ethanol and $75 \%$ infiltration solution and $10 \%$ ethanol and $90 \%$ infiltration solution and three times in $100 \%$ infiltration solution. Then embedding stubs were filled with embedding solution (infiltration solution, JB-4 
solution plus B-Accelerator) and the tissue transferred with tweezers in those stubs. The embedding stubs were fully filled with embedding solution. Then the embedding stubs were covered with parafilm and stored in a desiccator until hardened.

Table 2.1. Collected samples of Rhodophyllis membranacea and its parasites from different locations in New Zealand.

\begin{tabular}{|c|c|c|c|c|}
\hline Species & Date & Location & Coordinates & Collector \\
\hline $\begin{array}{l}\text { Rhodophyllis } \\
\text { membranacea } \\
\text { (ASH037) }\end{array}$ & 27.01 .08 & Thompson Sound & $\begin{array}{l}\text { S } 45^{\circ} 13^{\prime} 20^{\prime \prime} \\
\text { E } 166^{\circ} 58^{\prime} 20 "\end{array}$ & $\begin{array}{l}\text { C. Hepburn } \\
\text { D. Richards }\end{array}$ \\
\hline $\begin{array}{l}\text { Rhodophyllis } \\
\text { membranacea } \\
+ \text { parasite }\end{array}$ & 27.02 .12 & Houghton Bay & $\begin{array}{l}\text { S 41 }{ }^{\circ} 20^{\prime} 33^{\prime \prime} \\
\text { E } 174^{\circ} 47^{\prime} 6^{\prime \prime}\end{array}$ & P. Northcote \\
\hline $\begin{array}{l}\text { Rhodophyllis } \\
\text { membranacea } \\
+ \text { parasite }\end{array}$ & 04.03 .13 & Moa Point & $\begin{array}{l}\mathrm{S} 41^{\circ} 20^{\prime} 30^{\prime \prime} \\
\text { E } 174^{\circ} 48^{\prime} 38^{\prime \prime}\end{array}$ & M. Preuß \\
\hline $\begin{array}{l}\text { Rhodophyllis } \\
\text { membranacea } \\
+ \text { parasite }\end{array}$ & 08.03 .13 & Moa Point & $\begin{array}{l}\mathrm{S} 41^{\circ} 20^{\prime} 30^{\prime \prime} \\
\mathrm{E} 174^{\circ} 48^{\prime} 38^{\prime \prime}\end{array}$ & M. Preuß \\
\hline $\begin{array}{l}\text { Rhodophyllis } \\
\text { membranacea } \\
+ \text { parasite }\end{array}$ & 13.03 .13 & Cape Palliser & $\begin{array}{l}\mathrm{S} 41^{\circ} 36^{\prime} 48^{\prime \prime} \\
\mathrm{E} 175^{\circ} 17^{\prime} 30^{\prime \prime}\end{array}$ & M. Preuß \\
\hline $\begin{array}{l}\text { Rhodophyllis } \\
\text { membranacea } \\
+ \text { parasite }\end{array}$ & 05.04 .13 & Moa Point & $\begin{array}{l}\mathrm{S} 41^{\circ} 20^{\prime} 30^{\prime \prime} \\
\mathrm{E} 174^{\circ} 48^{\prime} 38^{\prime}\end{array}$ & M. Preuß \\
\hline $\begin{array}{l}\text { Rhodophyllis } \\
\text { membranacea } \\
+ \text { parasite }\end{array}$ & 26.04 .13 & Moa Point & $\begin{array}{l}\text { S } 41^{\circ} 20^{\prime} 30^{\prime \prime} \\
\text { E } 174^{\circ} 48 ’ 38^{\prime \prime}\end{array}$ & M. Preuß \\
\hline $\begin{array}{l}\text { Rhodophyllis } \\
\text { membranacea } \\
+ \text { parasite }\end{array}$ & 19.05 .13 & Blackhead & $\begin{array}{c}\text { S } 40^{\circ} 10^{\prime} 9^{\prime \prime} \\
\text { E } 176^{\circ} 49^{\prime} 37^{\prime \prime}\end{array}$ & M. Preuß \\
\hline $\begin{array}{l}\text { Rhodophyllis } \\
\text { membranacea } \\
+ \text { parasite }\end{array}$ & 20.05 .13 & Akitio Beach & $\begin{array}{l}\mathrm{S} 40^{\circ} 36^{\prime} 53^{\prime \prime} \\
\mathrm{E} 176^{\circ} 24^{\prime} 53^{\prime \prime}\end{array}$ & M. Preuß \\
\hline $\begin{array}{l}\text { Rhodophyllis } \\
\text { membranacea } \\
+ \text { parasite }\end{array}$ & 20.05 .13 & $\begin{array}{c}\text { Between Sandy } \\
\text { Beach and } \\
\text { Mataikona }\end{array}$ & $\begin{array}{l}\mathrm{S} 40^{\circ} 36^{\prime} 53^{\prime \prime} \\
\mathrm{E} 176^{\circ} 15^{\prime} 8^{\prime \prime}\end{array}$ & M. Preuß \\
\hline
\end{tabular}




\subsubsection{Sectioning}

The embedded tissue was sectioned with a diamond blade (Delaware Diamond Knives) on a microtome (American Optical Corporation, 860 Model). The tissue was first trimmed with a razor blade to fit in the sample holder of the microtome. Sections were $10 \mu \mathrm{m}$ thick. The sections were carefully transferred with tweezers to the surface of distilled water in a beaker and transferred on a microscopic slide after they had fully spread in the water. The microscopic slide was then dried and stored in a slide folder.

\subsubsection{Staining and microscopy}

All microscopic slides were either stained with $1.0 \mu \mathrm{g} / \mathrm{ml}$ DAPI in McIlvaine buffer ( $\mathrm{pH} 4.1$ ) or 1\% Aniline blue. DAPI was used to stain nuclei and Aniline blue for general structures in the tissue.

For DAPI staining, microscopic slides were stained in a coplin jars with 1.0 $\mu \mathrm{g} / \mathrm{ml}$ DAPI for 5 minutes and rinsed carefully with distilled water. For Aniline blue staining, microscopic slides were stained in coplin jars with $1 \%$ Aniline blue for 5 minutes, rinsed carefully with distilled water and fixed in $2 \% \mathrm{HCl}$ for 5 minutes, then air-dried.

The microscopic slides were examined under a fluorescence microscope (Olympus AX-70) with integrated camera (Olympus DP-70) and images were taken using either DP Controller (Olympus software) imaging software or Stream Enterprise (Olympus software). 


\subsubsection{Permanent slides}

The microscopic slides with Aniline blue stained tissue were covered with mounting medium (Depex mounting medium Gurr, Leuven, Belgium) and carefully covered with a cover slip. The mounting medium hardened within a day.

\subsubsection{DNA extraction}

DNA from fresh, or silica gel dried samples, was extracted either with 5\% Chelex or using a modified CTAB procedure. A list of all samples used can be found in Table 2.2.

Table 2.2. List of all samples of Rhodophyllis membranacea and its parasite used in molecular analysis. No. $=$ Code used for sample. Date, location, coordinates and host source of collection also shown. Host source described the host from which the parasite was removed.

\begin{tabular}{|c|c|c|c|c|c|}
\hline Species & No. & Date & Location & Coordinates & $\begin{array}{c}\text { Host } \\
\text { source }\end{array}$ \\
\hline $\begin{array}{l}\text { Rhodophyllis } \\
\text { membranacea }\end{array}$ & $12 \mathrm{H}$ & 27.01 .08 & Thompson Sound & $\begin{array}{l}\text { S } 45^{\circ} 13^{\prime} 20^{\prime \prime} \\
\text { E } 166^{\circ} 58^{\prime} 20^{\prime \prime}\end{array}$ & - \\
\hline $\begin{array}{l}\text { Rhodophyllis } \\
\text { membranacea }\end{array}$ & $2 \mathrm{H}$ & 27.02 .12 & Houghton Bay & $\begin{array}{l}\text { S } 41^{\circ} 20^{\prime} 33^{\prime \prime} \\
\text { E } 174^{\circ} 47^{\prime} 66^{\prime \prime}\end{array}$ & - \\
\hline $\begin{array}{l}\text { Rhodophyllis } \\
\text { membranacea }\end{array}$ & $3 \mathrm{H}$ & 27.02 .12 & Houghton Bay & $\begin{array}{l}\text { S } 41^{\circ} 20^{\prime} 33^{\prime \prime} \\
\text { E } 174^{\circ} 47^{\prime} 6^{\prime \prime}\end{array}$ & - \\
\hline $\begin{array}{l}\text { Rhodophyllis } \\
\text { membranacea }\end{array}$ & $4 \mathrm{H}$ & 27.02 .12 & Houghton Bay & $\begin{array}{l}\text { S } 41^{\circ} 20^{\prime} 33^{\prime \prime} \\
\text { E } 174^{\circ} 47^{\prime} 6^{\prime \prime}\end{array}$ & - \\
\hline $\begin{array}{l}\text { Rhodophyllis } \\
\text { membranacea }\end{array}$ & $5 \mathrm{H}$ & 27.02 .12 & Houghton Bay & $\begin{array}{l}\text { S } 41^{\circ} 20^{\prime} 33^{\prime \prime} \\
\text { E } 174^{\circ} 47^{\prime} 66^{\prime \prime}\end{array}$ & - \\
\hline $\begin{array}{l}\text { Rhodophyllis } \\
\text { membranacea }\end{array}$ & $8 \mathrm{H}$ & 04.03 .13 & Moa Point & $\begin{array}{l}\mathrm{S} 41^{\circ} 20^{\prime} 30^{\prime \prime} \\
\mathrm{E} 174^{\circ} 48^{\prime} 38^{\prime \prime}\end{array}$ & - \\
\hline $\begin{array}{l}\text { Rhodophyllis } \\
\text { membranacea }\end{array}$ & $9 \mathrm{H}$ & 08.03 .13 & Moa Point & $\begin{array}{l}\text { S } 41^{\circ} 20^{\prime} 30^{\prime \prime} \\
\text { E } 174^{\circ} 48^{\prime} 38^{\prime \prime}\end{array}$ & - \\
\hline $\begin{array}{l}\text { Rhodophyllis } \\
\text { membranacea }\end{array}$ & $14 \mathrm{H}$ & 13.03 .13 & Cape Palliser & $\begin{array}{l}\text { S } 41^{\circ} 36^{\prime} 48^{\prime \prime} \\
\text { E } 175^{\circ} 17^{\prime} 30^{\prime \prime}\end{array}$ & - \\
\hline $\begin{array}{l}\text { Rhodophyllis } \\
\text { membranacea }\end{array}$ & $15 \mathrm{H}$ & 13.03 .13 & Cape Palliser & $\begin{array}{l}\text { S } 41^{\circ} 36^{\prime} 48^{\prime \prime} \\
\text { E } 175^{\circ} 17^{\prime} 30^{\prime \prime}\end{array}$ & - \\
\hline
\end{tabular}




\begin{tabular}{|c|c|c|c|c|c|}
\hline Species & No. & Date & Location & Coordinates & $\begin{array}{l}\text { Host } \\
\text { source }\end{array}$ \\
\hline $\begin{array}{l}\text { Rhodophyllis } \\
\text { membranacea }\end{array}$ & $39 \mathrm{H}$ & 20.05 .13 & Akitio Beach & $\begin{array}{l}\mathrm{S} 40^{\circ} 36^{\prime} 53^{\prime \prime} \\
\mathrm{E} 176^{\circ} 24^{\prime} 53^{\prime \prime}\end{array}$ & - \\
\hline $\begin{array}{l}\text { Rhodophyllis } \\
\text { membranacea }\end{array}$ & $40 \mathrm{H}$ & 20.05 .13 & Akitio Beach & $\begin{array}{l}\mathrm{S} 40^{\circ} 36^{\prime} 53^{\prime \prime} \\
\mathrm{E} 176^{\circ} 24^{\prime} 53^{\prime \prime}\end{array}$ & - \\
\hline $\begin{array}{l}\text { Rhodophyllis } \\
\text { membranacea }\end{array}$ & $42 \mathrm{H}$ & 20.05 .13 & Akitio Beach & $\begin{array}{l}\mathrm{S} 40^{\circ} 36^{\prime} 53^{\prime \prime} \\
\mathrm{E} 176^{\circ} 24^{\prime} 53^{\prime \prime}\end{array}$ & - \\
\hline $\begin{array}{l}\text { Rhodophyllis } \\
\text { membranacea }\end{array}$ & $43 \mathrm{H}$ & 20.05 .13 & $\begin{array}{l}\text { Between Sandy Beach } \\
\text { and Mataikona }\end{array}$ & $\begin{array}{l}\text { S } 40^{\circ} 36^{\prime} 53^{\prime \prime} \\
\text { E } 176^{\circ} 15^{\prime} 8^{\prime \prime}\end{array}$ & - \\
\hline $\begin{array}{l}\text { Rhodophyllis } \\
\text { membranacea }\end{array}$ & $44 \mathrm{H}$ & 19.05 .13 & Blackhead & $\begin{array}{l}\mathrm{S} 40^{\circ} 10^{\prime} 9^{\prime \prime} \\
\mathrm{E} 176^{\circ} 49^{\prime} 37^{\prime \prime}\end{array}$ & - \\
\hline $\begin{array}{l}\text { Rhodophyllis } \\
\text { parasite }\end{array}$ & $2 \mathrm{P}$ & 27.02 .12 & Houghton Bay & $\begin{array}{l}\text { S } 41^{\circ} 20^{\prime} 33^{\prime \prime} \\
\text { E } 174^{\circ} 47^{\prime} 6^{\prime \prime}\end{array}$ & $2 \mathrm{H}$ \\
\hline $\begin{array}{l}\text { Rhodophyllis } \\
\text { parasite }\end{array}$ & $4 \mathrm{P}$ & 27.02 .12 & Houghton Bay & $\begin{array}{l}\mathrm{S} 41^{\circ} 20^{\prime} 33^{\prime \prime} \\
\mathrm{E} 174^{\circ} 47^{\prime} 6^{\prime \prime}\end{array}$ & $4 \mathrm{H}$ \\
\hline $\begin{array}{l}\text { Rhodophyllis } \\
\text { parasite }\end{array}$ & $5 \mathrm{P}$ & 27.02 .12 & Houghton Bay & $\begin{array}{l}\text { S } 41^{\circ} 20^{\prime} 33^{\prime \prime} \\
\text { E } 174^{\circ} 47^{\prime} 6^{\prime \prime}\end{array}$ & $5 \mathrm{H}$ \\
\hline $\begin{array}{l}\text { Rhodophyllis } \\
\text { parasite }\end{array}$ & $8 \mathrm{P}$ & 04.03 .13 & Moa Point & $\begin{array}{l}\mathrm{S} 41^{\circ} 20^{\prime} 30^{\prime \prime} \\
\mathrm{E} 174^{\circ} 48^{\prime} 38^{\prime \prime}\end{array}$ & $8 \mathrm{H}$ \\
\hline $\begin{array}{l}\text { Rhodophyllis } \\
\text { parasite }\end{array}$ & $9 \mathrm{P}$ & 08.03 .13 & Moa Point & $\begin{array}{l}\mathrm{S} 41^{\circ} 20^{\prime} 30^{\prime \prime} \\
\mathrm{E} 174^{\circ} 48^{\prime} 38^{\prime \prime}\end{array}$ & $9 \mathrm{H}$ \\
\hline $\begin{array}{l}\text { Rhodophyllis } \\
\text { parasite }\end{array}$ & $13 \mathrm{P}$ & 13.03 .13 & Cape Palliser & $\begin{array}{l}\mathrm{S} 41^{\circ} 36^{\prime} 48^{\prime \prime} \\
\mathrm{E} 175^{\circ} 17^{\prime} 30^{\prime \prime}\end{array}$ & $13 \mathrm{H}$ \\
\hline $\begin{array}{l}\text { Rhodophyllis } \\
\text { parasite }\end{array}$ & $14 \mathrm{P}$ & 13.03 .13 & Cape Palliser & $\begin{array}{l}\mathrm{S} 41^{\circ} 36^{\prime} 48^{\prime \prime} \\
\mathrm{E} 175^{\circ} 17^{\prime} 30^{\prime \prime}\end{array}$ & $14 \mathrm{H}$ \\
\hline $\begin{array}{l}\text { Rhodophyllis } \\
\text { parasite }\end{array}$ & $40 \mathrm{P}$ & 20.05 .13 & Akitio Beach & $\begin{array}{l}\mathrm{S} 40^{\circ} 36^{\prime} 53^{\prime \prime} \\
\mathrm{E} 176^{\circ} 24^{\prime} 53^{\prime \prime}\end{array}$ & $40 \mathrm{H}$ \\
\hline $\begin{array}{l}\text { Rhodophyllis } \\
\text { parasite }\end{array}$ & $42 \mathrm{P}$ & 20.05 .13 & Akitio Beach & $\begin{array}{l}\mathrm{S} 40^{\circ} 36^{\prime} 53^{\prime \prime} \\
\mathrm{E} 176^{\circ} 24^{\prime} 53^{\prime \prime}\end{array}$ & $42 \mathrm{H}$ \\
\hline $\begin{array}{l}\text { Rhodophyllis } \\
\text { parasite }\end{array}$ & $43 \mathrm{P}$ & 20.05 .13 & $\begin{array}{l}\text { Between Sandy Beach } \\
\text { and Mataikona }\end{array}$ & $\begin{array}{l}\mathrm{S} 40^{\circ} 36^{\prime} 53^{\prime \prime} \\
\mathrm{E} 176^{\circ} 15^{\prime} 8^{\prime \prime}\end{array}$ & $43 \mathrm{H}$ \\
\hline $\begin{array}{l}\text { Rhodophyllis } \\
\text { parasite }\end{array}$ & $44 \mathrm{P}$ & 19.05 .13 & Blackhead & $\begin{array}{l}\mathrm{S} 40^{\circ} 10^{\prime} 9^{\prime \prime} \\
\text { E } 176^{\circ} 49^{\prime} 37^{\prime \prime}\end{array}$ & $44 \mathrm{H}$ \\
\hline
\end{tabular}

For Chelex extraction, $100 \mu$ l Chelex solution (5\% Chelex-100, Bio-Rad, Hercules, California, USA; in $10 \mathrm{mM}$ Tris $\mathrm{pH} 8.0$ ) was added to a small amount of tissue in a $1.5 \mathrm{~mL}$ tube. The tissue was ground until no more tissue was visible and the solution became coloured. The tissue was heated to $100{ }^{\circ} \mathrm{C}$ for 10 minutes and centrifuged (Eppendorf) at full speed for 10 minutes. The supernatant was transferred 
carefully in a new tube and stored at $-20^{\circ} \mathrm{C}$.

For CTAB extraction, $500 \mu 1$ of a CTAB buffer $(2 \%$ CTAB, $0.1 \mathrm{M}$ Tris-HCl (pH 8.0), 1.4 M NaCl, $20 \mathrm{mM}$ EDTA, 1\% PVP) plus $50 \mu \mathrm{g}$ RNAse A and $80 \mu \mathrm{g}$ Proteinase $\mathrm{K}$ were added to $1.5 \mathrm{ml}$ tube with a piece of tissue and ground after the tissue was softened. The grinded tissue in the tube was heated to $60{ }^{\circ} \mathrm{C}$ for one hour. An equal volume of 24:1 chloroform:isoamyl alcohol solution was added, mixed and centrifuged at the highest speed for 5 minutes. The supernatant was transferred in a new tube. Then an equal volume of 24:1 chloroform: isoamyl alcohol was added, mixed and centrifuged at full speed for 5 minutes. The supernatant was transferred to a new tube. An equal volume of $100 \%$ isopropanol was added to the tube, waited for 30 minutes and centrifuged at the highest speed for 20 minutes. The supernatant was transferred in a new tube, $500 \mu 1$ of $70 \%$ ethanol was then added and the solution centrifuged for 5 minutes. The supernatant was decanted and the pellet air-dried. $50 \mu 1$ of $0.1 \times$ TE buffer (10 mM Tris-HCl, (pH 8.0), $1 \mathrm{mM}$ EDTA) was added to the dry pellet. The extracted samples were stored at $-20{ }^{\circ} \mathrm{C}$.

\subsubsection{Primers}

Two mitochondrial markers ( $\operatorname{cox} 1$ and $\operatorname{cox} 2-3$ spacer) and one nuclear marker (ITS2) were used for Rhodophyllis membranacea and its parasites. The forward primer GazF1 (TCA ACA AAT CAT AAA GAT ATT GG) and reverse primer GazR1 (ACT TCT GGA TGT CCA AAA AAY CA) were used to amplify the 5 prime end of cox 1 (Saunders, 2005). The forward primer cox2F (GTA CCW TCT TTD RGR RKD AAA TGT GAT GG) and reverse primer cox3R (GGA TCT ACW AGA TGR AAW GGA 
TGT C) were used to amplify the cox2-3 spacer (Zuccarello et al., 1999). The forward primer ITS3 (GCA TCG ATG AAG AAC GCA GC) and reverse primer ITS4 (TCC TCC GCT TAT TGA TAT GC) were used to amplify ITS2 (White et al., 1990).

\subsubsection{Primer Design for specific ITS2 primer}

The general ITS2 primers (above) were inefficient in the amplification and specific primer were designed using successful amplified Rhodophyllis membranacea and parasite sequences. Two forward primers ITS3F1 (CGA ATG CGA TAT GTA ATG) and ITS3F2 (AAT CAT CGA ATT TTT GAA CG) and one reverse primer ITS4R1 (CAA AAC GNT TCC CTC TCC TC) were created in Geneious (Biomatters Ltd., New Zealand) using the Primer3 software. Primer were manufactured by IDT (Integrated DNA Technologies, Inc.).

\subsubsection{PCR}

Amplification reaction were performed in a $30 \mu 1$ reaction of the final concentrations: $1 \mathrm{x}$ buffer (Biotherm), $0.2 \mathrm{mM}$ dNTP's, $2.5 \mathrm{mM} \mathrm{MgCl} 2,0.25 \%$ BSA (BSA, Sigma), 25 pmol of each primer, 1 U Taq polymerase (New England BioLabs, Inc.), and $1 \mu 1$ of template DNA. The PCR were performed using a MJR PTC100 Thermal Cycler. PCR was carried out with an initial denaturation at $94{ }^{\circ} \mathrm{C}$ for 5 minutes, followed by 36 cycles of $94^{\circ} / 45^{\circ} / 72^{\circ}$ for 1 minute each and a final step $72^{\circ} \mathrm{C}$ for 5 minutes. The PCR products were electrophoresed using $4 \mu$ of amplified template and 1 $\mu 1$ Gel Loading Buffer (65\% (w/v) Sucrose, 10 mM Tris-HCl (pH 7.5), 10 mM EDTA, $0.3 \%(\mathrm{w} / \mathrm{v})$ Bromophenol blue) in a 1\% agarose gel (0.5x TRIS-Borate-EDTA buffer). 
The length of the amplified product was determined by running a molecular ladder (Hyperladder II, Bioline) on every gel. Afterwards the agarose gel was stained with ethidium bromide $(0.01 \mu \mathrm{l} / \mathrm{ml})$ for 15 minutes and examined in an UV chamber (Uvitech). Successful amplifications were purified using Exo SAP-IT (Affymetrix, USB product, USA). $0.5 \mu 1$ Exo SAP-IT was added to approximately $25 \mu 1$ of PCR product. The tubes were heated to $37^{\circ} \mathrm{C}$ for 30 minutes and afterwards incubated at $80{ }^{\circ} \mathrm{C}$ for 15 minutes. The purified samples were sequenced commercially (Macrogen Inc, Korea).

\subsubsection{Alignment and haplotype networks}

Forward and reverse sequences were assembled and edited in Geneious (Biomatters Ltd., USA). All sequences were verified by matching a red algae species using Blast search. The edited sequences were aligned using MAFFT alignment using the default parameters. The alignment was checked and realigned by eye. The alignment of $\operatorname{cox} 1$ and ITS 2 from host and parasite was used to calculate haplotype networks using TCS 1.21 (Clement et al., 2000), due to the similarity between host and parasite samples phylogenetic analysis was not needed.

\subsubsection{Distribution}

On $8^{\text {th }}$ of April 2013, all herbarium samples of Rhodophyllis membranacea were provided by Jenn Dalen at the Museum of New Zealand Te Papa Tongarewa (Te Papa) in Wellington. All samples were searched for parasites under a dissecting microscope. Te Papa voucher, collection date, location and collector of all samples with observed parasites were recorded. 


\subsection{Results}

\subsubsection{Morphology of the Rhodophyllis parasite}

Habitat and seasonality. The red algal parasite grows on Rhodophyllis membranacea and was found from January to May. The surface of the host can have from one to over 20 parasites at a time. The parasite can be found close to the edges and tips of the host plant. The parasites never grow close to each other and vary in size.

Thallus. The parasite is coloured (light reddish) and less pigmented than the host, which makes the parasite easy to spot (Fig. 2.1A). The parasite thallus is on average 2.5 x $3 \mathrm{~mm}$ in size. The thallus is mostly bipinnately branched and the surface of the branches are smooth. The parasite has a single base attached to the host surface (stipe) that branches distally. The branches are terete and not flattened as in Rhodophyllis membranacea. The branch tips are blunt (Fig. 2.1B).

Male and female reproductive structures can be differentiated. Spermatangia are found on the surface on the thallus (Fig 2.1C). Carposporophytes form round structures on the branches (Fig. 2.1D). 

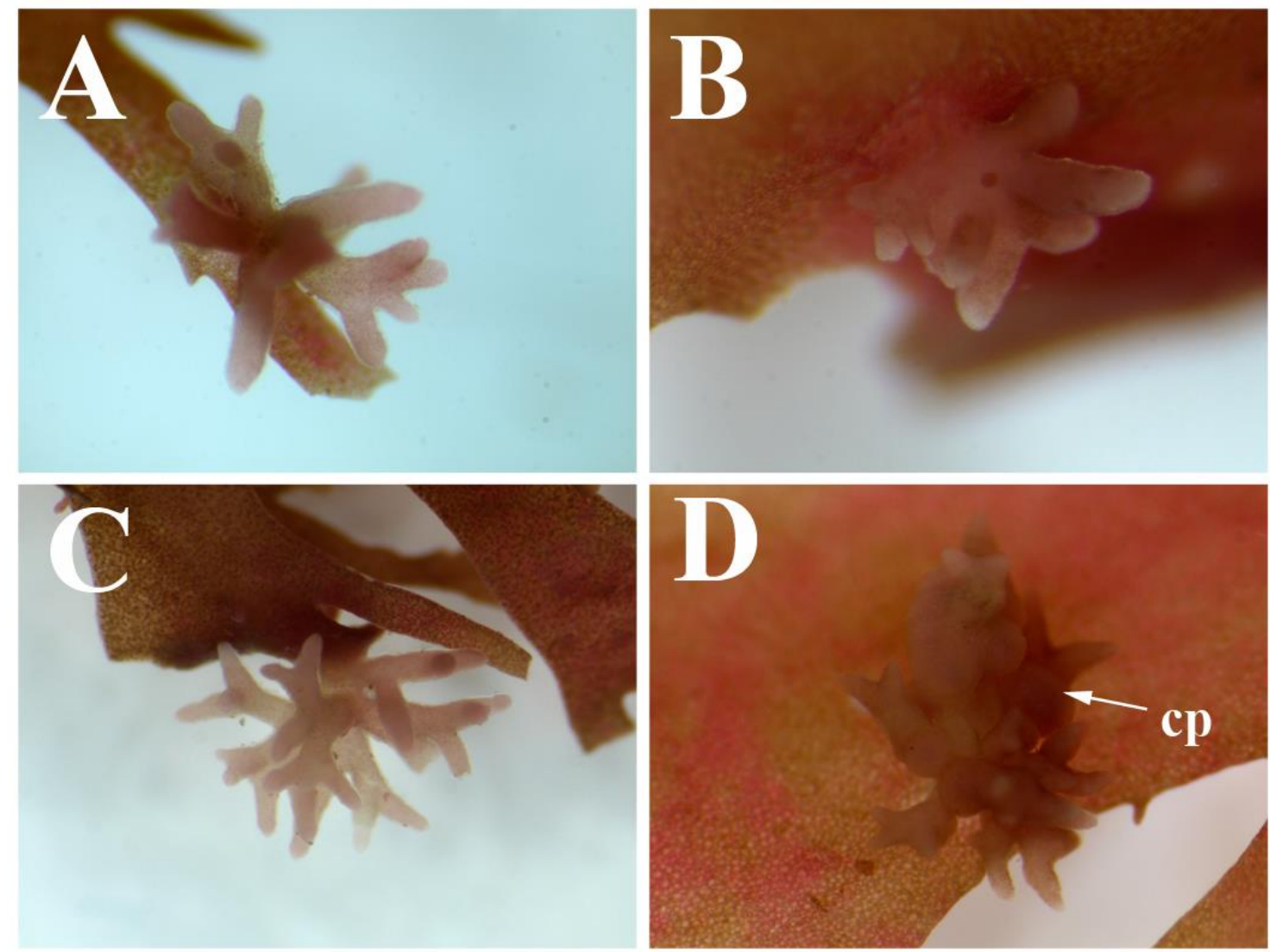

Figure 2.1A-D. Rhodophyllis parasite thallus on its host Rhodophyllis membranacea. Fig. 2.1A-B.

Vegetative structure of the Rhodophyllis parasite. Fig 2.1A. The parasite is bipinnately branched and less pigmented than its host. Fig. 2.1B. The parasite has a single base attached to the host tissue.

Fig. 2.1C-2.1D. Monoeious gametophytes of Rhodophyllis parasite. Fig. 2.1C. Male gametophyte.

Fig. 2.1D. Arrowhead indicates carpospores (cp) structure within the branches of a female parasite.

Vegetative structure. The thallus of the parasite is composed in an irregular massive cell network (Fig. 2.2A). The area, which connects the host and parasite, has elongated cells of various lengths and smaller cells. This area also contains embedded host cells in the parasite cells and vice versa. The cortical cells of the host seem to be bigger in this area than the surrounding host tissue (Fig. 2.2B). The parasite cells form primary pit connection with other parasitic cells and secondary pit connect with host cells (Fig. 
2.2C). Primary pit connections can be found between smaller parasite cells in the center of the parasite thallus and the branch tips. Secondary pit connections can be found between large cortical host cells and small parasitic cells in the contact area. The small cells cannot be host cells as the host has a very regular cell distribution pattern (Fig. 2.2D). The vegetative structure of Rhodophyllis membranacea consists of one or two inner layers of large cortical cells, an outer layer of smaller epidermal cells and a cuticle. DAPI-staining showed highly fluorescent parasitic nuclei in the host and parasite contact area. The parasite thallus further away from the host surface consists of pigmented round cells and elongated cells.

Development. The normal cell layer structure of Rhodophyllis membranacea is disrupted by the infection of the parasite. The disruption of parasite filaments is localised and those parasite filaments are a long way from where the parasite is found (Fig. 2.2E). DAPI-staining revealed an accumulation of parasite nuclei in rhizoidal parasite cells in the host, which are probably parasite nuclei due to the high number of nuclei in the cells and host thalli don't have this layer of filamentous cells (Fig. 2.2F). 

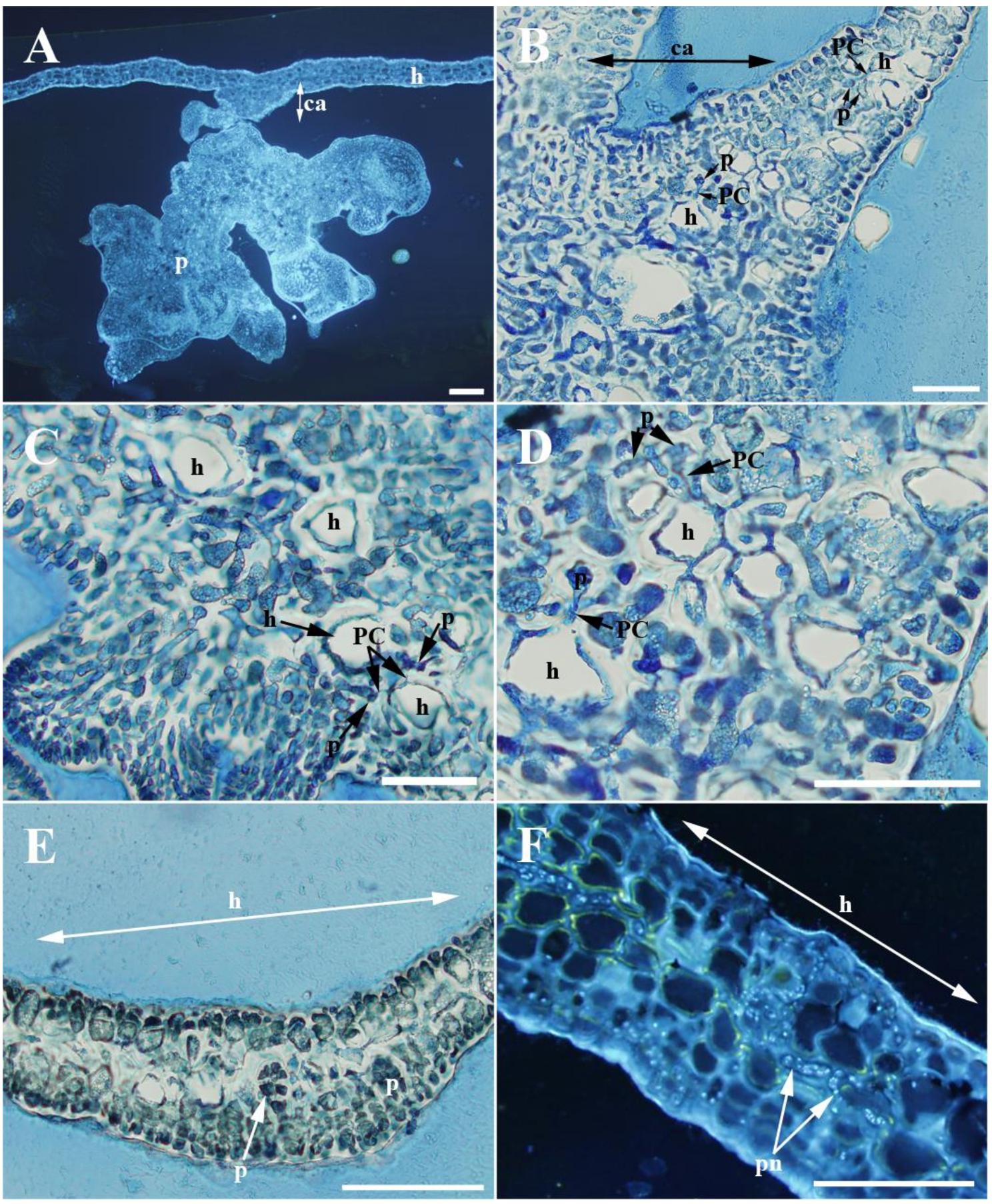

Figure 2.2A-F. Vegetative structure of Rhodophyllis parasite. Fig. 2.2A. DAPI-staining of vegetative structure of Rhodophyllis membranacea (h) and its parasite (p). The parasite penetrates deep beyond the superficial layer of the host cells. Host and parasite cells can be both found in the contact area between host and parasite (ca). Arrowhead indicates contact area between host and parasite (ca). Scale $=250 \mu \mathrm{m}$. Fig. 2.2B. Aniline blue staining of contact area between host and 
parasite (ca). Parasite disrupts the cell layer structure of the host. The parasite forms secondary pit connection (PC) with Rhodophyllis membranacea (h). Arrowhead indicates contact area between host and parasite (ca). Scale $=100 \mu \mathrm{m}$. Fig 2.2C-D. Contact area between host (h) and parasite (p) stained with Aniline blue. Parasite forms secondary pit connection (PC) with its host. Arrowheads indicate the parasite cells (p), host cells (h) or secondary pit connections (PC). Scale $=\mathbf{5 0} \mu \mathrm{m}$ (Fig. 2.2C) and $100 \mu \mathrm{m}$ (Fig. 2.2D). Fig. 2.2E. Vegetative structure of host cell layers after infection by parasite stained with Aniline blue. Parasite cells (p) grow in the host thallus (h) and disrupt the cell layer structure of the host. Arrowhead indicates parasite cells (p) or the host thallus (h). Scale= $100 \mu \mathrm{m}$. Fig. 2.2F. DAPI staining of vegetative structure of Rhodophyllis membranacea (h) with parasite nuclei (pn) in parasite rhizoidal cells in the host. Arrowhead indicate parasite nuclei (pn) or host thallus. Scale $=100 \mu \mathrm{m}$.

Reproductive structures. Carposporophytes, spermatangia and tetrasporangia were observed. The parasite has monoeious gametophytes (Fig. 2.3A).

Carposporophyte. The carposporophyte contains an accumulation of carpospores. The carpospores are oval shaped with an average size of $20 \mu \mathrm{m}(\mathrm{n}=5)$ and are pigmented. Cystocarps are marginal in the branches of the parasite (Fig. 2.3B). Carposporophytes are $230 \times 330 \mu \mathrm{m}(\mathrm{n}=3)$ and surrounded by a pericarp. The pericarp is approximately 5 10 cells thick $(200 \mu \mathrm{m} ; \mathrm{n}=3)$ (Fig. $2.3 \mathrm{C})$. 

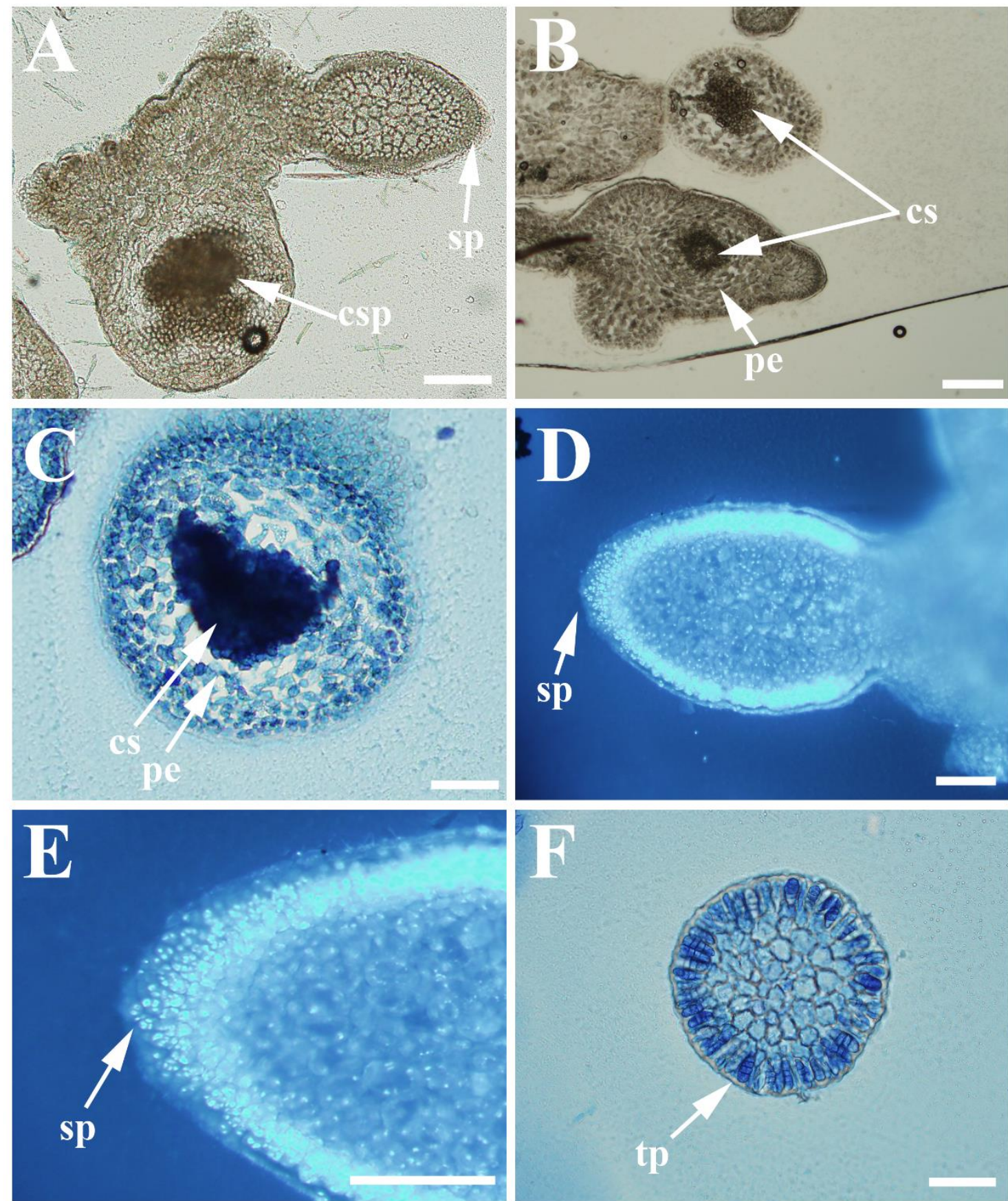

Figure 2.3A-F. Reproductive structure of the Rhodophyllis parasite. Fig 2.3A. Monoeious

gametophyte with spermatangia (sp) and carposporophyte (csp). Unstained. Scale $=200 \mu \mathrm{m}$. Fig.

2.3B-C. Unstained (B) and Aniline blue stained (C) carposporophyte containing an accumulation of carpospores (cs) and surrounded by a pericarp (pe). Scale $=100 \mu \mathrm{m}$ (Fig. 2.3B) and scale $=200 \mu \mathrm{m}$

(Fig. 2.3C). Fig. 2.3D. DAPI-staining of dense patches of spermatangia (sp) on the parasite surface. 
Scale $=100 \mu \mathrm{m}$. Fig. 2.3E. Great magnification of DAPI -stained spermatangia. Spermatia visible (sp). Scale $=100 \mu \mathrm{m}$. Fig. 2.3F. Aniline blue stained tetrasporangia (ts) of the parasite.

Tetrasporangium contains four zonately divided tetraspores. Scale $=\mathbf{1 0 0} \mu \mathrm{m}$.

Males. Spermatangia are in dense patches on the surface of the parasite thallus (Fig.

2.3D). Spermatia are less than $10 \mu \mathrm{m}$ in diameter and are round. DAPI-staining shows a high concentration of DNA in the spermatia (Fig. 2.3E).

Tetrasporophyte. Tetrasporangia are scattered and numerous on the surface. Each tetrasporangium contains four tetraspores, which are zonately divided (Fig. 2.3F). Tetrasporangia are pigmented and an average size from $48 \times 20 \mu \mathrm{m}(\mathrm{n}=10)$.

\subsubsection{Comparison of morphological characters between host and parasite}

Rhodophyllis membranacea and its parasite differ in: 1) size (thallus and reproductive structure), 2) cell structure and 3) sexuality. Both have the shape and the location of their reproductive structures in common (Table 2.3). 
Table 2.3. Comparison of vegetative and reproductive structures between Rhodophyllis

membranacea and its parasite.

\begin{tabular}{|c|c|c|}
\hline & $\begin{array}{l}\text { Rhodophyllis } \\
\text { membranacea }\end{array}$ & $\begin{array}{c}\text { Rhodophyllis } \\
\text { parasite }\end{array}$ \\
\hline Reference & $\begin{array}{l}\text { (Chapman, 1969, Nelson, } \\
\text { 2013, Womersley, 1994) }\end{array}$ & This study \\
\hline \multicolumn{3}{|l|}{ Thallus } \\
\hline Size & $6-15 \mathrm{~cm}$ long & $2.5 \times 3 \mathrm{~mm}$ \\
\hline Branches & Flattened & Terete \\
\hline Cells Layers & $\begin{array}{l}\text { Two type of cell layers ( } \\
\text { layers of large cortical } \\
\text { cells and one layer of } \\
\text { small epidermal cells) }\end{array}$ & $\begin{array}{c}\text { Cells scattered of } \\
\text { various sizes (small, } \\
\text { large and elongated } \\
\text { cells) }\end{array}$ \\
\hline \multicolumn{3}{|c|}{ Reproductive structures } \\
\hline Sexuality & Dioecious & Monoecious \\
\hline \multicolumn{3}{|l|}{ Carpospores } \\
\hline Shape & Ovoid & Ovoid \\
\hline Size & $15-25 \mu \mathrm{m}$ (diameter) & $20 \mu \mathrm{m}$ (diameter) \\
\hline \multicolumn{3}{|c|}{ Tetrasporangia } \\
\hline Location & Scattered & Scattered \\
\hline Form & Zonately divided & Zonately divded \\
\hline Size & 20-35 $\mu \mathrm{m}$ diameter & $20 \mu \mathrm{m}$ diameter \\
\hline \multicolumn{3}{|l|}{ Spermatangia } \\
\hline Location & Scattered on surface & Scattered on surface \\
\hline Form & Superficial patches & Superficial patches \\
\hline \multicolumn{3}{|l|}{ Spermatia } \\
\hline Size & - & approx. $10 \mu \mathrm{m}$ \\
\hline
\end{tabular}

\subsubsection{Phylogeny of Rhodophyllis parasite}

ITS2. The ITS2 alignment contained 22 samples of collected Rhodophyllis membranacea and parasite samples (11 hosts, 11 parasites) and had a length of 512 base pairs (Appendix 1). Three ITS2 ribotypes were found within samples: A1, A2 and A3 and differ by up to 2 base pairs. Lineage A1 contains all ITS2 sequences of Rhodophyllis membranacea $(\mathrm{n}=11)$ and one parasite sequence. Lineage A2 and A3 contain only parasite sequences. Lineage A3 is the most common ribotype within the 
parasite (n=7) (Fig. 2.4A). The two parasite ribotypes A2 and A3 were each found in the same collection location and therefore are not correlate with location.

A

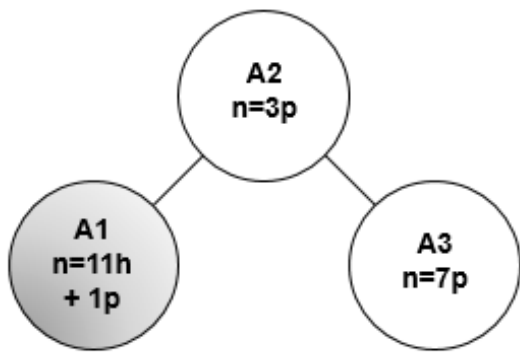

host $\bigcirc$ parasite
B

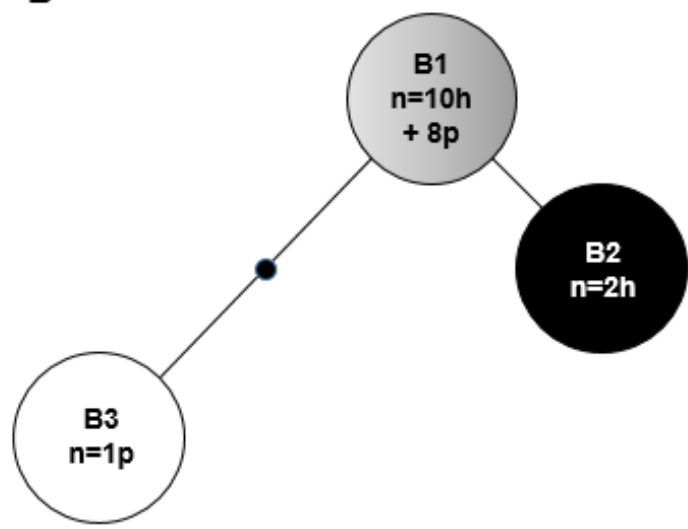

Figure 2.4A-B. Networks of Rhodophyllis membranacea and its parasite sequence data. Fig. 2.4A. ITS2 ribotype network with three lineages represented (A1, A2, A3). Fig. 2.4B. cox1 haplotype network with three lineages represented (B1, B2, B3). Line is one base pair difference. Small black circle is missing haplotype. Number of samples (n) divided in host (h) and parasite sequences (p). Grey area shows lineage, which is found in parasite and host.

Cox1. The cox 1 alignment contained 21 samples of Rhodophyllis membranacea and parasite samples (12 hosts, 9 parasites) and had a length of 676 base pairs (Appendix 2). Three haplotpyes were found within the cox 1 sequences of Rhodophyllis membranacea and its parasite: B1, B2 and B3 and differ by up to 3 base pairs. Lineage B1 contains most $(\mathrm{n}=18)$ host and parasite sequences (10 host and 8 parasite). Lineage B2 contains two host sequences. Lineage B3 contains one parasite sequences (Fig. 2.4B).

Cox2-3 spacer. The cox2-3 spacer alignment contained 15 samples of Rhodophyllis 
membranacea and parasite samples (10 hosts, 5 parasites) and had a length of 356 base pairs. All cox2-3 spacer sequences of Rhodophyllis membranacea and its parasite are identical except one parasite sample, which shows one base pair difference (Appendix $3)$.

\subsubsection{Distribution of the Rhodophyllis parasite}

The Te Papa herbarium collection of Rhodophyllis membranacea contained over 60 specimens and 29 of those had red algal parasites on them. A list of all samples with date of collection and collector is shown in Table 2.4. The parasite is widespread and can be found throughout New Zealand. Samples with parasites can be found on the subantarctic islands (Auckland Islands) and Stewart Island to the islands north of the North Island (Three Kings Islands). The parasite can be found in collections year round except in June and July. 
Table 2.4. Te Papa vouchers of Rhodophyllis membranacea with red algal parasites on them.

\begin{tabular}{|c|c|c|c|}
\hline Te Papa voucher & $\begin{array}{c}\text { Collection } \\
\text { date }\end{array}$ & Location & Collector \\
\hline A1573 & 31.01 .1968 & Houghton Bay, Wellington & N. M. Adams \\
\hline A2686 & 10.04 .1969 & Karehana Bay, Plimmerton & E. Harris \\
\hline A4151 & 07.01 .1971 & Lyall Bay, Wellington & N. M. Adams \\
\hline A4240 & 15.02 .1971 & Kaikoura Peninsula & Baker \\
\hline A7201 & 20.02 .1972 & Port Pegasus, Stewart Island & G. Moreland \\
\hline A7200 & 28.02 .1972 & Port Pegasus, Stewart Island & N. M. Adams \\
\hline A10189 & 16.09 .1978 & Port Ross, Auckland Island & C. H. Hay \\
\hline A10423 & 23.10 .1978 & Great Island, Three King Island & H. Choat \\
\hline A14765 & 14.02 .1980 & Preservation Inlet, Fiordland & - \\
\hline A11577 & 08.02 .1981 & Aorere Point, North Otago & N. M. Adams \\
\hline A11580 & 10.02 .1981 & Shag Point, North Otago & N. M. Adams \\
\hline A13411 & 25.02 .1982 & $\begin{array}{l}\text { Between Lyall Bay \& Houghton } \\
\text { Bay, Wellington }\end{array}$ & W. Nelson \\
\hline A14250 & 02.12 .1983 & T449 Bushett's Shoal & C. H. Hay \\
\hline A14215 & 05.12 .1983 & $\begin{array}{c}7459 \text { Cape Campbell Scuba } \\
\text { Street }\end{array}$ & C. H. Hay \\
\hline A14206 & 14.12 .1983 & Chetwode Island (Nukuwaita) & C. H. Hay \\
\hline A22508 & 11.05 .1986 & Preservation Inlet, Gulches Head & G. Scringer \\
\hline A25901 & - & Doubtful Sound, Fiordland & S. Wing \\
\hline A18456a & 04.03 .1987 & Point Gap Bay, Chatham Island & D. Schiel \\
\hline A18459b & 04.03 .1987 & Chatham Island & W. Nelson \\
\hline A026481 & 27.03 .1987 & $\begin{array}{l}\text { Karorio stream mouth, } \\
\text { Wellington }\end{array}$ & C. H. Hay \\
\hline A18630a & 11.08 .1987 & Chetwode Island (Nukuwaita) & C. H. Hay \\
\hline A19277 & 28.03 .1990 & Fighting Bay, Marlborough & C. H. Hay \\
\hline A19048 & 26.04 .1990 & Horahora, Kakahu Island & C. Duffy \\
\hline A21013 & 10.11 .1994 & Dusky Sound, Lama Island & E. Villouta \\
\hline A029799 & 01.09 .1996 & Kaikoura Peninsula & $\begin{array}{l}\text { W. Nelson \& } \\
\text { G. Knight }\end{array}$ \\
\hline A22424 & 08.02 .1999 & $\begin{array}{l}\text { Smoothwater Bay, South } \\
\text { Westland }\end{array}$ & Neale \\
\hline $\mathrm{A} 022772$ & 20.02 .2000 & Dagg Sound, Four Fanthom Bank & F. Smith \\
\hline A022771 & 23.02 .2000 & Chalky Inlet, Edwardson Sound & C. Mundy \\
\hline A024446 & 22.02 .2007 & Tarakena Bay, Wellington & K. Neill \\
\hline
\end{tabular}




\subsection{Discussion}

Morphological analysis revealed a close similarity between Rhodophyllis membranacea and its parasite. The parasite is small, less pigmented than its host and secondary pit connections were formed between parasite and host cells. Morphological analysis showed also that the parasite has most of the characteristics used to define red algal parasite, which are 1) reduced size; 2) reduced pigmentation; 3) presence of both gametophyte and sporophytes on the same host plant; and 4) formation of secondary pit connections between host and parasite cells (Wynne \& Scott, 1989). Due to the morphological and genetic similarity of red algal parasite and host it is suggested that the parasite evolved from its host. The red algal parasite is widespread throughout New Zealand.

\subsubsection{Morphology of Rhodophyllis parasite}

The parasite penetrates beyond the superficial cells of Rhodophyllis membranacea, has a reduced thallus and is less pigmented that its host. The deep penetration of the parasite is correlated with the disruption of host cell layers. This has been observed in other red algal parasite-host symbioses (Fujii \& Toyota, 1999, Goff \& Coleman, 1984, Noble \& Kraft, 1983). Examples of the disruption of cell layers in the host by parasites, are the red algal parasite Neohalosacciocolax aleutica Lee et Kurogi, which contains cortical cells of its host Halosaccion minjaii Lee after penetration and disruption of the host (Lee \& Kurogi, 1978) and Neotenophycus ichthyosteus Kraft et Abbott, which inserts its basal cells progressively into the host tissue of Neosiphonia poko (Hollenberg) Abbott (Kraft \& Abbott, 2002). 
The parasite is less pigmented than its hosts Rhodophyllis membranacea. Studies showed that the parasite Choreocolax polysiphonia Reinsch, which varies in pigmentation, could still do photosynthesis after being removed from its host (Callow et al., 1979). Measuring the parasite photosynthesis after removing it from its host Rhodophyllis membranacea could show if the parasite is able to grow by itself and if not, this would suggest that the parasite probably depends on its host.

Another character used in the description of red algal parasites, were the presence of sporophyte and gametophyte of the parasite on the same host plant (Wynne $\&$ Scott, 1989). At this point of the study, there are only slides of gametophytes and sporophytes collected from the same location but it is not possible to tell if they are from the same host plant. Further investigation of this character needs to be done to fulfil all previous mentioned characters in the description of new red algal parasites.

Another important character to describe red algal parasites were the observations of $2^{\circ} \mathrm{PC}$ between Rhodophyllis membranacea and its parasite. Secondary pit connections between host and parasite were observed in all described red algal parasites (Apt \& Schlech, 1998, Goff \& Zuccarello, 1994, Kim \& Cho, 2010, Kraft \& Abbott, 2002). An attached parasite spore on a host surface penetrates into the host via an infection peg, which fuses with either an epidermal cell or with the underlying cortical cell (Goff \& Coleman, 1987). The red algal parasite Sorellocolax stellaris Yoshida et Mikami uses its infections peg to fuse with an epidermal cell of its host Sorello repens (Okamura) Hollenberg (Yoshida \& Mikami, 1996). In contrast, the red algal parasite Dawsoniocolax bostrychiae (Joly et Yamaguishi-Tomita) Joly et Yamaguishi-Tomita uses its infection peg to fuse with the underlying cell layer of the host Bostrychia 
radians (Lamouroux) J. Agardh (Zuccarello \& West, 1994b). This suggests that secondary pit connections are an essential feature not only for the early developmental stages of the parasite (Zuccarello et al., 2004) but are also essential for parasite-host development as it is suggested that the transfer of nutrients to the parasite is only possible through physiological changes in infected host cells connected to parasite cells via $2^{\circ} \mathrm{PC}$ (Goff \& Coleman, 1985, Zuccarello \& West, 1994b).

$2^{\circ}$ pit connections allow the parasite to transfer nuclei and cytoplasmic organelles to host cells and the nuclei in some red algal parasites are able to divide in the host cytoplasm (Goff \& Coleman, 1984). In other cases the parasite nuclei do not divide, e.g. Bostrychiocolax australis Zuccarello et West (Zuccarello \& West, 1994b). $2^{\circ}$ pit connections appear to give the parasite control over the host cells (Goff \& Coleman, 1987) and the parasite changes the metabolism within the infected host cells and transforms the morphology of host cells (Goff \& Zuccarello, 1994). Even though $2^{\circ}$ pit connections are observed between the parasite and Rhodophyllis membranacea, changes in host cell morphology were not observed.

Mistakes have been made in describing red algal parasites where growths caused by other non-algal 'pathogens' have been misidentified as parasites (Künzenbach \& Brucker, 1960). Lobocolax deformans was described by Howe (1914) as a red algal parasite but it is known to be an bacterial infection on Prionitis lanceolata (Harvey) Harvey (Ashen \& Goff, 1998). Catenellocolax leeuwenii was described by Weber-van Bosse (1928) as a red algal parasite on Catenella impudia (Montagne) J. Agardh but this is doubtful as Catenella nipae Zanardini forms similar galls, which are caused by fungal infections (Zuccarello, 2008). 
Red algal parasite descriptions are difficult because some species are rare or small in size. The red algal parasite Tylocolax microcarpus Schmidt on Lenormandia spectabilis Sonder, seems to be one of those rare species because it was only recorded once (Schmitz \& Falkenberg, 1897). One example for small size is the parasite Aiocolax pulchella Pocock growing on Falkenbergiella caespitosa Pocock with a maximum size of 202-375 $\mu \mathrm{m}$ (Pocock, 1956). A careful examination and description of red algal parasites is important due to the fact that some parasites are quite small or rare and for a good description of a parasite it is important to collect as many morphological characters as possible. I showed that Rhodophyllis membranacea and its parasite share many morphological and reproduction features but the parasite has still enough differences from Rhodophyllis membranacea to be recognised as its own species. The parasite differs from its host in: 1) size of thallus and reproductive structures; 2) sexuality; and 3) number of cell layers. The reduction of the thallus is a well-known character for red algal parasites (Setchell, 1918, Wynne \& Scott, 1989). The difference in sexuality is already known in other red algal parasites (Goff, 1982). The red algal parasite Champiocolax sarae Bula-Meyer is monoecious and its host species Champia parvula (C. Agardh) Harvey, Champia salicornioides Harvey and Champia compressa Harvey are dioecious (Bula-Meyer, 1985). A monoecious gametophyte can be an advantage for the parasite because of the ability to reproduce without finding individuals of the opposite sex (Les, 1991).

The morphological and reproductive characters as well as genetic data are quite similar between Rhodophyllis membranacea and its parasite. This similarity suggests that the parasite evolved from its host. This close relationship between the parasite to its 
host is not surprising as $80 \%$ of all described red algal parasites are closely related to their hosts (Goff, 1982).

Rhodophyllis membranacea is in the family Cystocloniaceae. In this order, there is another red algal parasite, Hypneocolax stellaris Børgesen, which grows on its taxonomically closely related host Hypnea musciformis (Wulfen) Lamouroux (Børgesen, 1920). The family itself has currently 93 taxonomically described species (Guiry \& Guiry, 2013).

\subsubsection{Phylogeny of Rhodophyllis parasite}

Nuclear (ITS2) and mitochondrial (cox1, cox2-3 spacer) markers showed that parasite and host are closely related to each other. Due to the very close genetic similarity it is suggested that the parasite is newly evolved from its host. The close relationship between host and parasite was shown by using ITS data in the red algal parasite Asterocolax gardneri (Setchell) Feldmann et Feldmann, which is more closely related to the North Pacific host Polyneura latissima (Harvey) Kylin than to the North Atlantic Asterocolax and suggests a polyphyletic origin of the parasite (Goff et al., 1997). SSU and ITS data revealed that the red algal parasite Faucheocolax attenuata Setchell is more closely related to its host Fauchea laciniata J. Agardh than it is to its other host Fauchea fryeana Setchell, which suggest that the parasite evolved on Fauchea laciniata and switched host to another closely related species (Goff et al., 1996). SSU data from the red algal parasite Harveyella mirabilis (Reinsch) Schmitz et Reinke revealed that the parasite has a single origin but switched hosts several times and grows on distantly related species: Rhodomela confervoides (Hudson) Silva, Odonthalia 
washingtoniensis Kylin and Gonimophyllum skottsbergii Setchell (Zuccarello et al., 2004).

The three ITS2 ribotypes and cox 1 haplotypes each found in this study weren't exclusive between host and parasite. Identical sequences could be due to host contamination or due to close similarity between parasite and host. Host contamination was lowered by using parasite tissue from areas further away from the base of the parasite without embedded host cells. Host contamination is unlikely but can't be excluded. Close similarity due to ancestral sequences could be tested by separating only parasite tissue, for example freshly released parasite spores (Goff et al., 1997). As previous mentioned the morphological and reproductive characters are quite similar so genetic similarity is expected and this would support our results.

The cox2-3 spacer sequences between host and parasite were identical except for one sequence, which was one base pair different. Other studies showed that the cox 2-3 spacer is a highly variable marker (Saunders \& Moore, 2013). The identical cox2-3 spacer sequences would suggest that the parasite is recently new evolved from its host. The recent new evolution of the parasite is also supported by the other sequences ( $\operatorname{cox} 1$ and ITS) and the morphological data.

\subsubsection{Distribution of Rhodophyllis parasite}

The red algal parasite on Rhodophyllis membranacea is widespread and can be found almost all year throughout New Zealand. The earliest herbarium sample of Rhodophyllis membranacea and its parasites from Te Papa was collected in 1968 but the parasite was not described. Only two or three of the vouchers from Te Papa mentioned 
parasites at all. As previously mentioned the small size is the reason for red algal parasites to be overlooked. Diversity of red algal parasites in the world is probably higher than expected and new red algal parasite species are still being described (Kim \& Cho, 2010). There are probably many undescribed red algal parasite species in New Zealand because New Zealand is known for its high endemism and biodiversity (Gordon et al., 2010). Herbarium samples can be helpful to determine distribution patterns over time and space and biodiversity (Nelson et al., 2013). In the case of red algal parasites, herbarium samples are helpful to determine the distribution of the parasite and its host and find collection locations in which parasite and host could be found. Distribution pattern of red algal parasites and their host are generally unknown because the literature only lists sampling locations used in their studies. A careful examination of herbarium vouchers could help to described new red algal parasites.

Rhodophyllis membranacea is also know from Australia (Womersley, 1994). It would be interesting to check herbarium samples of Rhodophyllis membranacea from Australian museums for the parasite to extend the distribution of the parasite.

\subsubsection{Placement and naming of the Rhodophyllis parasite}

The red algal parasite evolved from its host Rhodophyllis membranacea. Phylogenetic analysis revealed that the red algal parasite and its host Rhodophyllis membranacea are closely related to each other. Morphological and reproductive structures are also quite similar between host and parasite. Those results suggest that the parasite evolved from its host. There are five described species in the genus Rhodophyllis in New Zealand: Rhodophyllis acanthocarpa (Harvey) J. Agardh, 
Rhodophyllis centrocarpa (Montagne) Wynne, Rhodophyllis gunnii (Harvey) Harvey, Rhodophyllis lacerata Harvey and Rhodophyllis membranacea (Cotton, 1908). The red algal parasite is easily distinguishable from those species due to its small size and parasitic lifestyle on Rhodophyllis membranacea. There are no known red algal parasites in the genus Rhodophyllis. For those reasons, this algae should be considered as the new species Rhodophyllis parasitica sp. nov.

The morphological characters of Rhodophyllis parasitica such as protruding and oval carposporophytes with an aggregation of oval carpospores and scattered tetrasporangium supports the placement in the genus Rhodophyllis (Kützing, 1847). The tetraspores are also known to be zonately divided as in all Rhodophyllis species (Cotton, 1908). Another shared character between the parasite and Rhodophyllis species (Rhodophyllis acanthocarpa, Rhodophyllis gunnii and Rhodophyllis membranacea) is spermatangia, which are scattered in patches on the surface (Chapman, 1969, Womersley, 1994).

Red algal parasites were always placed in a new genus since their first description (Fan \& Papenfuss, 1959, Lee \& Kurogi, 1978, Wynne \& Scott, 1989). Red algal parasites have special morphological characters like their small size and reduced pigmentation due to their parasitic lifestyle but most parasites still have similar morphology to their host and thereby to the host genus (Goff, 1982). These similarities suggest that they should be grouped in the same genus as the host, but they are not. Genetic methods introduced modern classification that are used to produce monophyletic genera based on the assumption that the genes and tree-building programs reflect the species relationship and paraphyly and polyphyly are not to be accepted in 
phycological classification (Zuccarello, 2011). Modern phylogenetic analyses revealed that parasite and host are often closer related to each other than to species in the same genus but new described parasites are still grouped in a new genus (Kim \& Cho, 2010). These new parasitic genera are often, based on molecular sequences, nested within the host genus (Kurihara et al., 2010, Ng et al., 2013, Saunders et al., 2004). For example, the red algal parasites Bostrychiocolax australis and Dawsoniocolax bostrychiae are nested within the host genus, thus making the host genus Bostrychia paraphyletic (Zuccarello et al., 2004). The paraphyletic genus is after strictly modern classification methods not acceptable and this would lead to the question if it's not easier to add the parasite characters to the host genus to maintain the monophyly than to always describe a new genus?

Rhodophyllis parasitica is considered part of the genus Rhodophyllis to maintain the monophyly of the genus. A revision is necessary of either all morphological characters in the genus Rhodophyllis or the characters of the genus are maintained with additional characters of the parasite because there appears to be only one.

\section{Rhodophyllis parasitica Preuß et Zuccarello sp. nov.}

Diagnosis: thalli coloured (light reddish), size $2.5 \times 3 \mathrm{~mm}$, branches bipinnately and terete with smooth surface and blunt branch tips. Monoeicous gametophyte. Carposporophyte $230 \times 330 \mu \mathrm{m}$, surrounded by pericarp, contain oval carpospores. Carpospores $20 \mu \mathrm{m}$ in diameter, pigmented, marginal in branches. Spermatangia $10 \mu \mathrm{m}$ in diameter, dense patches on thallus. Tetrasporangia scattered on surface, zonately divided, pigmented, 48 × $20 \mu \mathrm{m}$. Parasitic on Rhodophyllis membranacea. Type locality: RPPZ0212; S 4120 33, E 17447 6; growing on Rhodophyllis 
membranacea, collected as drift on 27.02.2012 at Houghton Bay, New Zealand.

Etymology: parasitica refers to the parasitic lifestyle of the red algae. Rhodophyllis parasitica is neither a legitimate scientific name nor synonym of species within in the genus Rhodophyllis based on known literature.

\subsubsection{Future work on Rhodophyllis parasitica}

Rhodophyllis parasitica could be an interesting organism to test if the parasite infects other closely related species in the same genus. Parasites have different evolutionary histories to their hosts, where some red algal parasites evolved from their host and only infect the host, other red algal parasite evolved and parasitizes on its host and also parasitizes on other closely related species (Goff et al., 1996). Culture experiments of Rhodophyllis parasitica and the four other species of Rhodophyllis in New Zealand (Cotton, 1908) and species in other closely related genera (Calliblepharis, Craspedocarpus, Hypnea) could be used to determine the host-specificity of the parasite. Due to the close phylogenetic similarity between Rhodophyllis parasitica and its host Rhodophyllis membranacea, it would be expected that if the parasite can infect other species they have to be closely related to the parasite. The infection of closely related species was shown in the experimental studies of the red algal parasite Bostrychiocolax australis, which has a broad host range and could not only parasitize its closely related host species Bostrychia radicans (Montagne) Montagne but also the closely related taxa: Bostrychia moritziana (Sonder) J. Agardh and Bostrychia kelanensis Grunow (Zuccarello \& West, 1994a, Zuccarello et al., 2004). Surprisingly, experimental studies in the red algal Leachiella pacifica Kugrens showed that the 
parasites growing on Polysiphonia can not infect Pterosiphonia and vice versa

(Zuccarello \& West, 1994c), which suggests the parasite developed special host specific characters. 


\section{Chapter 3: A phylogenetic study of the red algal parasite Pterocladiophila hemisphaerica}

\subsection{Introduction}

Red algal parasites are common on other red algae and make up approximately $10 \%$ of all described red algal genera (Goff, 1982). Red algal parasites are successful because they form secondary pit connection with their hosts (Goff \& Coleman, 1987) and these are essential for early parasite development (Zuccarello et al., 2004). Secondary pit connections have been observed in all red algal parasite and host combinations (Apt \& Schlech, 1998, Evans et al., 1978, Goff \& Coleman, 1984, Kim \& Cho, 2010, Norris, 1988, Wetherbee \& Quirk, 1982) and are used to transfer parasite nuclei and other organelles (mitochondria, plastids) from the parasite into a host cell (Goff \& Coleman, 1995).

$80 \%$ of red algal parasites are called "adelphoparasites" and are taxonomically closely related to their hosts (Goff, 1982). "Adelphoparasites" are often more closely related to their hosts than their host is to other species in the same genus (Goff et al., 1996). The minority of red algal parasites are called "alloparasites" and are taxonomically not closely related to their hosts (Goff, 1982). One example is the red algal parasite Harveyella mirabilis (Reinsch) Schmitz et Reinke in which small subunit ribosomal RNA (SSU) data showed that the parasite has a single origin but switched hosts several time and grows on the distantly related species: Rhodomela confervoides (Hudson) Silva, Odonthalia washingtoniensis Kylin and Gonimophyllum skottsbergii Setchell (Zuccarello et al., 2004). The terms "adelphoparasite" and "alloparasites" are 
still used but controversial as there is a continual gradation of different levels of relatedness between parasites and their hosts, and it is hypothesised that all parasite originated from a closely related species but this relationship can be changed with host switching (Zuccarello et al., 2004).

Host-switching is known in red algal parasites and has been confirmed genetically using ITS data in the red algal parasite Plocamiocolax pulvinata Setchell, who is more closely related to Plocamium violaceum Farlow than to its host Plocamium cartilagineum (Linnaeus) Dixon, which suggests that the parasite evolved on Plocamium violaceum and switched hosts to Plocamium cartilagineum (Goff et al., 1996).

The taxonomy of red algal parasites is mostly based on morphology, and this includes the few described red algal parasites from New Zealand (Goff, 1982). Often however the relationship between host and parasite can not be resolved based solely on morphological characters because host and parasite are very different and diagnostic characters are too conserved (Zuccarello et al., 2004).

There have been few molecular studies of red algal parasites but these are a helpful tool to understand the genomic changes in parasites (Hancock et al., 2010) and the evolutionary relationships between host and parasite (Zuccarello et al., 2004). Gene sequences of plastid DNA showed that plastids are identical between host and parasite, which suggests that the red algal parasite retains the host chloroplast (Goff \& Coleman, 1995). Nuclear markers (SSU, large subunit ribosomal RNA) and mitochondrial marker (Cytochrome c oxidase subunit I) showed differences between host and parasite sequences (Kurihara et al., 2010). The genetic difference suggest that the red algal 
parasite keeps its own mitochondria and nucleus and this can be used to determine the parasites origin (Goff \& Coleman, 1995).

Atp8 is one of the essential coding genes for components of ATP synthase (Blouin \& Lane, 2012). Sequencing of the whole mitochondrial genome in the red algal parasite Plocamiocolax pulvinata revealed that the atp 8 gene is missing and the mitochondrial genome in the red algal parasite Gracilariophila oryzoides Setchell et Wilson showed that in this species it is a pseudogene because the sequences showed a frameshift mutation and premature stop codon (Hancock et al., 2010).

This study focuses on Pterocladiophila hemisphaerica Fan et Papenfuss from New Zealand, which parasitize Pterocladia lucida (Brown) J. Agardh (order Gelidiales) and was first described in 1959 by Fan and Papenfuss. The parasite thallus looks like a hemispherical solid tubercle with an uneven surface, which can be 0.4-1 mm wide and 0.4-0.8 $\mathrm{mm}$ high. The branching is irregular and the parasite cells penetrate deep into the host tissue. The cystocarps, spermatangia and tetrasporangia are formed in conceptacles. The carpogonial branch is two-celled, spermatangia are produced in chains and tetrasporangia divided zonately. Pterocladiophila hemisphaerica was placed in a new family Pterocladiophilaceae in the Cryptonemiales (Fan \& Papenfuss, 1959). Later, Pterocladiophilaceae including the parasites Holmsella and Gelidiocolax were transferred into the Gracilariales because it was proposed that Holmsella belonged to the Gracilariales (Fredericq \& Hommersand, 1990). Phylogenetic analysis of nuclear genes confirmed that Holmsella pachyderma (Reinsch) Sturch is grouped in the Gracilariales (Zuccarello et al., 2004).

This study will address the following questions: What are the evolutionary 
relationships of the red algal parasite Pterocladiophila hemisphaerica to its host Pterocladia lucida? Is the red algal parasite part of the Gracilariales or does it belong to the Gelidiales like the host? Has host-switching occurred? Is the atp 8 gene missing or a pseudogene in Pterocladiophila hemisphaerica?

\subsection{Material and Methods}

\subsubsection{Sampling}

Samples of Pterocladia lucida and its parasite Pterocladiophila hemisphaerica were collected in 2011 and 2013 at different locations in New Zealand. A list of all collected samples and locations is shown in Table 3.1. All host and parasite tissue was collected as drift on the beach. Only tissue without any sign of degradation was collected. All tissue was collected and transported in plastic bags to the lab.

\subsubsection{DNA extraction}

DNA from fresh or silica gel dried samples were extracted either with 5\% Chelex or using a modified CTAB procedure outlined in Chapter 2 (2.2.6 DNA extraction). 
Table 3.1. All samples of Pterocladia lucida and its parasite Pterocladiophila hemisphaerica used in molecular analysis. No.= Code used in the chapter. Date and location, with coordinates, and collector of collection also shown. Host source described the host from which the parasite was removed.

\begin{tabular}{|c|c|c|c|c|c|c|}
\hline 苋 & $\dot{\mathbf{z}}$ & ڤે & 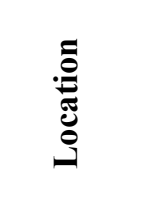 & 苞 & ن⿺辶e & 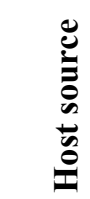 \\
\hline Pterocladia lucida & $45 \mathrm{H}$ & 19.05 .13 & $\begin{array}{c}\text { Kairakau } \\
\text { Beach }\end{array}$ & $\begin{array}{l}\text { S 39 58' } 18^{\prime \prime} \\
\text { E } 1765453.7\end{array}$ & M. Preuß & - \\
\hline Pterocladia lucida & $46 \mathrm{H}$ & 19.05 .13 & $\begin{array}{c}\text { Aramonan } \\
\mathrm{a}\end{array}$ & $\begin{array}{c}\text { S 40 } 8^{\prime} 51^{\prime \prime} \\
\text { E } 176^{\circ} 50^{\prime} 27^{\prime \prime}\end{array}$ & M. Preuß & - \\
\hline Pterocladia lucida & G214 & 27.11 .11 & $\begin{array}{l}\text { Akitio } \\
\text { Beach }\end{array}$ & $\begin{array}{c}\text { S } 40^{\circ} 36^{\prime} 53^{\prime \prime} \\
\text { E } 176^{\circ} 24^{\prime} 53^{\prime \prime}\end{array}$ & J. Zuccarello & - \\
\hline $\begin{array}{c}\text { Pterocladiophila } \\
\text { hemisphaerica }\end{array}$ & $45 \mathrm{P}$ & 19.05 .13 & $\begin{array}{l}\text { Kairakau } \\
\text { Beach }\end{array}$ & $\begin{array}{l}\text { S } 39^{\circ} 58^{\prime} 18^{\prime \prime} \\
\text { E } 176^{\circ} 54^{\prime} 53^{\prime \prime}\end{array}$ & M. Preuß & $45 \mathrm{H}$ \\
\hline $\begin{array}{c}\text { Pterocladiophila } \\
\text { hemisphaerica }\end{array}$ & $45 \mathrm{P} .2$ & 19.05 .13 & $\begin{array}{l}\text { Kairakau } \\
\text { Beach }\end{array}$ & $\begin{array}{l}\text { S } 39^{\circ} 58^{\prime} 18^{\prime \prime} \\
\text { E } 176^{\circ} 54^{\prime} 53^{\prime \prime}\end{array}$ & M. Preuß & $45 \mathrm{H}$ \\
\hline $\begin{array}{c}\text { Pterocladiophila } \\
\text { hemisphaerica }\end{array}$ & G215 & 27.11 .11 & $\begin{array}{l}\text { Akitio } \\
\text { Beach }\end{array}$ & $\begin{array}{l}\text { S } 40^{\circ} 36^{\prime} 53^{\prime \prime} \\
\text { E } 176^{\circ} 24^{\prime} 53^{\prime \prime}\end{array}$ & J. Zuccarello & G214 \\
\hline $\begin{array}{c}\text { Pterocladiophila } \\
\text { hemisphaerica }\end{array}$ & G215.2 & 27.11 .11 & $\begin{array}{l}\text { Akitio } \\
\text { Beach }\end{array}$ & $\begin{array}{l}\text { S } 40^{\circ} 36^{\prime} 53^{\prime \prime} \\
\text { E } 176^{\circ} 24^{\prime} 53^{\prime \prime}\end{array}$ & J. Zuccarello & G214 \\
\hline
\end{tabular}

\subsubsection{Primer}

One chloroplast marker (Ribulose-1,5-bisphospate carboxylase/oxygenase $=$ RuBisCO), one mitochondrial marker (cox1) and two nuclear markers (LSU, SSU) were used. The forward primer- ori.pts.for (TGT GGA CCT CTA CAA ACA GC) and the reverse primer ori.pts.rev (CCC CAT AGT TCC CAA T) were used to amplify the RUBISCO spacer (Maggs et al., 1992). The forward primer GazF1 (TCA ACA AAT CAT AAA GAT ATT GG) and the reverse primer GazR1 (ACT TCT GGA TGT CCA AAA AAY CA) were used to amplify cox1 (Saunders, 2005). The forward primer Z.LSU.for (GCA ACG GGC AAA GGG AAT CCG) and the reverse primer Z.LSU.rev 
(TGA TAG GAA GAG CCG ACA TCG A) were used to amplify partial sequences of LSU (Harper \& Saunders, 2001). Most of SSU was amplified using three combinations of forward (GO1, GO4, GO6) and reverse (GO8, JO4, 18S rev) primers (Saunders \& Kraft, 1994). The forward GO1 (CAC CTG GTT GAT CCT GCC AG) and the reverse primer GO8 (GAA CGG CCA TGC ACC ACC ACC) primer combination was used to amplify the first part of the SSU sequence. The forward GO4 (CAG AGG TGA AAT TCT TGG AT) and the reverse primer JO4 (AAA CCT TGT TAC GAC TTC TCC) were used to amplify the middle part of the SSU sequence. The forward primer GO6 (GTT GGT GGT GCA TGG CCG CCT TC) and the reverse primer 18S rev (CCC GGG ATC CAA GCT TGA TCC TTC TGC AGG TTC ACC TAC) were used to amplify the last part of the SSU sequence.

\subsubsection{Primer Design}

Mitochondrial genomes were used to design new primer to check the presence of the atp 8 gene. Four whole mitochondrial genomes of Chondrus crispus (NC_001677), Gracilariophila oryzoides (HQ586059), Gracilariopsis andersonii (NC_014772) and Plocamiocolax pulvinata (NC_014773) were downloaded into Geneious. The contiguous gene region of atp6-atp8-nad5 was removed and aligned. Forward primer were designed to start in the 3-prime end of atp 6 and reverse primer in the 5-prime end of nad5 gene to capture the whole intervening atp 8 gene. Three new forward ATP6_F1 (CAA GCT TAY GTT TTT ACV TTA TTA AC), ATP6_F2 (CCT TAY AGY TTT ACW GTT AC) and ATP6_F3 (GCA AAT ATG ACD TCW GGY CAY AC) and two new reverse primer NAD5_R1 (CTT TWA WTG CSG ATT GAT TAG C) and NAD5_R2 (GTT AAW AAT AAW ATA AKT AAA TAC) were designed by hand. All 
primer were tested individually in Geneious to ensure primer binding. Primer were produced by IDT (Integrated DNA Technologies, Inc.). All primers were successfully used in the amplification.

\subsubsection{PCR-Gel}

PCR and sequencing followed procedure following outlined in Chapter 2 (PCRGel 2.2.9).

\subsubsection{Assembly and alignment}

Forward and reverse sequences were individually assembled and edited.

Difficult to read bases were deleted at the end and bases, which had two different base pair peaks were changed using the nucleotide ambiguity code (IUPAC). Only good readable sequences were used. All edited sequences were Blast searched for closest match and all sequences downloaded from one marker were aligned using MAFFT alignment (Katoh et al., 2002) in Geneious. The alignment for SSU and LSU were checked by eye and changed if necessary.

DNA sequences from Genbank were downloaded to add to the aligned dataset. The sequences were selected by three different criteria: 1) species in the same genus, 2) top ten blast search hits and 3) one representative of a family within the Florideophyceae. A combined list of all sequences used from Genbank are shown in Appendix 4.

The cox 1 alignment contained sequences from Pterocladia lucida, Pterocladiophila hemisphaerica, different Pterocladiella species (Genbank) and Acanthopeltis longiramulosa Lee et Kim (Genbank) as an outgroup. 
The partial LSU alignment contained sequences from Pterocladia lucida, Pterocladiophila hemisphaerica, species in the order Gracilariales and Gelidiales, the top ten blast search host for the parasite (Table 3.2) and Caloglossa stipitata Post (Ceramiales) as an outgroup.

Table 3.2. List of top ten species from Blast search hits of the Pterocladiophila hemisphaerica LSU sequence. All samples were downloaded from Genbank. Taxonomic Order, Genbank Accession No. and E-value of the Blast hit are shown.

\begin{tabular}{|l|l|l|l|}
\hline \multicolumn{1}{|c|}{ Species } & \multicolumn{1}{|c|}{ Order } & \multicolumn{1}{|c|}{$\begin{array}{c}\text { Genbank } \\
\text { Accession No. }\end{array}$} & \multicolumn{1}{|c|}{ E-value } \\
\hline $\begin{array}{l}\text { Dilsea integra (Kjellman) } \\
\text { Rosenvinge }\end{array}$ & Gigartinales & FJ848966 & $1.96 \mathrm{e}^{-169}$ \\
\hline $\begin{array}{l}\text { Farlowia mollis (Harvey et Bailey) } \\
\text { Farlow et Setchell }\end{array}$ & Gigartinales & GU176299 & $196 \mathrm{e}^{-169}$ \\
\hline $\begin{array}{l}\text { Furcellaria lumbricalis (Hudson) } \\
\text { Lamouroux }\end{array}$ & Gigartinales & HM600853 & $1.96 \mathrm{e}^{-169}$ \\
\hline Gainia mollis Moe & Gigartinales & GQ406351 & $1.96 \mathrm{e}^{-169}$ \\
\hline Hyalosiphonia caespitosa Okamura & Gigartinales & JN403057 & $1.96 \mathrm{e}^{-169}$ \\
\hline Lesleigha sp. & Sebdeniales & JN602193 & $2.52 \mathrm{e}^{-173}$ \\
\hline $\begin{array}{l}\text { Neodilsea borealis } \text { (Abbott) } \\
\text { Lindstrom }\end{array}$ & Gigartinales & EF033610 & $1.96 \mathrm{e}^{-169}$ \\
\hline Neodilsea natashae Lindstrom & Gigartinales & JF928825 & $1.96 \mathrm{e}^{-169}$ \\
\hline Predaea kraftiana Millar et Guiry & Nemastomatales & EF033618 & $2.52 \mathrm{e}^{-170}$ \\
\hline $\begin{array}{l}\text { Sphaerococcus coronopifolius } \\
\text { Stackhouse }\end{array}$ & Gigartinales & FJ84974 & $1.96 \mathrm{e}^{-169}$ \\
\hline
\end{tabular}

For the SSU alignment, sequences from Pterocladia lucida, Pterocladiophila hemisphaerica and species from different families within the Florideophyceae were used. SSU alignment of Florideophyceae were obtained from Prof. Olivier DeClerck and modified as needed. Pyropia tenera (Bangiophyceae) was used as outgroup. 


\subsubsection{Phylogenetic analysis}

RAxML 7.2.8 (Stamatakis, 2006) was used to construct maximum-likelihood trees (ML) to show the most likely tree from the data set. RAxML was performed with all three codons partitioned for cox 1 but not for LSU and SSU and the GTR+gamma model and 500 non-parametric bootstrap replicates (Felsenstein, 1985).

Further Maximum-likelihood trees were constructed using PHYML (Guindon \& Gascuel, 2003). PHYML analyses were performed using Geneious (GTR model) with 100 non-parametric bootstrapping pseudoreplicates.

Bayesian inference was performed with MrBayes v.3.1.2 (Ronquist \& Huelsenbeck, 2003). Analyses consisted of two independent simultaneous runs of one cold and three incrementally heated chains, and $3 \times 10^{6}$ generations with sampling every 1000 generations. A "burn-in" of $5 \times 10^{5}$ generations was used and 25000 trees were saved to make the consensus tree.

Bootstrap support from RAxML and PHYML and Bayesian posterior probability was added to the constructed RAxML Maximum-likelihood tree to get better supported for our branches using different algorithm.

\subsubsection{Analysis of atp 8 gene}

The edited sequences were searched for open reading frames (ORF) using the genetic code for mold and protozoan mitochondria and a minimum size of 100 base pairs in Geneious. Blastx in Genbank was used to search the protein database for matches for the found open reading frames. The atp 8 gene in Pterocladiophila hemisphaerica, Pterocladia lucida and Gelidium vagum were aligned using MAFFT and pairwise distance calculated. The atp 8 protein sequence of Gelidium vagum 
(YP_008963212) was downloaded from Genbank.

\subsection{Results}

\subsubsection{Chloroplast}

The alignment of the RuBisCO spacer sequences of Pterocladia lucida and Pterocladiophila hemisphaerica was 316 base pairs (Appendix 5). We sequenced two host-parasite combinations from two locations in New Zealand: Kairakau Beach and Akitio Beach. Host and parasite from the same location have identical RuBisCO spacers. Host and parasite combinations were one base pair different in the spacer region between these two locations in New Zealand (Fig. 3.1).

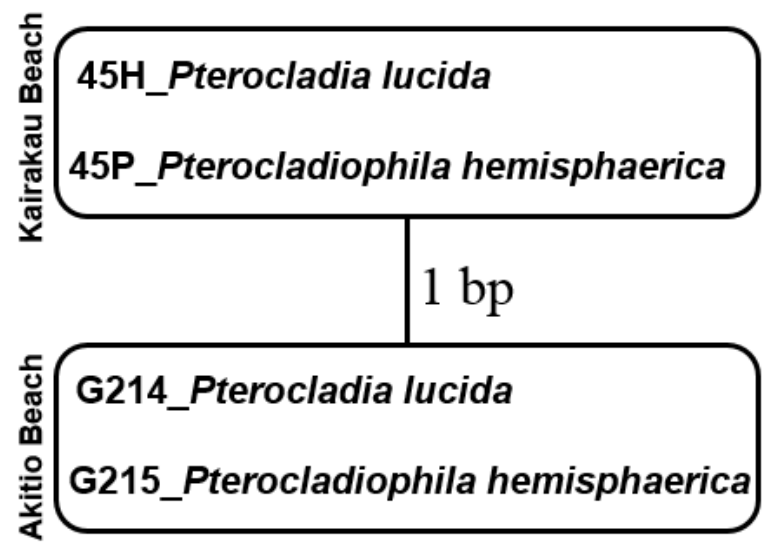

Figure 3.1. Two host-parasite combinations of Pterocladia lucida and Pterocladiophila hemisphaerica from two different locations in New Zealand: Kairakau Beach and Akitio Beach. Samples of hostparasite combinations from the same location have identical RuBisCO spacer and the samples between locations are different by one base pair. 


\subsection{2 $\operatorname{Cox} 1$}

The alignment of partial cox 1 gene sequences was 542 base pairs long (Appendix 6). The cox 1 data set resolved three groups: one containing the host Pterocladia lucida, the second Pterocladiella species (Pterocladiella caerulescens, Pterocladiella capillacea, Pterocladiella psammophila) and the last containing one Pterocladiella capillacea sequence (HQ422696) and the parasite Pterocladiophila hemisphaerica (moderate support). The Pterocladiella capillacea sequence HQ422696 is from Hawaii (USA) and the other Pterocladiella capillacea sequence (HM629885) is from South Korea. Both samples of the host Pterocladia lucida form a well-supported group. Most of the Pterocladiella species form a moderate supported group (Fig. 3.2).

\subsubsection{LSU}

The alignment of the LSU gene sequences is 920 base pairs long (Appendix 7). The partial LSU data resolved three groups (Fig. 3.3): one containing members of the order Gracilariales (Gracilaria spp. and Melanthalia sp.) with strong support. The second group contains the parasite Pterocladiophila hemisphaerica and its 10 closest blast search result but this collection of samples has no bootstrap or Bayesian posterior probability support. The last group containing members of the order Gelidiales (Gelidiella, Gelidium, Pterocladia and Pterocladiella) is negligible supported, especially with PHYML analysis. The parasite Pterocladiophila hemisphaerica groups with Predaea kraftiana (order: Nemastomatales) but without support. Pterocladiophila hemisphaerica groups neither with species in the Gelidiales or Gracilariales. 


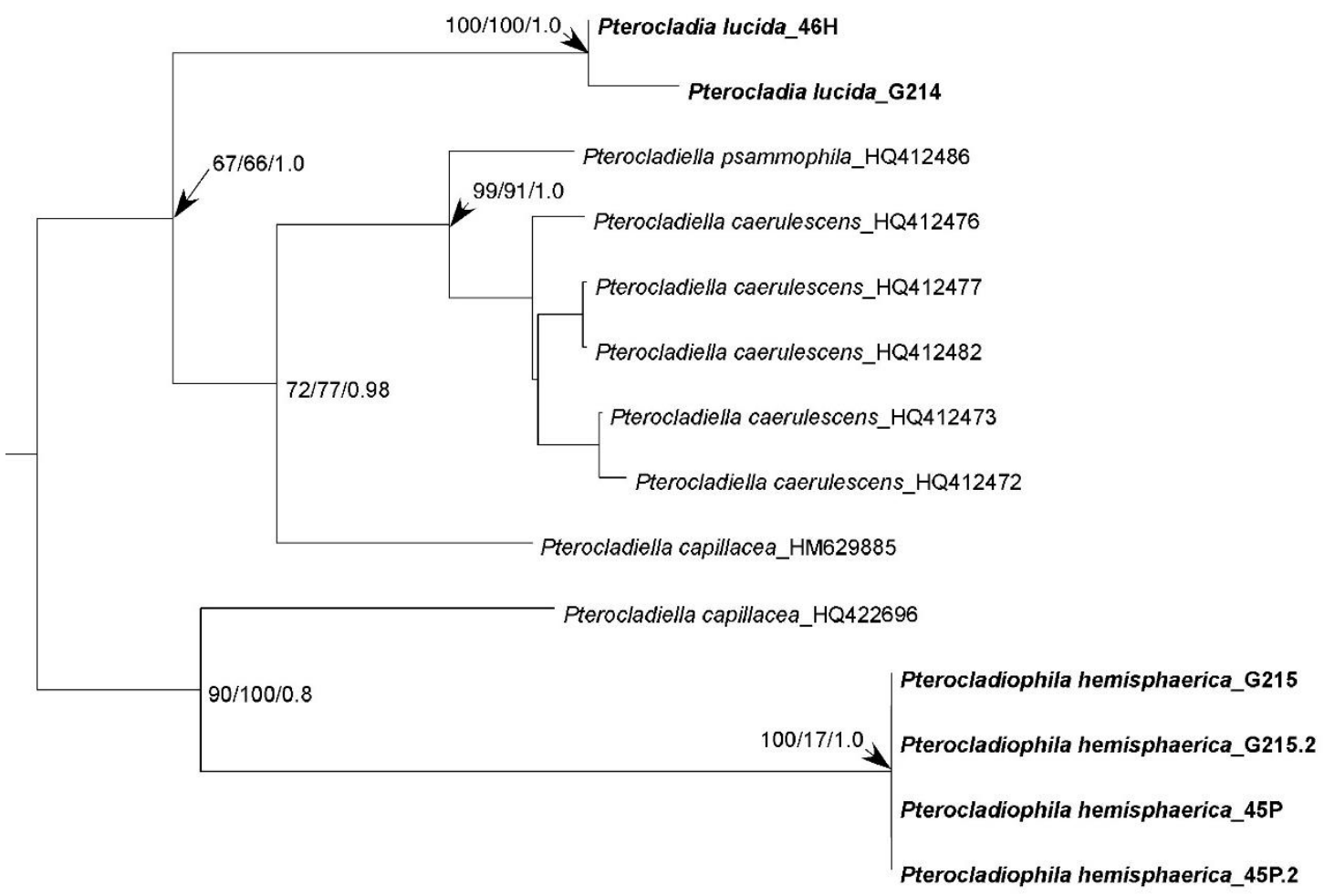

Figure 3.1. ML reconstruction of relationships based on cox1 sequences of Pterocladiophila hemisphaerica, Pterocladia lucida and downloaded Genbank samples of Pterocladiella species. Branches show Bootstrap support by RAxML and PHYLIP, and Bayesian posterior probabilities. Species are followed by their sample number or Genbank accession number. Outgroup removed for clarity.

\subsubsection{SSU}

The alignment of the SSU sequence was 1525 base pairs long (Appendix 8). The SSU data resolved several groups within the Florideophyceae. We will focus on Pterocladiophila hemisphaerica and its relationship to species in the Gracilariales and Gelidiales. Pterocladiophila hemisphaerica is not part of the well-supported group of species in the Gelidiales. Our Pterocladia lucida sequences is grouped with the other Gelidiales. The order Gracilariales is also well supported. All three samples of 
Pterocladiophila hemisphaerica group together and are well supported.

Pterocladiophila hemisphaerica groups with Trematocarpus fragilis but with poor support (Fig. 3.4).

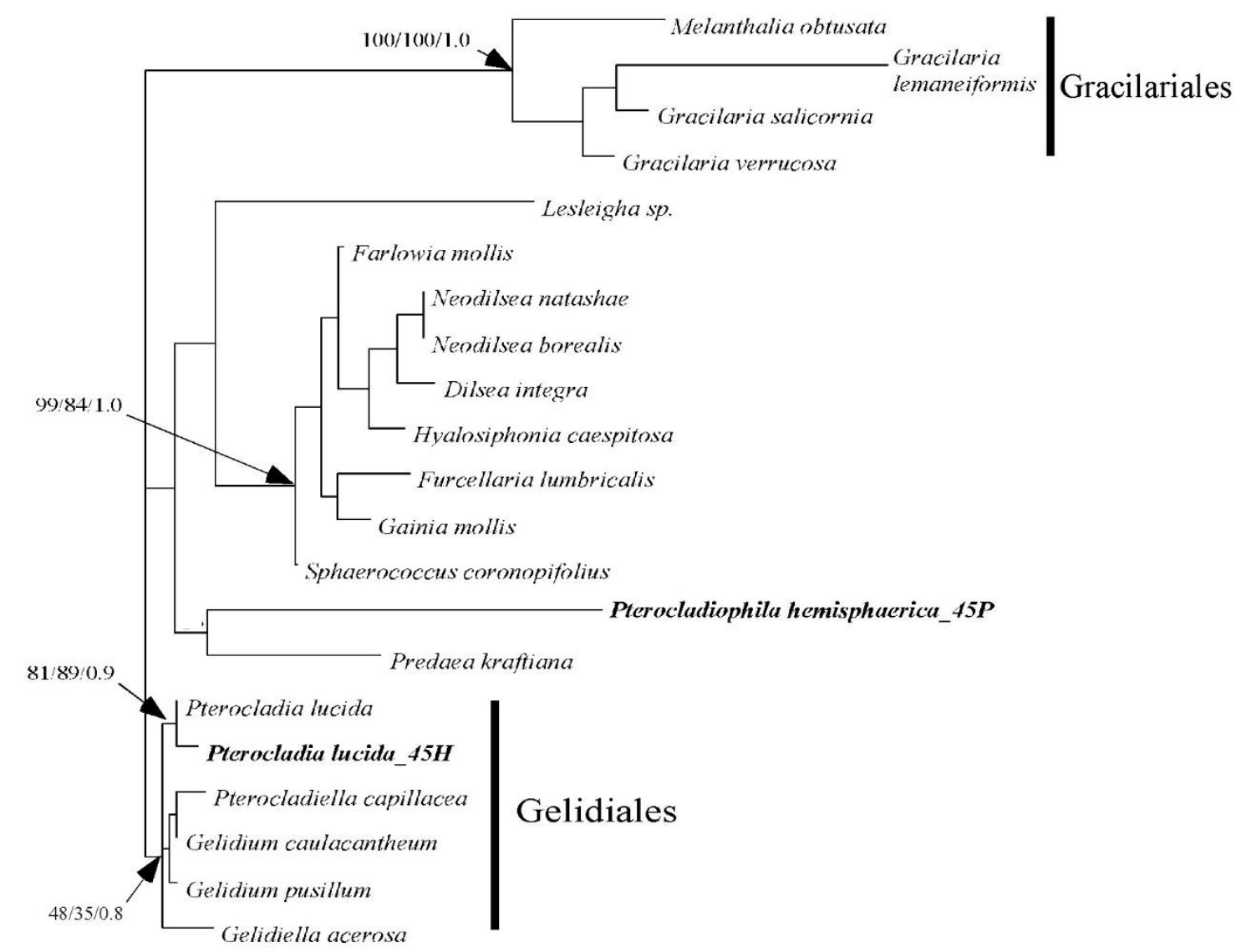

Figure 3.2. ML reconstruction of Pterocladiophila hemisphaerica, Pterocladia lucida and downloaded Genbank samples of species in the Gelidiales (Gelidiella acerosa, Gelidium caulacantheum, Gelidium pusillum, Pterocladia lucida, Pterocladiella capillacea) species in Gracilariales (Gracilaria lemaneiformis, Gracilaria salicornia, Gracilaria verrucosa, Melanthalia obtusata) and top ten blast search for the parasite sample (Dilsea integra, Farlowia mollis, Furcellaria lumbricalis, Gainia mollis, Hyalosiphonia caespitosa, Lesleigh sp., Neodilsea borealis, Neodilsea natashae, Predaea kraftiana, Sphaerococcus coronopifolius) based on LSU data. Branches show Bootstrap support by RAxML and PHYML, and Bayesian posterior probability. Species are followed by their sample number. Outgroup was removed for clarity. 


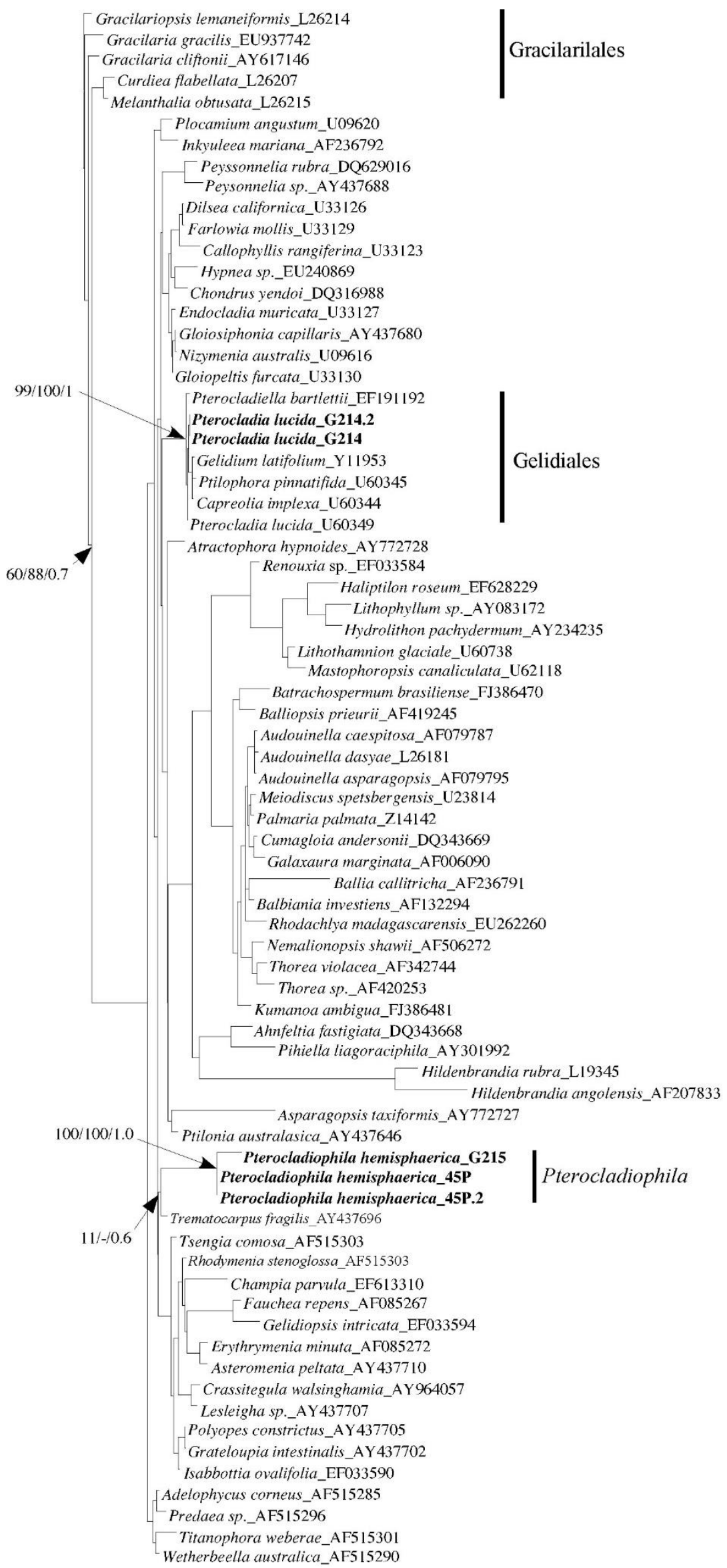


Figure 3.3. ML reconstruction of SSU sequences of member of the Florideophyceae, including Pterocladiophila hemisphaerica, Pterocladia lucida and species downloaded by Genbank. Branches show Bootstrap support by RAxML and PHYML and Bayesian posterior probabilities. Species are followed by their sample number or Genbank accession number. Outgroup was removed for clarity.

\subsubsection{Atp8}

A combination of the forward ATP6F3 and reverse NAD5R2 primer amplified three Pterocladia lucida (45H, 46H, G214) and one Pterocladiophila hemisphaerica sequence (45P). The edited parasite sequence was 615 base pairs long and one open reading was best matched by Blastx to the atp 8 protein from Gracilariopsis andersonii (YP_004062191). The reading frame was from position 209 to 592 and was 383 base pairs long (Appendix 9). The amino acid sequence of the atp 8 sequence of Pterocladiophila hemisphaerica are shown in Fig. 3.5.

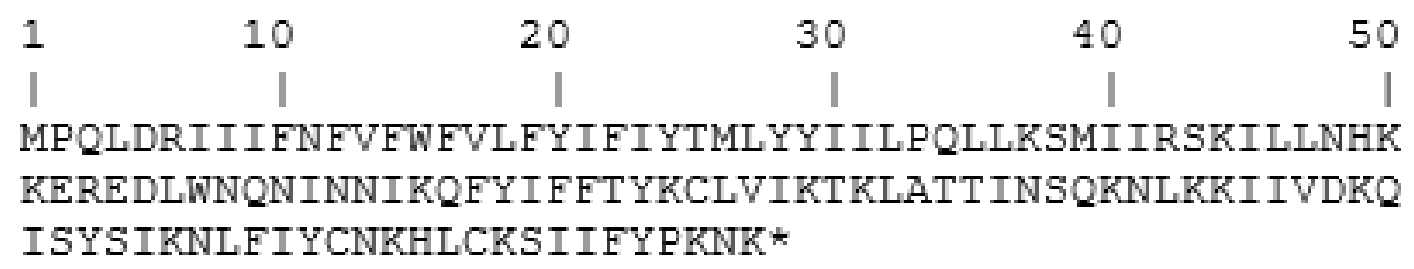

Figure 3.4. Amino acid sequence of the atp8 sequence of Pterocladiophila hemisphaerica.

All edited host sequence contain one open reading frame that matched the atp 8 protein from Gracilariopsis andersonii. The open reading frame of atp 8 was 414 base pairs long in the $45 \mathrm{H}$ and $46 \mathrm{H}$ sample and 402 base pair in the G214 Pterocladia lucida sample (Appendix 10). 
The alignment of the translated amino acid sequences of the atp 8 protein of Pterocladia lucida, Pterocladiophila hemisphaerica and Gelidium vagum showed that the parasite sequence is quite different from the host. One Pterocladia lucida sequence (G214), the Gelidium vagum and Pterocladiophila hemisphaerica have deletion at the end of their sequence but the parasite also shows a deletion in the middle of its sequence (Fig. 3.6).

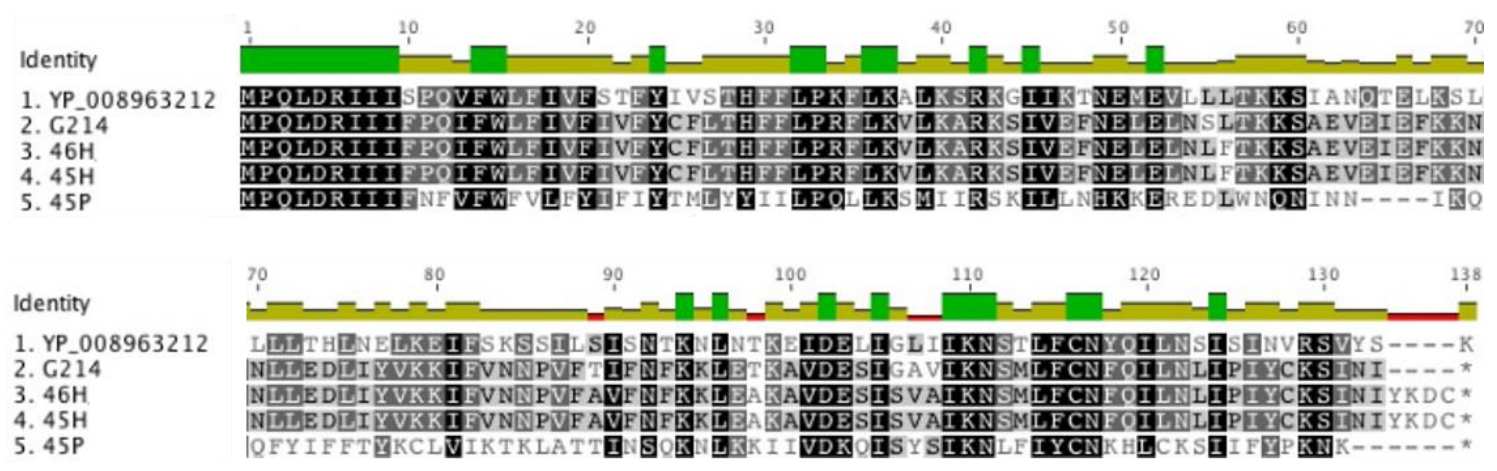

Figure 3.5. Atp8 amino acid alignment of Gelidum vagum (YP_008963232), Pterocladia lucida (45H,

46 H, G214) and Pterocladiophila hemisphaerica (45P). Similarity is highlighted.

Pairwise distance between the atp 8 amino acid sequence show that the sequence of Pterocladiophila hemisphaerica are closer to Gelidium vagum than to the Pterocladia lucida sequence (Tab. 3.3). 
Table 3.3. Pairwise distance between the atp 8 amino acid sequence of Gelidium vagum, Pterocladia lucida and Pterocladiophila hemisphaerica.

\begin{tabular}{|l|c|c|c|c|c|}
\hline & G. vagum & $\begin{array}{c}\text { P. lucida } \\
(45 \mathrm{H})\end{array}$ & $\begin{array}{c}\text { P. lucida } \\
(46 \mathrm{H})\end{array}$ & $\begin{array}{c}\text { P. lucida } \\
(\mathrm{G} 214)\end{array}$ & $\begin{array}{c}\text { Pt. } \\
\text { hemisphaerica }\end{array}$ \\
\hline Gelidium vagum & - & & & & \\
\hline $\begin{array}{l}\text { Pterocladia lucida } \\
\text { (45H) }\end{array}$ & 0.63 & - & & & \\
\hline $\begin{array}{l}\text { Pterocladia lucida } \\
\text { (46H) }\end{array}$ & 0.63 & 0.00 & - & & \\
\hline $\begin{array}{l}\text { Pterocladia lucida } \\
\text { (G214) }\end{array}$ & 0.59 & 0.06 & 0.06 & - & - \\
\hline $\begin{array}{l}\text { Pterocladiophila } \\
\text { hemisphaerica }\end{array}$ & 1.34 & 1.24 & 1.24 & 1.88 & \\
\hline
\end{tabular}

\subsection{Discussion}

Phylogenetic analysis revealed a complex evolutionary relationship between Pterocladiophila hemisphaerica and its host Pterocladia lucida. Phylogenetic analysis showed that Pterocladiophila hemisphaerica has identical RuBisCO spacer with its host Pterocladia lucida, similar mitochondrial genes to Pterocladiella capillacea and nuclear sequences within the Florideophyceae but the nuclear sequences of the parasite neither groups in the Gelidiales or the Gracilariales. The atp 8 gene in Pterocladiophila hemisphaerica seems to be a pseudogene.

The identical RuBisCO spacer sequence between host and parasite suggest that Pterocladiophila hemisphaerica contains the chloroplast of its host. Pterocladiophila hemisphaerica has mitochondrial sequence closer to one sample of Pterocladiella capillacea from Hawaii than to its host Pterocladia lucida suggesting that Pterocladiella capillacea or a related alga was a previous host. Nuclear markers indicated that Pterocladiophila hemisphaerica originated from a different red algal 
order from either the Gelidiales, which contains its host, or Gracilariales, where the parasite has been placed when the family Pterocladiophiloceae was moved.

\subsubsection{Chloroplast}

The identical gene sequences of the chloroplast between host and parasite from the same location and a slight different between host and parasite sequences from different locations in New Zealand, suggest that either only the host chloroplasts were amplified or that the parasite and host share the same chloroplasts. Identical chloroplasts between host and parasite have been found in the parasite Plocamiocolax pulvinata Setchell and its host Plocamium cartilagineum (Linneaus) Dixon using RFLP pattern (Goff \& Coleman, 1995). The identical chloroplasts between host and parasite could be explained by the retention of the chloroplasts by the parasite cell after parasitizing a particular host.

Why does the parasite retain the chloroplast from the host and is it important for the parasite or is it just a coincidence? The easiest explanation for gaining the chloroplast from the host would be photosynthesis, which could be an essential function for the parasite. The red algal parasite Choreocolax polysiphonae Reinsch increases the fixation of $\mathrm{CO}_{2}$ when the parasite is detached from its host Polysiphona lanosa (Linnaeus) Tandy (Callow et al., 1979). No pigmented or non-pigmented red algal parasites are known to be without chloroplasts (Goff, 1982) suggesting a function of these plastids. Other functions of chloroplasts besides photosynthesis are amino acid biosynthesis (Singh \& Matthews, 1994), fatty acid synthesis (Wang \& Benning, 2012), pyrimidine synthesis (Kafer \& Thornburg, 1999) and immune response (Nomura et al., 
2012). Due to the fact that identical chloroplasts are found between other red algal parasites and their hosts (Goff \& Coleman, 1995) it suggests that it is unlikely to be a coincidence. It is likely that the parasite needs particular fatty acids and can not function without them.

\subsubsection{Mitochondria}

Cox 1 gene sequences showed that the red algal parasite Pterocladiophila hemisphaerica is more closely related to one Pterocladiella capillacea sample (HQ422696) from Hawaii than to its host Pterocladia lucida, which suggests that the Hawaiian Pterocladiella capillacea or a related algae is a former host before the parasite switched to Pterocladia lucida. The cox 1 sequence of the parasite shares a common origin with the Hawaiian Pterocladiella capillacea sample to the exclusion of its own host or anyone else so far sequenced. While we tried we were unable to collect and sequence any Pterocladiella capillacea from New Zealand. The parasite had to somehow gain the mitochondria from the Hawaiian Pterocladiella capillacea to show a common origin of the cox 1 gene. A likely explanation would be that Pterocladiophila hemisphaerica gained it from a former host like Pterocladiella capillacea or something related to it. This would indicate that the parasite switched hosts, assuming that the Hawaiian Pterocladiella is a former host. Host-switching seems to be a natural process in the evolution of parasitism (Jackson, 1999) and it is also known in some red algal parasites (Goff et al., 1996, Zuccarello et al., 2004). One example for host-switching is the red algal parasite Ululania stellate Apt et Schlech, where mitochondria (cox1) and nuclear (LSU) are more closely related to Chondria species than to its host Acanthophora pacifica (Setchell) Kraft, which suggest that Ululania stellata shares a 
common origin with a Chondria species, and then switched to an unrelated host (Kurihara et al., 2010).

In red algal parasites there are examples known where the parasite switched hosts but remained on the host of origin or switched hosts and is not growing on the host of origin anymore. One example for the parasite no longer growing on the host of origin is Faucheocolax attenuata Setchell, which grows on Fauchea fryeana Setchell but is more closely related to Fauchea laciniata J. Agardh (Goff et al., 1996). One example for parasitizing two species is Holmsella pachyderma (Reinsch) Sturch, which grows on two species in the same family: Gracilaria gracilis (Stackhouse) Steentoft, Irvine et Farnham and Gracilariopsis longissima (Gmelin) Steentoft, Irvine et Farnham but is closer related to Gracilaria gracilis (Zuccarello et al., 2004). Our study shows that Pterocladiophila hemisphaerica grows neither on its host of origin or on Pterocladiella capillacea but grows on Pterocladia lucida and indicates at least two host-switches of the parasite. The possible two host-switches of the parasite could indicate an old age of the origin of the parasite. The complex history of Pterocladiophila hemisphaerica is the first known case of three different origin of mitochondria, nucleus and chloroplast and this also shows that our knowledge of red algal parasites is still quite limited.

The sequence of Pterocladiella capillacea which groups with the parasite comes from Hawaii. While the other sequences of Pterocladiella capillacea, which groups with all other Pterocladiella species comes from South Korea. A misidentification of one or the other Pterocladiella capillacea would explain why they are not grouped together. The misidentification of the Hawaiian Pterocladiella sample would falsify the 
common origin of the mitochondria between Pterocladiella capillacea and Pterocladiophila hemisphaerica.

Pterocladiella capillacea is also known from New Zealand and it would be interesting to see what the relationship between the parasite and other Pterocladiella samples are. I tried to collected samples of Pterocladiella capillacea from New Zealand but was unsuccessful because Pterocladia lucida and Pterocladiella capillacea are morphological quite similar and hard to distinguish.

\subsubsection{Nuclear DNA}

Partial LSU and SSU showed that the red algal parasites Pterocladiophila hemisphaerica is neither grouped in the Gracilariales or with its hosts order, the Gelidiales. The origin of the parasite could not be resolved. The parasite nuclear sequences always grouped in the Florideophyceae but even when the parasite grouped with another species it was poorly supported. Neither using top ten Blast searches nor using one representative from every family in the Florideophyceae could resolve the nuclear origin of the parasite.

The taxonomic history of Pterocladiophila hemisphaerica is complex. The description of the red algal parasite Pterocladiophila hemisphaerica led to the description of the new family Pterocladiophilaceae, and this was placed in the Cryptonemiales (Fan \& Papenfuss, 1959). Later, Holmsella and Gelidiocolax were added to the family but the family was then grouped in the Gracilariales because of the similarities of Holmsella pachyderma to the Gracilariales. The family was regrouped in the order Gracilariales, including Pterocladiophila hemisphaerica (Fredericq \& Hommersand, 1990). SSU data confirmed that Holmsella pachyderma is closely related 
to species in the Gracilariales (Zuccarello et al., 2004). It seems rather hasty to transfer a whole family because of the similarity of morphological characters between one red algal parasite and its host species. Our data shows that Pterocladiophila hemisphaerica is not a part of the Gracilariales. The family Pterocladiophilaceae has to be removed from the Gracilariales and a new family described for Holmsella. The family Pterocladiophilaceae was created by the morphological characters of Pterocladiophila hemisphaerica (Fan \& Papenfuss, 1959) and the family name must remain with this entity. A new family for Holmsella is recommend. Phylogenetic data is needed to determine the relationships of Gelidioloax to the other red algal parasites placed in the family Pterocladiophilaceae.

The origin of Pterocladiophila hemisphaerica is still unknown but it is clear that the parasite is not part of the Gelidiales. The nuclear DNA of the parasite has a different origin than the mitochondria. A better resolved phylogeny based on nuclear DNA could reveal from where Pterocladiophila hemisphaerica evolved.

\subsubsection{Atp8}

The atp 8 gene could be amplified with our designed primers and atp 8 seems to be present in the parasite Pterocladiophila hemisphaerica but is probably a pseudogene.

Is our open reading frame the atp 8 gene? Our primers were designed to amplify the flanking regions between atp6 and nad5. Open reading frames, which matched the atp 6 and nad5 genes, were found in the $45 \mathrm{H}$ and $46 \mathrm{H}$ Pterocladia lucida sequences and in the Pterocladiophila hemisphaerica sequence. The amplified host sequences had different lengths and the minimum identified size of the open reading frame of 100 base 
pairs would explain why atp6 and nad5 wasn't found in all host sequences. Next, whole sequencing of the mitochondria in red algae showed that all genes are collinear (Burger et al., 1999, Hancock et al., 2010, Hwang et al., 2013, Leblanc et al., 1995, Ohta et al., 1998, Yang et al., 2013, Zhang et al., 2012). Therefore we would expect atp8 between atp 6 and nad5. The Blast search from our atp 8 protein sequences matched it to atp 8 protein sequences in other algal species. Lastly, the atp8 gene in Pterocladiophila hemisphaerica is 383 base pairs long but in Pterocladia lucida $(45 \mathrm{H}, 46 \mathrm{H})$ it is 414 base pairs and in the other Pterocladia lucida sequence (G214) 402 base pairs long, which is a similar size of the atp 8 in Pyropia tenera (402 base pairs, (Hwang et al., 2013), Gracilariopsis lemaneiformis (405 base pairs, (Zhang et al., 2012) and Gelidium vagum (405 base pairs, (Yang et al., 2013). The differences in the length of the atp 8 sequences could be explained by mutations, deletions or insertion in the mitochondria genome. The finding of the flanking regions, the collinear genes in algal mitochondria, the blast search to other atp 8 in other red algae and the similar length of the sequences suggest that the found open reading frame is the atp 8 gene in Pterocladiophila hemisphaerica. A previous paper (Hancock et al., 2010) indicates that atp8 is non-functional in other parasites, e. g. in Gracilariophila oryzoides. The Pterocladiophila hemisphaerica gene is shorter that in its host, so the question is, is it functional in this parasite? There are two reasons to suggest that atp8 in Pterocladiophila hemisphaerica is nonfunctional: 1) there is a deletion of four amino acid in a conserved region in the middle of the parasite sequence; and 2) there are fewer conserved amino acid regions in Pterocladiophila hemisphaerica when compared to the sequences of Pterocladia lucida and Gelidium vagum. Overall, atp8 in Pterocladiophila hemisphaerica is present but it 
is probably a pseudogene because of the deletion in a conserved region and fewer conserved regions.

\subsubsection{Phylogenetic studies in red algal parasites}

A possible scenario to explain the origin and results of the organelles is that Pterocladiophila hemisphaerica originated on an unknown red algal species, and this relationship is revealed by nuclear DNA sequences. It retained a mitochondria after switching hosts to Pterocladiella capillacea and then gained the host chloroplast when it switched host to Pterocladia lucida.

This is the first study using nuclear (SSU, LSU) and mitochondrial marker (cox1) to show that the parasite is not closely related to its host and in another family. The evolutionary history of Pterocladiophila hemisphaerica is the first known case with at least two host-switches. The complex evolutionary history of the parasite suggests that at some point there was a close relationship to its host when the parasite originated but because of host-switching the close relationship between the parasite and its host of origin changed and therefore there isn't a clear distinction of "adelphoparasite" and "alloparasite", which was already indicated by other studies (Goff et al., 1996, Zuccarello et al., 2004). Interestingly, there are more red algal parasites that are closely related to their host than red algal parasites which are not closely related to their hosts (Goff et al., 1997, Goff \& Coleman, 1995, Goff et al., 1996, Kurihara et al., 2010, Ng et al., 2013, Zuccarello et al., 2004). Is host-switching in red algal parasite to another order the exception and most red algal parasite stay on closely related species? This question could probably only be answered with further phylogenetic studies in red algal parasites as only a small subset have been studied so far. 


\section{Discussion}

This study has four main findings: 1) the description of a new red algal parasite Rhodophyllis parasitica sp. nov. which is closely related to its host Rhodophyllis membranacea; 2) the evolutionary relationships of red algal parasite Pterocladiophila hemisphaerica showing it evolved in the Florideophyceae but it originated neither from the Gracilariales or Gelidiales; 3) the host switching of Pterocladiophila hemisphaerica at least two times, shown by three different origins of its chloroplast, mitochondria and nuclear DNA; and 4) atp8 is present in Pterocladia lucida and Pterocladiophila hemisphaerica, but atp8 in Pterocladiophila hemisphaerica is probably a pseudogene.

The red algal parasite Rhodophyllis parasitica sp. nov. is morphologically and genetically similar to its host Rhodophyllis membranacea, which suggests that the parasite evolved recently from its host. Rhodophyllis parasitica is easily distinguishable from the described Rhodophyllis species in New Zealand but shares morphological characters with Rhodophyllis. The monophyly of the genus Rhodophyllis can only be maintained when the parasite is grouped in it.

Pterocladiophila hemisphaerica is placed in the family Pterocladiophilaceae (Fan \& Papenfuss, 1959) which is presently part of the order Gracilariales (Fredericq \& Hommersand, 1990). This is not supported by our data. Another member of the Pterocladiophilaceae is the red algal parasite Holmsella pachyderma (Reinsch) Sturch, which is closely related to species in the Gracilariales (Zuccarello et al., 2004). The different relationships of the two red algal parasites make it clear that the family Pterocladiophilaceae needs to be reevaluated and probably split.

The relatively newly evolved red algal parasite Rhodophyllis parasitica 
compared to the more anciently evolved parasites Pterocladiophila hemisphaerica shows the complexity of diversity in the evolution of parasitic red algae. Some parasites are relatively young and very similar to their hosts. One example for a relatively young parasite is Congracilaria babae Yamatoto growing on Gracilaria salicornis Yamamoto, where host and parasite nuclear DNA are more closely related to each other than to other species in the Gracilariales (Ng et al., 2013). Some parasites are older and more distantly related to their hosts. This is shown by the red algal parasite Plocamiocolax pulvinata Setchell growing on Plocamium cartilagineum (Linnaeus) Dixon while the parasite is more closely related to Plocamium violaceum Farlow, which suggests that the parasite evolved on Plocamium violaceum, radiated to its current host and now is not found on Plocamium violaceum anymore (Goff et al., 1996). Then there are parasites like Pterocladiophila hemisphaerica that are not even in the same order as their hosts.

Even though atp 8 is an essential coding gene for the ATP synthase, it is assumed to be a pseudogene in the parasite Gracilariophila oryzoides Setchell et Wilson and is even missing in the parasite Plocamiocolax pulvinata (Hancock et al., 2010). The atp8 is present in Pterocladiophila hemisphaerica but we suggest that it is a pseudogene also.

This study adds to the knowledge of red algal and red algal parasite diversity in New Zealand. It's the first study with a phylogenetic analysis of red algal parasites in New Zealand and one of a few studies to described development of red algal parasites. Rhodophyllis parasitica sp. nov. is the first described red algal parasite species in New Zealand in 55 years and Pterocladiophila hemisphaerica is the first parasite with organelles and nuclei with different histories of origin. 
Future research in red algae parasite is important to get a better understanding of red algal parasite evolution. What are the genomic consequences of becoming parasitic? Whole genome sequencing could address this question (Schuster, 2008). Comparisons of whole genomes between different parasites and their hosts could help to understanding which genes are lost or expanded and which organelles are reduced after a red algae becomes parasitic. Another research project could be the study of the development in different parasitic red algae species in New Zealand. There are only a few developmental studies on red algal parasites and further research would give an insight in the different infection mechanism and show the similarities and differences in parasite infection, cell transformation and changes in the infected hosts between parasitic species. Another possibility is the further study of the phylogenetic relationships of the other red algal parasites and their hosts in New Zealand? There are also several more known but undescribed red algal parasites in New Zealand, for example on Polysiphonia atterima Greville, Callophyllis calliblepharoides J. Agardh and Sarcodia sp. 


\section{References}

Adl, S. M., Simpson, A. G. B., Farmer, M. A., Andersen, R. A., Anderson, O. R., Barta, J. R., Bowser, S. S., Brugerolle, G., Fensome, R. A., Fredericq, S., James, T. Y., Karpov, S., Kugrens, P., Krug, J., Lane, C. E., Lewis, L. A., Lodge, J., Lynn, D. H., Mann, D. G., McCourt, R. M., Mendoza, L., Moestrup, Ø., MozleyStandridge, S. E., Nerad, T. A., Shearer, C. A., Smirnov, A. V., Spiegel, F. W. \& Taylor, M. F. J. R. 2005. The New Higher Level Classification of Eukaryotes with Emphasis on the Taxonomy of Protists. Journal of Eukaryotic Microbiology 52:399-451.

Apt, K. E. \& Schlech, K. E. 1998. Ululania stellata gen. et sp. nov. (Rhodomelaceae), a new genus and species of parasitic red algae from Hawaii. Phycologia 37:15761.

Ashen, J. B. \& Goff, L. J. 1998. Galls on the Marine Red Alga Prionitis lanceolata (Halymeniaceae): Specific Induction and Subsequent Development of an AlgalBacterial Symbiosis. American Journal of Botany 85:1710.

Bäckhed, F., Ley, R. E., Sonnenburg, J. L., Peterson, D. A. \& Gordon, J. I. 2005. HostBacterial Mutualism in the Human Intestine. Science 307:1915-20.

Ball, S., Colleoni, C., Cenci, U., Raj, J. N. \& Tirtiaux, C. 2011. The evolution of glycogen and starch metabolism in eukaryotes gives molecular clues to understand the establishment of plastid endosymbiosis. Journal of Experimental Botany 62:1775-801.

Bary, A. d. 1879. Die Erscheinungen der Symbiose. Karl J. Trübner, Strassbourg,

Batters, E. A. L. 1895. On some New British Marine Algae. Annals of Botany os-9:30721.

Björk, M., Mohammed, S. M., Björklund, M. \& Semesi, A. 1995. Coralline Algae, Important Coral-reef Builders Treatened by Pollution. Ambio 24:502-05.

Blouin, N. A. \& Lane, C. E. 2012. Red algal parasites: Models for a life history evolution that leaves photosynthesis behind again and again. BioEssays : news and reviews in molecular, cellular and developmental biology 34:226-35.

Børgesen, F. 1920. Part 3. Rhodophyceae. The marine algae of the Danish West Indies. Dansk Botanisk Arkiv.

Bula-Meyer, G. 1985. Champiocolax sarae gen. et sp. nov., an adelphohemiparasite of the Champiaceae (Rhodymeniales, Rhodophyta). Phycologia 24:429-35.

Burger, G., Saint-Louis, D., Gray, M. W. \& Lang, B. F. 1999. Complete Sequence of the Mitochondrial DNA of the Red Alga Porphyra purpurea: Cyanobacterial Introns and Shared Ancestry of Red and Green Algae. The Plant Cell 11.

Callow, J. A., Callow, M. E. \& Evans, L. V. 1979. Nutritional Studies on the Parasitic Red Alga Choreocolax polysiphoniae. New Phytol 83:451-62.

Chapman, V. J. 1969. Marine Algae of New Zealand. J. Cramer,

Chenuil, A. 2006. Choosing the right molecular genetic markers for studying biodiversity: from molecular evolution to practical aspects. Genetica 127:10120.

Clement, M., Posada, D. \& Crandall, K. A. 2000. TCS: a computer program to estimate gene genealogies. Molecular Ecology 9:1657-9. 
Cotton, A. D. 1908. The New Zealand Species of Rhodophyllis. Bulletin of Miscellaneous Information (Royal Gardens, Kew) 1908:97-102.

Evans, L. V., Callow, J. A. \& Callow, M. E. 1978. Parasitic Red Algae: An Appraisal. In: Irvine, D. E. G. \& Price, J. G. [Eds.] Modern Approaches to the Taxonomy of Red and Brown Algae. Academic Press, London and New York, pp. 87-109.

Fan \& Papenfuss 1959. Red algal parasites occurring on members of the Gelidiales. Madroño 15:33-38.

FAO 2012. The state of World Fisheries and Aquaculture. In: Nations, F. a. A. O. o. t. U. [Ed.]. Rome.

Felsenstein, J. 1985. Confidence-Limits on Phylogenies - an Approach Using the Bootstrap. Evolution 39:783-91.

Flint, J., Harding, R. M., Clegg, J. B. \& Boyce, A. J. 1992. Why are some genetic diseases common? Human Genetics 91:91-117.

Fredericq, S. \& Hommersand, M. 1990. Morphology and Systematics of Holmsella pachyderma (Pterocladiophilaceae, Gracilariales). British Phycological Journal 25:39-51.

Freshwater, D. W., Fredericq, S., Butler, B. S., Hommersand, M. H. \& Chase, M. W. 1994. A gene phylogeny of the red algae (Rhodophyta) based on plastid $r b c \mathrm{~L}$. Proceedings of the National Academy of Sciences of the United States of America 91:7281-5.

Fujii, M. \& Toyota, G. 1999. Morphological studies of the parasitic red alga Janczewskia moriformis (Rhodomelaceae, Ceramiales) from Brazil. Phycologia 38:1-7.

Gilmore, D. P., Da Costa, C. P. \& Duarte, D. P. F. 2001. Sloth biology: an update on their physiological ecology, behavior and role as vectors of arthropods and arboviruses. Brazilian Journal of Medical and Biological Research 34:9-25.

Goff, L. \& Coleman, A. W. 1984. Transfer of nuclei from a parasite to its host. Proceedings of the National Academy of Sciences of the United States of America 81:5420-24.

Goff, L. \& Coleman, A. W. 1985. The role of secondary pit connections in red algal parasitism. J Phycol 21:483-508.

Goff, L. \& Coleman, A. W. 1987. Nuclear Transfer from Parasite to Host. In: Lee, J. J. \& Fredrick, J. F. [Eds.] Endocytobiology. New York Academy of Sciences, New York, pp. 402-23.

Goff, L. J. 1982. The biology of parasitic red algae. In: Round, F. E. \& Chapman, D. J. [Eds.] Progress in Phycological Research. Elsevier Biomedical Press, Amsterdam, pp. 289-369.

Goff, L. J., Ashen, J. \& Moon, D. 1997. The evolution of parasites from their hosts: A case study in the parasitic red algae. Evolution 51:1068-78.

Goff, L. J. \& Coleman, A. W. 1995. Fate of Parasite and Host Organelle DNA during Cellular-Transformation of Red Algae by Their Parasites. Plant Cell 7:1899-911.

Goff, L. J., Moon, D. A., Nyvall, P., Stache, B., Mangin, K. \& Zuccarello, G. 1996. The evolution of parasitism in the red algae: Molecular comparisons of adelphoparasites and their hosts. J Phycol 32:297-312.

Goff, L. J. \& Zuccarello, G. 1994. The Evolution of Parasitism in Red Algae - Cellular Interactions of Adelphoparasites and Their Hosts. J Phycol 30:695-720. 
Gordon, D. P., Beaumont, J., MacDiarmid, A., Robertson, D. A. \& Ahyong, S. T. 2010. Marine Biodiversity of Aotearoa New Zealand. PLoS One 5:e10905.

Graham, L. E. \& Wilcox, L. W. 1999. Algae. Benjamin Cummings,

Guindon, S. \& Gascuel, O. 2003. A simple, fast, and accurate algorithm to estimate large phylogenies by maximum likelihood. Systematic biology 52:696-704.

Guiry, M. D. \& Guiry, G. M. 2013. Algaebase.

Hancock, L., Goff, L. \& Lane, C. 2010. Red algae lose key mitochondrial genes in response to becoming parasitic. Genome biology and evolution 2:897-910.

Harper, J. T. \& Saunders, G. W. 2001. The application of sequences of the ribosomal cistron to the systematics and classification of the florideophyte red algae (Florideophyceae, Rhodophyta). Cah Biol Mar 42:25-38.

Harvey 1855. Some Account of the Marine Botany of the Colony of Western Australia.

Hwang, M. S., Kim, S. O., Ha, D. S., Lee, J. E. \& Lee, S. R. 2013. Complete sequence and genetic features of the mitochondrial genome of Pyropia tenera (Rhodophyta). Plant Biotechnol Rep 7:435-43.

Jackson 1999. Analysis of parasite host-switching: limitations on the use of phylogenies. Parasitology 119:111-23.

Kafer \& Thornburg 1999. Pyrimidine Metabolism in Plants. Paths Pyrimidines:14-24.

Katoh, K., Misawa, K., Kuma, K. \& Miyata, T. 2002. MAFFT: a novel method for rapid multiple sequence alignment based on fast Fourier transform. Nucleic acids research 30:3059-66.

Kim, M.-S. \& Cho, G.-Y. 2010. A new red algal parasite, Sympphycolax koreana gen. et. sp. nov. (Rhodomelaceae, Ceramiales), from Korea. Algae 25:105-13.

Koga, R., Tsuchida, T. \& Fukatsu, T. 2003. Changing partners in an obligate symbiosis: a facultative endosymbiont can compensate for loss of the essential endosymbiont Buchnera in an aphid. Proceedings of the Royal Society of London. Series B: Biological Sciences 270:2543-50.

Konig, H., Li, L. \& Frohlich, J. 2013. The cellulolytic system of the termite gut. Applied microbiology and biotechnology 97:7943-62.

Kraft, G. T. \& Abbott, I. A. 2002. The anatomy of Neotenophycus ichthyosteus gen. et sp. nov. (Rhodomelaceae, Ceramiales), a bizarre red algal parasite from the central Pacific. European Journal of Phycology 37:269-78.

Künzenbach, R. \& Brucker, W. 1960. Zur Bildung von "Tumoren" an Meeresalgen II. Berichte der Deutschen Botanaischen Gesellschaft 73:8-18.

Kurihara, A., Abe, T., Tani, M. \& Sherwood, A. R. 2010. Molecular Phylogeny and Evolution of Red Algal Parasites: A Case Study of Benzaitenia, Janczewskia, and Ululania (Ceramiales)1. J Phycol 46:580-90.

Kützing, F. T. 1843. Phycologia generalis oder Anatomie, Physiologie und Systemkunde der Tange. F. A. Brockhaus, Leipzig,

Kützing, F. T. 1847. Diagnosen und Bemerkungen zu neuen oder kritischen Algen. Botanische Zeitung 5.

Kylin, H. 1941. Californische Rhodophyceen. Acta Universitatis Lundensis,

Leblanc, C., Boyen, C., Richard, O., Bonnard, G., Grienenberger, J. M. \& Kloareg, B. 1995. Complete Sequence of the Mitochondrial DNA of the Rhodophyte Chondrus crispus (Gigartinales). Gene Content and Genome Organization. Journal of molecular biology 250:484-95. 
Lee, I. K. \& Kurogi, M. 1978. Neohalosacciocolax aleutica gen. et sp. nov. (Rhodophyta), parasitic on Halosaccion minjaii I. K. Lee from the North Pacific. British Phycological Journal 13:131-39.

Les, D. H. 1991. Genetic Diversity in the Monoecious Hydrophile Ceratophyllum (Ceratophyllaceae). American Journal of Botany 78:1070-82.

Maggs, Douglas, Fenety \& Bird 1992. A molecular and morphological analysis of the Gymnogrongus devoniensis (Rhodophyta) complex in the North Atlantic. $J$ Phycol 28.

Muscatine, L. \& Porter, J. W. 1977. Reef Corals: Mutualistic Symbioses Adapted to Nutrient-Poor Environments. BioScience 27:457-60.

Nelson, W. 2013. New Zealand Seaweeds. Museum of New Zealand Te Papa Tongarewa, Wellington,

Nelson, W. A., Dalen, J. \& Neill, K. F. 2013. Insights from natural history collections: analysing the New Zealand macroalgal flora using herbarium data. PhytoKeys:121.

Neuhauser, C. \& Fargione, J. E. 2004. A mutualism-parasitism continuum model and its application to plant-mycorrhizae interactions. Ecological modelling 177:337-52.

Ng, P.-K., Lim, P.-E., Kato, A. \& Phang, S.-M. 2013. Molecular evidence confirms the parasite Congracilaria babae (Gracilariaceae, Rhodophyta) from Malaysia. Journal of Applied Phycology.

Noble, J. M. \& Kraft, G. T. 1983. Three new species of parasitic red aglae (Rhodophyta) from Australia: Holmsella australis sp. nov., Meridiocolax bracteata sp. nov. and Trichidium pedicellatum gen. et sp. nov. British Phycological Journal 18:391-413.

Nomura, H., Komori, T., Uemura, S., Kanda, Y., Shimotani, K., Nakai, K., Furuichi, T., Takebayashi, K., Sugimoto, T., Sano, S., Suwastika, I. N., Fukusaki, E., Yoshioka, H., Nakahira, Y. \& Shiina, T. 2012. Chloroplast-mediated activation of plant immune signalling in Arabidopsis. Nature communications 3:926.

Norris, R. E. 1988. A review of Colacopsis and Melanocolax, red algal parasites on South African Rhodomelaceae (Rhodophyta). British Phycological Journal 23:229-37.

Ohkuma, M. 2008. Symbioses of flagellates and prokaryotes in the gut of lower termites. Trends in microbiology 16:345-52.

Ohta, N., Sato, N. \& Kuroiwa, T. 1998. Structure and organization of the mitochondrial genome of the unicellular red alga Cyanidioschyzon merolae deduced from the complete nucleotide sequence. Nucleic acids research 26:5190-8.

Oliveira, M. C. \& Bhattacharya, D. 2000. Phylogeny of the Bangiophycidae (Rhodophyta) and the secondary endosymbiotic origin of algal plastids. American Journal of Botany 87:482-92.

Paracer, S. \& Ahmadjian, V. 2000. Symbiosis: An introduction to biological associations. Oxford University Press,

Parniske, M. 2008. Arbuscular mycorrhiza: the mother of plant root endosymbioses. Nature Reviews Microbiology 6:763-75.

Pirozynski, K. A. \& Malloch, D. W. 1975. The origin of land plants: a matter of mycotrophism. Bio Systems 6:153-64.

Pocock, M. A. 1956. South African Parasitic Florideae and Their Hosts: 3. Four Minute 
Parasitic Florideae. Proceedings of the Linnean Society of London 167:11-41.

Porter, J. W. 1976. Autotrophy, Heterotrophy, and Resource Partitioning in Caribbean Reef-Building Corals. The American Naturalist 110:731-42.

Poulin, R. \& Morand, S. 2000. The diversity of parasites. The Quarterly Review of Biology 75:277-93.

Pueschel, C. M. 1990. Cell structure. In: M.;, C. K. \& G., S. R. [Eds.] Biology of the Red Algae. Cambridge University Press, Cambridge.

Reyes-Prieto, A., Weber, A. P. \& Bhattacharya, D. 2007. The origin and establishment of the plastid in algae and plants. Annual review of genetics 41:147-68.

Ronquist, F. \& Huelsenbeck, J. P. 2003. MrBayes 3: Bayesian phylogenetic inference under mixed models. Bioinformatics 19:1572-4.

Roossinck, M. J. 2011. The good viruses: viral mutualistic symbioses. Nature 9:99-108.

Saunders, G. W. 2005. Applying DNA barcoding to red macroalgae: a preliminary appraisal holds promise for future applications. Philosophical Transactions of the Royal Society B: Biological Sciences 360:1879-88.

Saunders, G. W., Chiovitti, A. \& Kraft, G. T. 2004. Small-subunit rDNA sequences from representatives of selected families of the Gigartinales and Rhodymeniales (Rhodophyta). 3. Delineating the Gigartinales sensu stricto. Canadian Journal of Botany 82:43-74.

Saunders, G. W. \& Hommersand, M. H. 2004. Assessing red algal supraordinal diversity and taxonomy in the context of contemporary systematic data. American Journal of Botany 91:1494-507.

Saunders, G. W. \& Kraft, G. T. 1994. Small-subunit rRNA gene sequences from representatives of selected families of the Gigartinales and Rhodymeniales (Rhodophyta). 1. Evidence for the Plocamiales ord.nov. Canadian Journal of Botany 72:1250-63.

Saunders, G. W. \& Moore, T. E. 2013. Refinements for the amplification and sequencing of red algal DNA barcode and RedToL phylogenetic markers: a summary of current primers, profiles and strategies. Algae 28:31-43.

Schmitz, F. \& Falkenberg, P. 1897. Rhodomelaceae. In: Engler, A. \& Prantl, K. [Eds.] Die natürlichen Pflanzenfamilien nebst ihren Gattungen und wichtigeren Arten insbesondere den Nutzpflanzen unter Mitwirkungen zahlreicher hervorragender Fachgelehrten. Verlag von Wilhelm Engelmann, pp. 421-80.

Schneider, C. W. \& Wynne, M. J. 2007. A synoptic review of the classification of red algal genera a half century after Kylin's "Die Gattungen der Rhodophyceen”. Botanica Marina 50.

Schussler, A., Schwarzott, D. \& Walker, C. 2001. A new fungal phylum, the Glomeromycota: phylogeny and evolution. Mycol Res 105:1413-21.

Schuster, S. C. 2008. Next-generation sequencing transforms today's biology. Nature methods 5:16-8.

Setchell, W. A. 1918. Parasitism among the red algae. Proceedings of the American Philosophical Society 57:155-72.

Singh, B. K. \& Matthews, B. F. 1994. Molecular regulation of amino acid biosynthesis in plants. Amino acids 7:165-74.

Smit, A. J. 2004. Medicinal and pharmaceutical uses of seaweed natural products: A review. Journal of Applied Phycology 16:245-62. 
Smith, D. C. \& Douglas, A. E. 1987. The Biology of Symbiosis. Arnold, Edward, London,

Stamatakis, A. 2006. RAxML-VI-HPC: maximum likelihood-based phylogenetic analyses with thousands of taxa and mixed models. Bioinformatics 22:2688-90.

Stoddart, D. R. 1969. Ecology and Morphology of Recent Coral Reefs. Biol Rev 44:433-\&.

Trampuz, A., Jereb, M., Muzlovic, I. \& Prabhu, R. M. 2003. Clinical review: Severe malaria. Critical care 7:315-23.

van den Hoek, C., Mann, D. \& Jahns, H. M. 1996. Algae: An introduction to phycology. Cambridge University Press,

Wang, Z. \& Benning, C. 2012. Chloroplast lipid synthesis and lipid trafficking through ER-plastid membrane contact sites. Biochemical Society transactions 40:457-63.

Waters, A. P., Higgins, D. G. \& McCutchan, T. F. 1991. Plasmodium falciparum appears to have arisen as a result of lateral transfer between avian and human hosts. Proceedings of the National Academy of Sciences 88:3310-144.

Wetherbee, R. \& Quirk, H. M. 1982. The Fine Structure and Cytology of the Association Between the Parasitic Red Alga Holmsella australis and Its Red Algal Host Gracilaria furcellata. Protoplasma 110:153-65.

White, Bruns, Lee \& Taylor 1990. Amplification and direct sequencing of fungal ribosomal RNA genes for phylogenetics. In: Michael A. Innis, David H. Gelfand, John J. Sninsky \& White, T. J. [Eds.] PCR Protocols: A guide to Methods and Applications. Academic Press, Orlando, pp. 315-22.

Wikfors, G. H. \& Ohno, M. 2001. Impact of algal research in aquaculture. J Phycol 37:968-74.

Womersley, H. B. S. 1994. The marine benthic flora of Southern Australia Australian Biological Resources Study, Canberra,

Wynne, M. J. \& Scott, F. 1989. Pitycolax, a new genus of Adelphoparasitic red algae from Ile Amsterdam, Southern Indian Ocean. Cryptogamie, Algologie 10:23-32.

Yang, E. C., Kim, K. M., Boo, G. H., Lee, J. H., Boo, S. M. \& Yoon, H. S. 2013. Complete mitochondrial genome of the agarophyte red alga Gelidium vagum (Gelidiales). Mitochondrial DNA.

Yoon, H. S., Hackett, J. D., Ciniglia, C., Pinto, G. \& Bhattacharya, D. 2004. A Molecular Timeline for the Origin of Photosynthetic Eukaryotes. Molecular Biology and Evolution 21:809-18.

Yoon, H. S., Hackett, J. D., Pinto, G. \& Bhattacharya, D. 2002. The single, ancient origin of chromist plastids. Proceedings of the National Academy of Sciences of the United States of America 99:15507-12.

Yoon, H. S., Muller, K. M., Sheath, R. G., Ott, F. D. \& Bhattacharya, D. 2006. Defining the major lineages of red algae (Rhodophyta). J Phycol 42:482-92.

Yoon, H. S., Zuccarello, G. C. \& Bhattacharya, D. 2010. Evolutionary history and taxonomy of red algae. Red algae in the genomic age. Springer, pp. 25-42.

Yoshida, T. \& Mikami, H. 1996. Sorellocolax stellaris gen. et sp. nov., a hemiparasitic alga (Delesseriaceae, Rhodophyta) from the east coast of Honshu, Japan. Phycological Research 44:125-28.

Zhang, L., Wang, X., Qian, H., Chi, S., Liu, C. \& Liu, T. 2012. Complete Sequences of the Mitochondrial DNA of the Wild Gracilariopsis lemaneiformis and Two 
Mutagenic Cultivated Breeds (Gracilariaceae, Rhodophyta). PLoS One 7:e40241.

Zuccarello, G. \& West, J. 1994a. Host specificity on the red algal parasites Bostrychioclax australis and Dawsoniocolax bostrychiae (Choreocolacaceae, Rhodophyta). J Phycol 30:762-473.

Zuccarello, G. C. 2008. A fungal gall of Catenella nipae (Caulacanthaceae, Rhodophyta) and a review of Catenellocolax leeuweni. Botanica Marina 51:436-40.

Zuccarello, G. C., Burger, G., West, J. A. \& King, R. J. 1999. A mitochondrial marker for red algal intraspecific relationships. Molecular Ecology 8:1443-7.

Zuccarello, G. C., Moon, D. \& Goff, L. J. 2004. A Phylogenetic Study of Parasitic Genera Placed in the Family Choreocolacaceae (Rhodophyta). J Phycol 40:93745.

Zuccarello, G. C. \& West, J. A. 1994b. Comparative Development of the Red Algal Parasites Bostrychiocolax australis gen. et sp. nov. and DawsoniocolaxBostrychiae (Choreocolacaceae, Rhodophyta). J Phycol 30:137-46.

Zuccarello, G. C. \& West, J. A. 1994c. Genus and race specificity in the red algal parasite Leachiella pacifica (Choreocolacaceae, Rhodophyta). Phycologia 33:213-18.

Zuccarello, J. 2011. What Are You Eating? It May Be Nori, but It Is Probably Not Porphyra Anymore! J Phycol 47:967-68. 


\section{Appendices}

\section{Appendix 1}

ITS alignment of Rhodophyllis membranacea $(2 \mathrm{H}, 3 \mathrm{H}, 4 \mathrm{H}, 5 \mathrm{H}, 9 \mathrm{H}, 12 \mathrm{H}, 14 \mathrm{H}$,

$15 \mathrm{H}, 40 \mathrm{H}, 43 \mathrm{H}, 44 \mathrm{H})$ and it's parasite (2P, 3P, 4P, 5P, 9P, 13P, 14P, 40P, 42P, 43P, 44P)

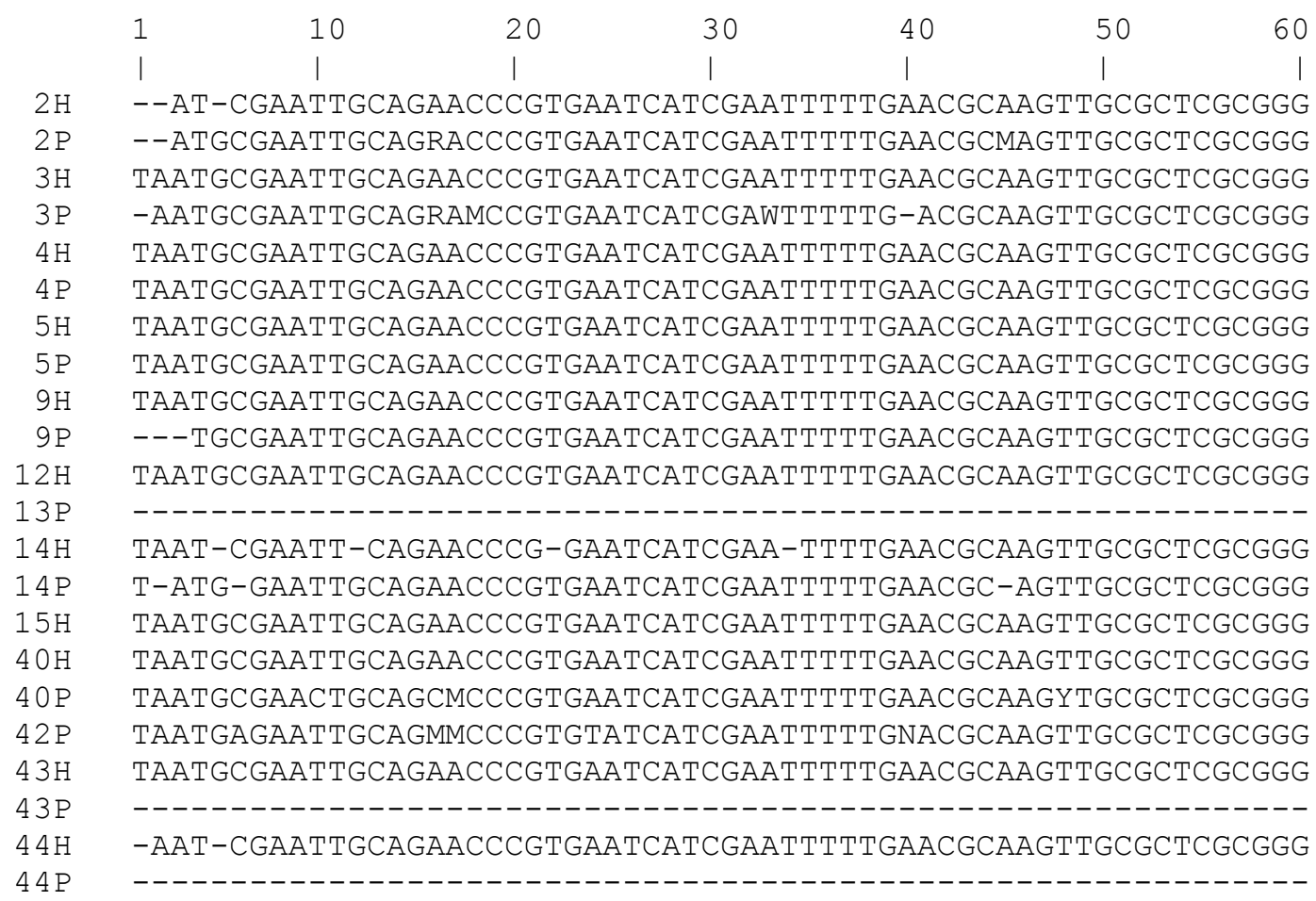


$\begin{array}{lllllll}61 & 70 & 80 & 90 & 100 & 110 & 120\end{array}$

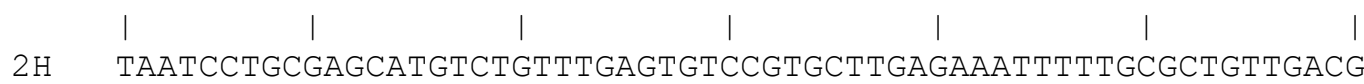

2P TAATCCTGCGAGCATGTCTGTTTGAGTGTCCGTGCTTGAGAAATTTTTGCGCTGTTGACG

3н TAATCCTGCGAGCATGTCTGTTTGAGTGTCCGTGCTTGAGAAATTTTTGCGCTGTTGACG

3P TAATCCTGCGAGCATGTCTGTTTGAGTGTCCGTGCTTGAGAAATTTTTGCGCTGTTGACG

4H TAATCCTGCGAGCATGTCTGTTTGAGTGTCCGTGCTTGAGAAATTTTTGCGCTGTTGACG

$4 \mathrm{P}$ TAATCCTGCGAGCATGTCTGTTTGAGTGTCCGTGCTTGAGAAATTTTTGCGCTGTTGACG

5H TAATCCTGCGAGCATGTCTGTTTGAGTGTCCGTGCTTGAGAAATTTTTGCGCTGTTGACG

5P TAATCCTGCGAGCATGTCTGTTTGAGTGTCCGTGCTTGAGAAATTTTTGCGCTGTTGACG

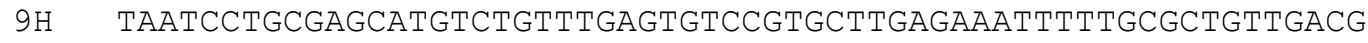

9P tAATCCTGCGAGCATGTCTGTTTGAGTGTCCGTGCTTGAGAAATTTTTGCGCTGTTGACG

12H TAATCCTGCGAGCATGTCTGTTTGAGTGTCCGTGCTTGAGAAATTTTTGCGCTGTTGACG

$13 \mathrm{P}$

$14 \mathrm{H}$

TAATCCTGCGAGCATGTCTGTTTGAGTGTCCGTGCTTGAGAAATTTTKGCGCTGTTGACG TAATCCTGCGAGCATGTCTGTTTGAGTGTCCGTGCTTGAGAAATTTTTGCGCTGTTGACG TAATCCTGCGAGCATGTCTGTTTGAGTGTCCGTGCTTGAGAAATTTTTGCGCTGTTGACG TAATCCTGCGAGCATGTCTGTTTGAGTGTCCGTGCTTGAGAAATTTTTGCGCTGTTGACG TAATCCTGCGAGCATGTCTGTTTGAGTGTCCGTGCTTGAGAAATTTTTGCGCTGTTGACG TAATCCTGCGAGCATGTCTGTTTGAGTGTCCGTGCTTGAGAAATTTTTGCGCTGTTGACG TAATCCTGCGAGCATGTCTGTTTGAGTGTCCGTGCTTGAGAAATTTTTGCGCTGTTGACG

TAATCCTGCGAGCATGTCTGTTTGAGTGTCCGTGCTTGAGAAATTTTTGCGCTGTTGACG

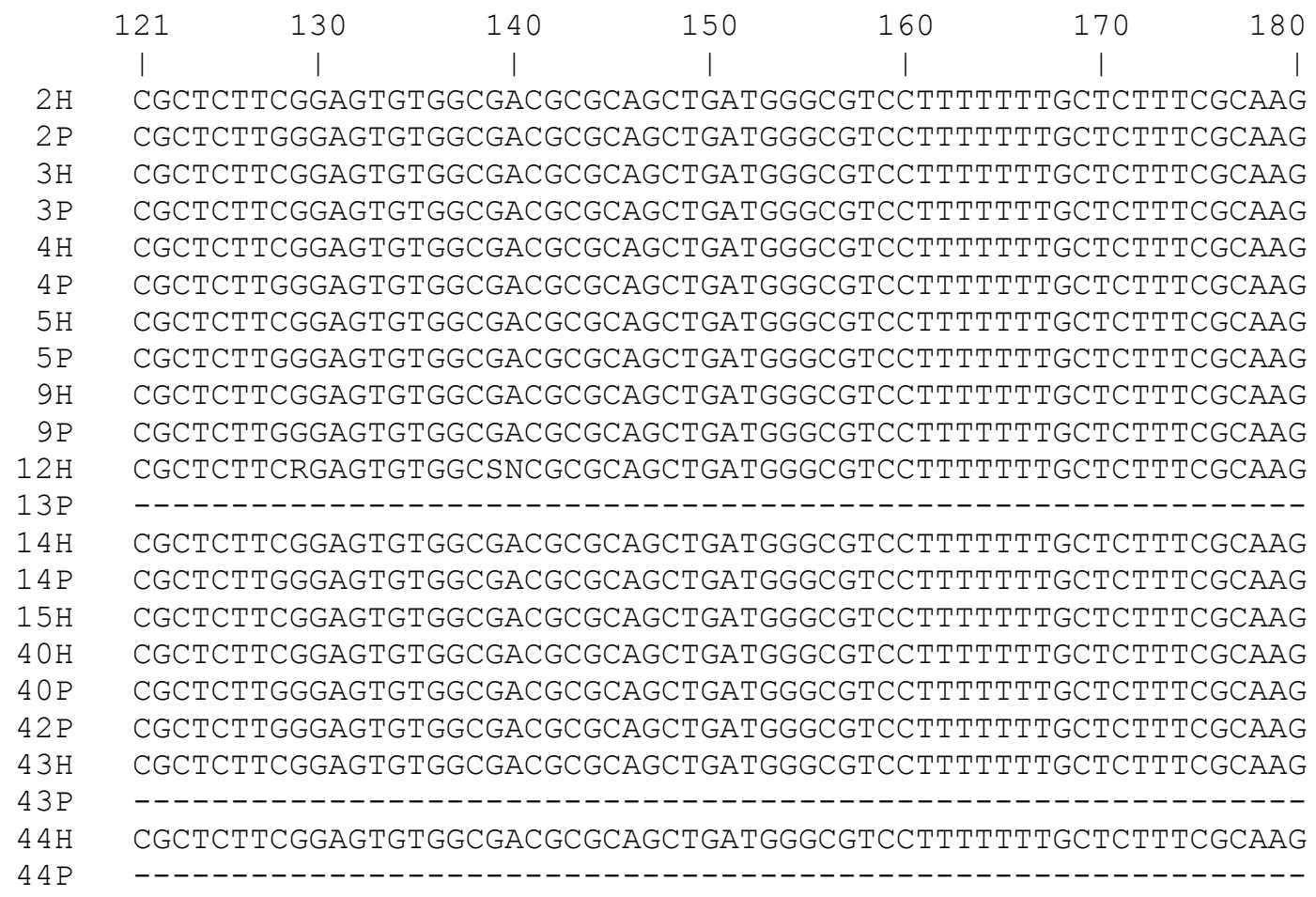




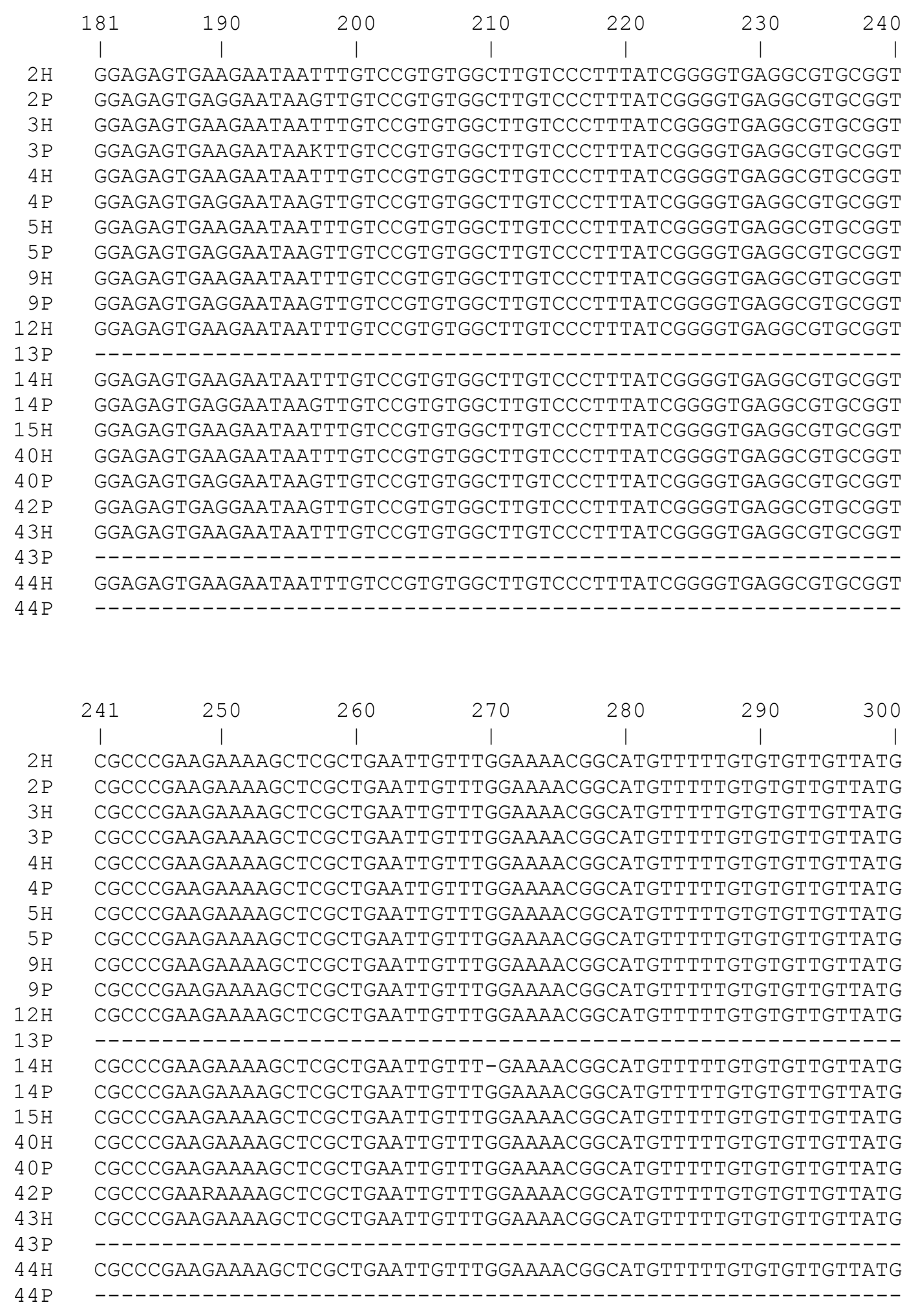




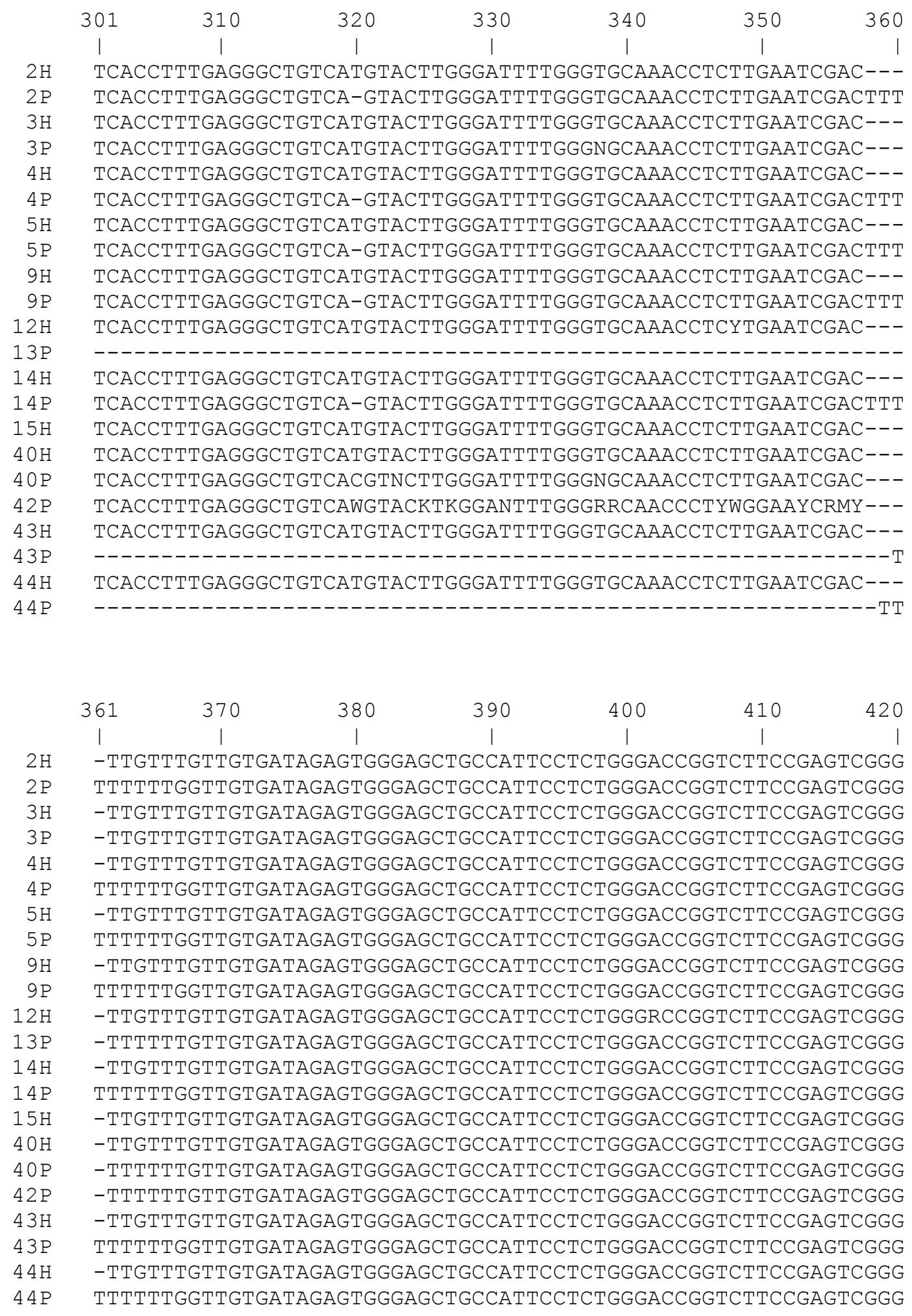




$\begin{array}{ccccccc}421 & 430 & 440 & 450 & 460 & 470 & 480 \\ \mid & \mid & \mid & \mid & \mid & \mid\end{array}$

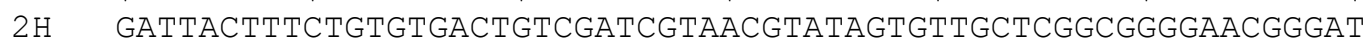

2P GATTACTTTCTGTGTGACTGTCGATCGTAACGTATAGTGTTGCTCGGCGGgGAACGgGAT

3н GATTACTTTCTGTGTGACTGTCGATCGTAACGTATAGTGTTGCTCGGCGGGGAACGgGAT

3P GATTACTTTCTGTGTGACTGTCGATCGTAACGTATAGTGTTGCTCGGCGGGGAACGGGAT

4H GATTACTTTCTGTGTGACTGTCGATCGTAACGTATAGTGTTGCTCGGCGGGGAACGgGAT

4P GATTACTTTCTGTGTGACTGTCGATCGTAACGTATAGTGTTGCTCGGCGGGGAACGGGAT

5H GATTACTTTCTGTGTGACTGTCGATCGTAACGTATAGTGTTGCTCGGCGGGGAACGGGAT

5P GATTACTTTCTGTGTGACTGTCGATCGTAACGTATAGTGTTGCTCGGCGGGGAACGGGAT

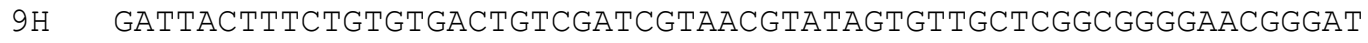

9P GATTACTTTCTGTGTGACTGTCGATCGTAACGTATAGTGTTGCTCGGCGGGGAACGGGAT

12H GATTACTTTCTGTGTGACTGTCGATCGTARCGYAWARTGTTSCYCGGCGGGGAMCSGGAT

13P GATTACTTTCTGTGTGACTGTCGATCGTAACGTATAGTGTTGCTCGGCGGGGAACGGGAT

$14 \mathrm{H}$ GATTACTTTCTGTGTGACTGTCGATCGTAACGTATAGTGTTGCTCGGCGGGGAACGGGAT

$14 \mathrm{P}$ GATTACTTTCTGTGTGACTGTCGATCGTAACGTATAGTGTTGCTCGgCGgGGAACGgGAT

15H GATTACTTTCTGTGTGACTGTCGATCGTAACGTATAGTGTTGCTCGGCGGGGAACGGGAT

40H GATTACTTTCTGTGTGACTGTCGATCGTAACGTATAGTGTTGCTCGGCGGGGAACGGGAT

40P GATTACTTTCTGTGTGACTGTCGATCGTAACGTATAGTGTTGCTCGGCGGGGAACGgGAT

42P GATTACTTTCTGTGTGACTGTCGATCGTAACGTATAGTGTTGCTCGGCGGGGAACGGGAT

43H GATTACTTTCTGTGTGACTGTCGATCGTAACGTATAGTGTTGCTCGGCGGGGAACGGGAT

43P GATTACTTTCTGTGTGACTGTCGATCGTAACGTATAGTGTTGCTCGGCGgGGAACGgGAT

$44 \mathrm{H}$ GATTACTTTCTGTGTGACTGTCGATCGTAACGTATAGTGTTGCTCGGCGGGGAACGGGAT

$44 \mathrm{P}$ GATTACTTTCTGTGTGACTGTCGATCGTAACGTATAGTGTTGCTCGGCGGgGAACGgGAT

$\begin{array}{rlc} & 481 & 400\end{array}$




\section{Appendix 2}

Cox1 alignment of Rhodophyllis membranacea $(4 \mathrm{H}, 5 \mathrm{H}, 8 \mathrm{H}, 9 \mathrm{H}, 12 \mathrm{H}$,

$14 \mathrm{H}, 15 \mathrm{H}, 39 \mathrm{H}, 40 \mathrm{H}, 42 \mathrm{H}, 43 \mathrm{H}, 44 \mathrm{H})$ and its parasite $(5 \mathrm{P}, 8 \mathrm{P}, 9 \mathrm{P}, 13 \mathrm{P}, 14 \mathrm{P}, 40 \mathrm{P}, 42 \mathrm{P}$, 43P, 44P)

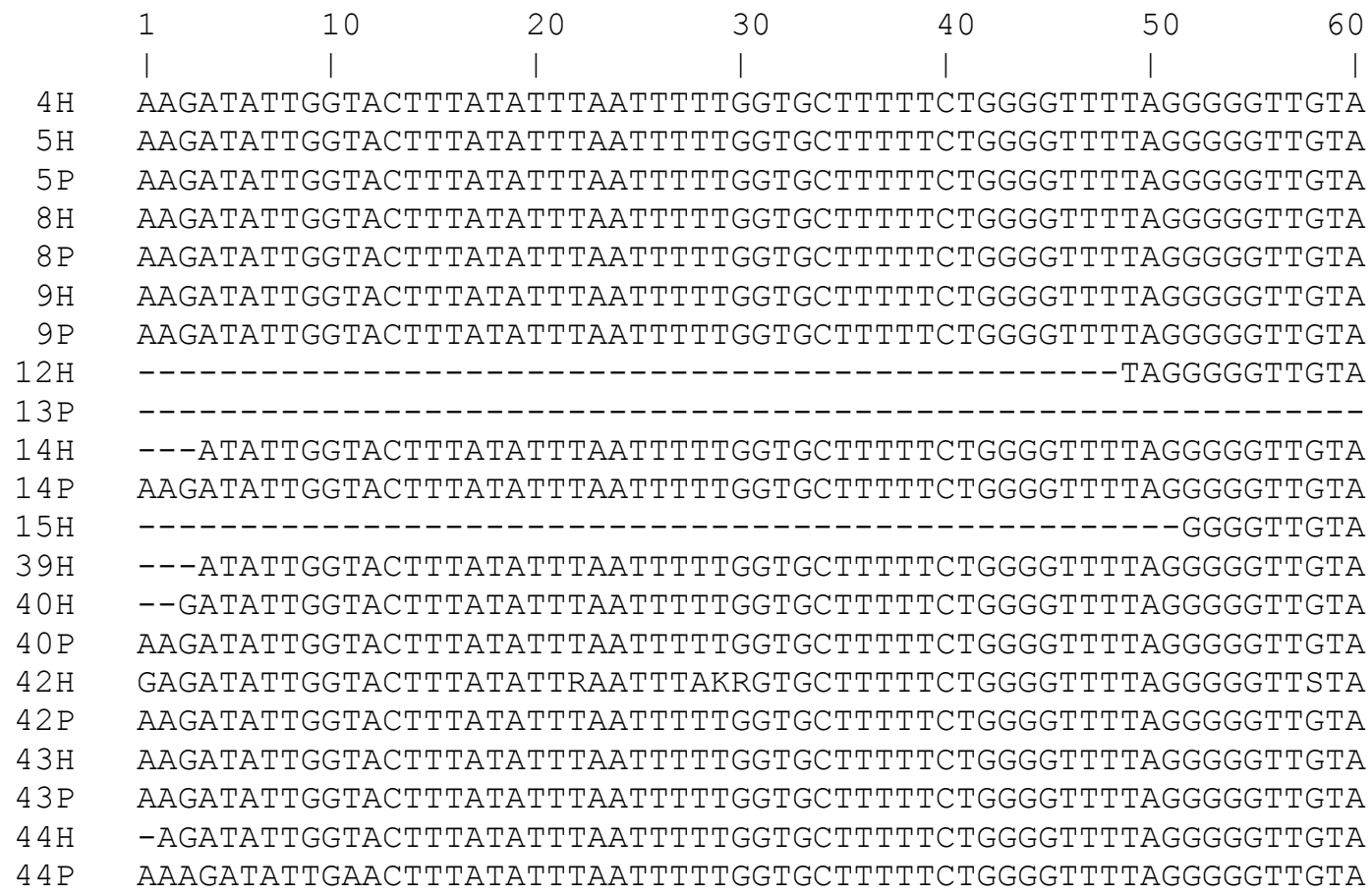




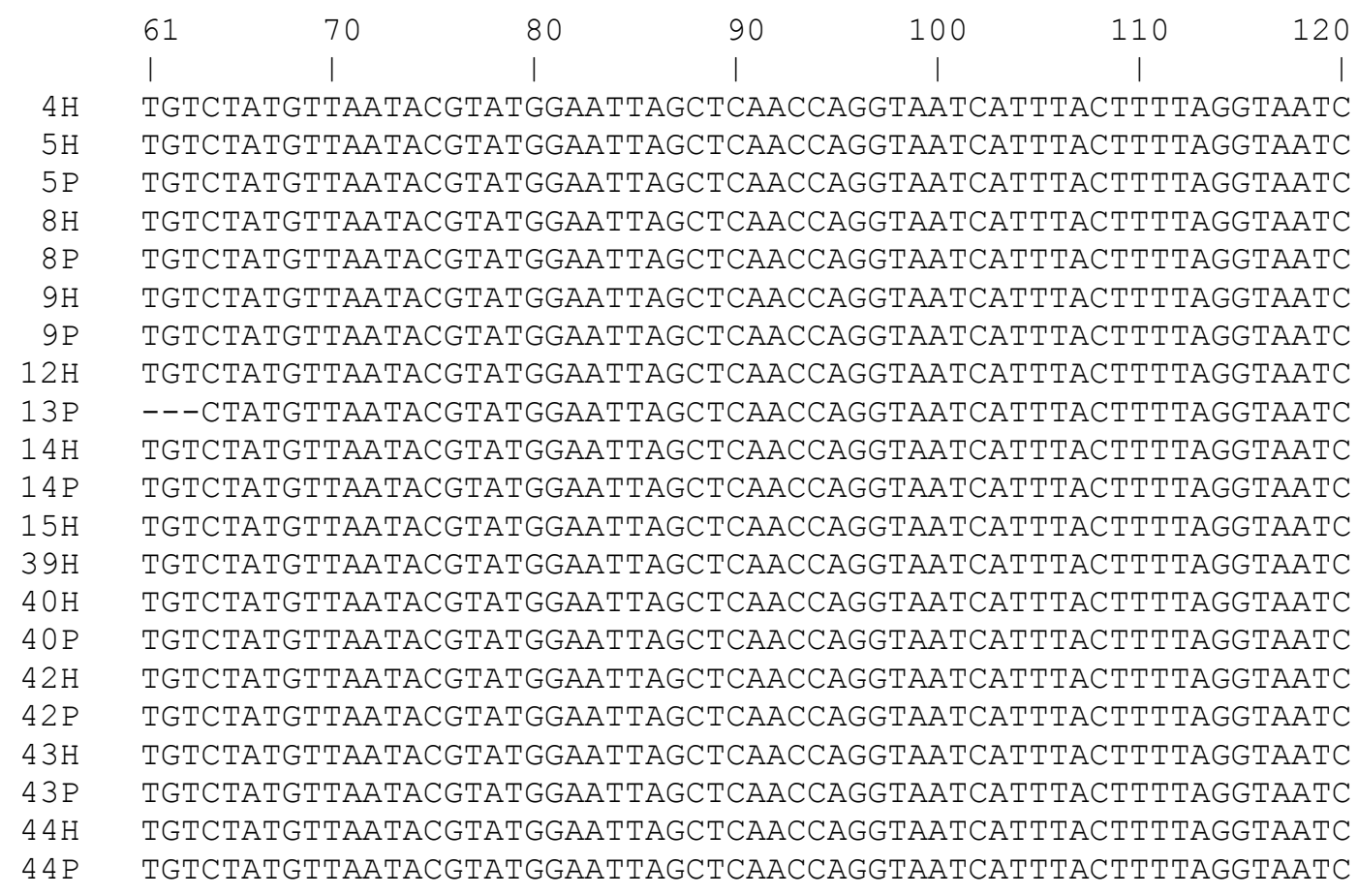

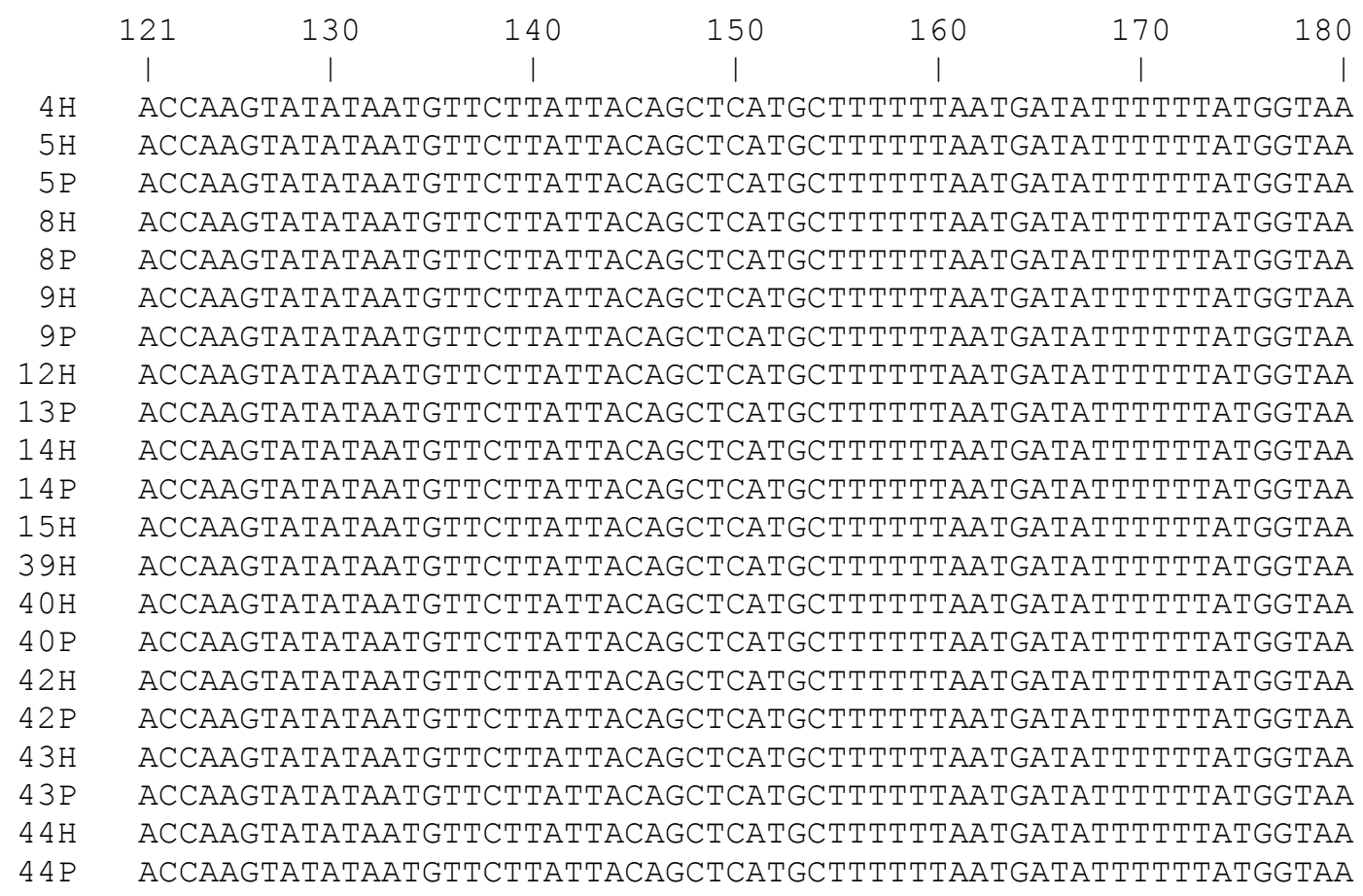




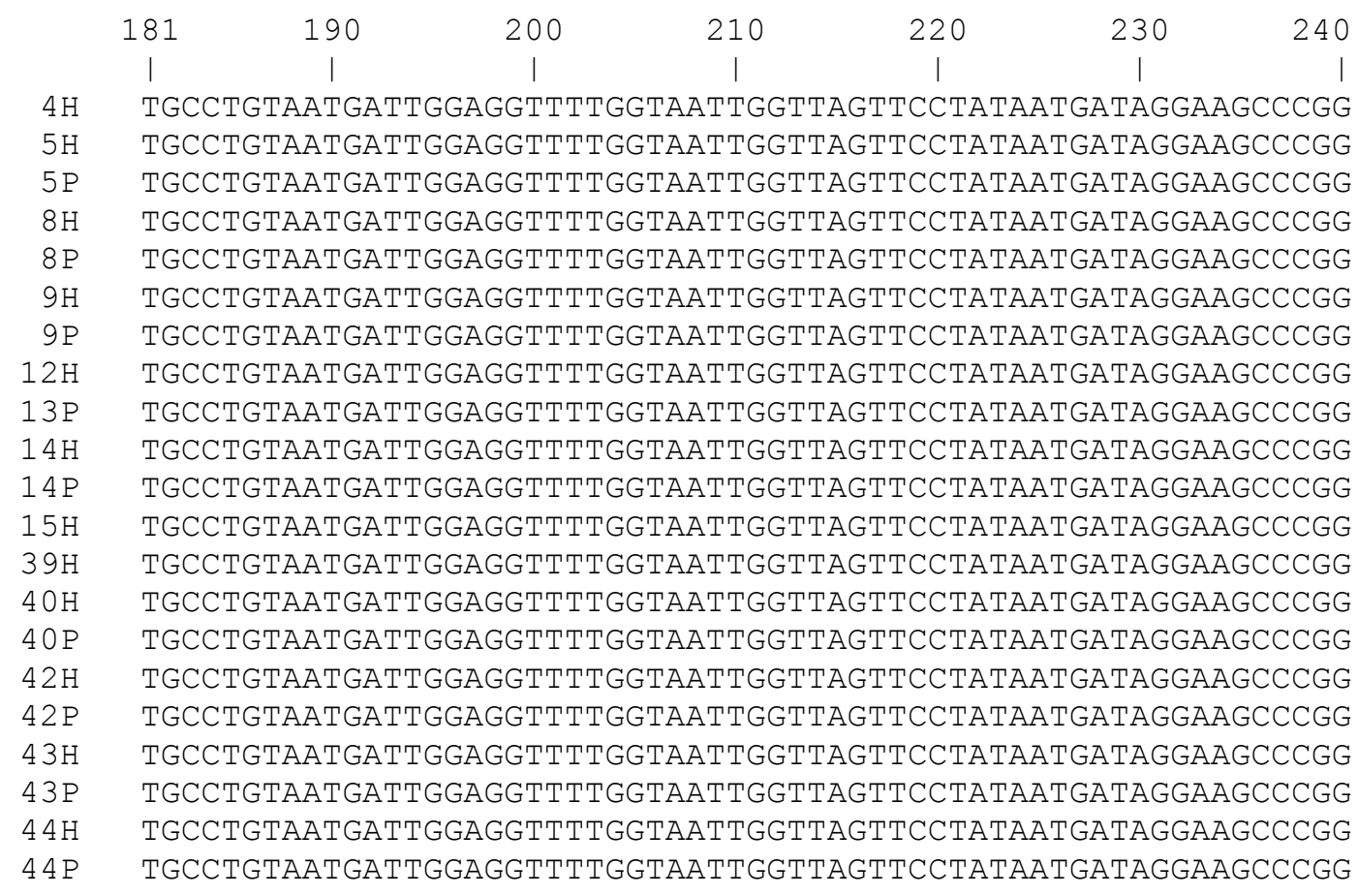

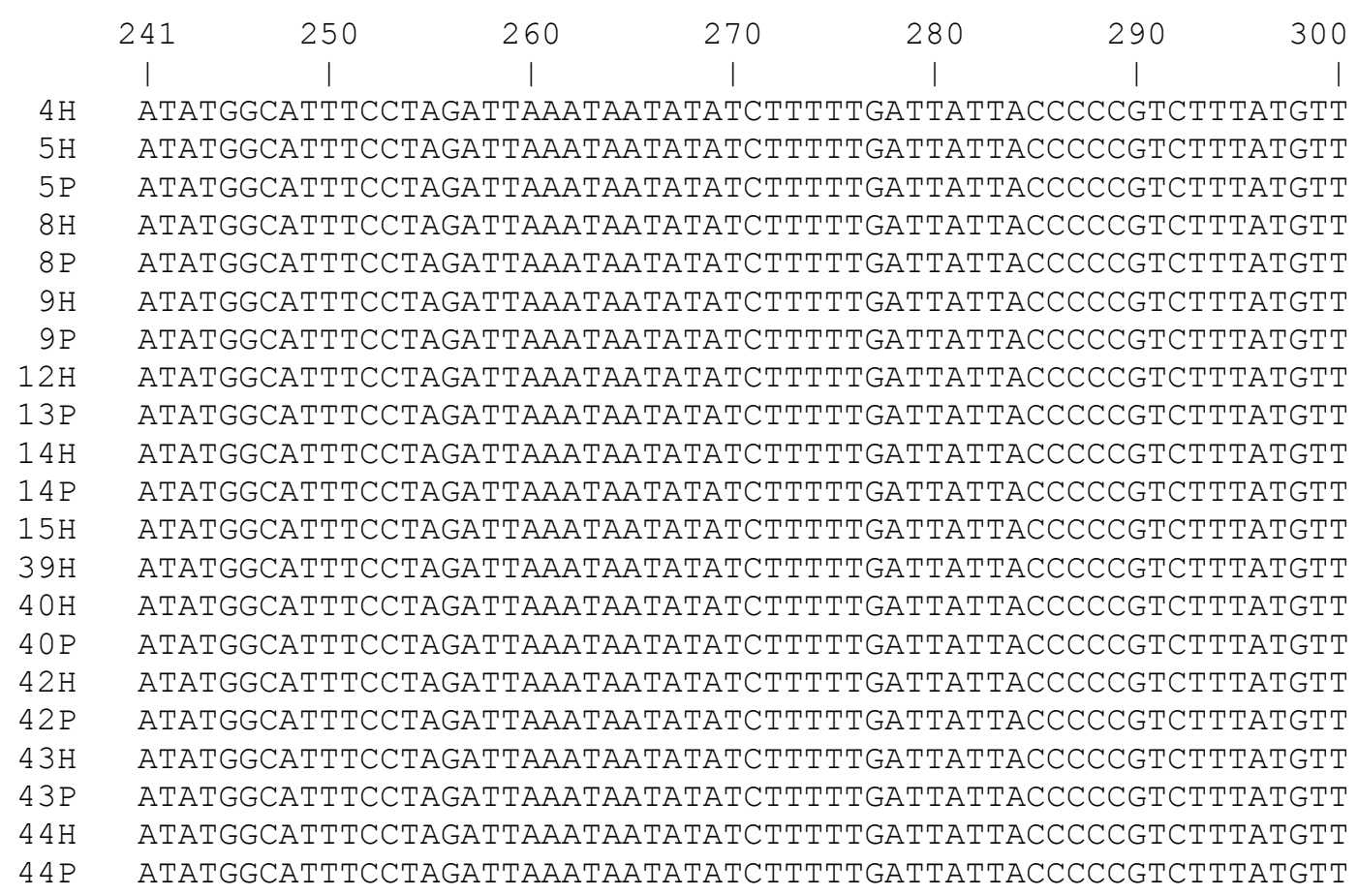




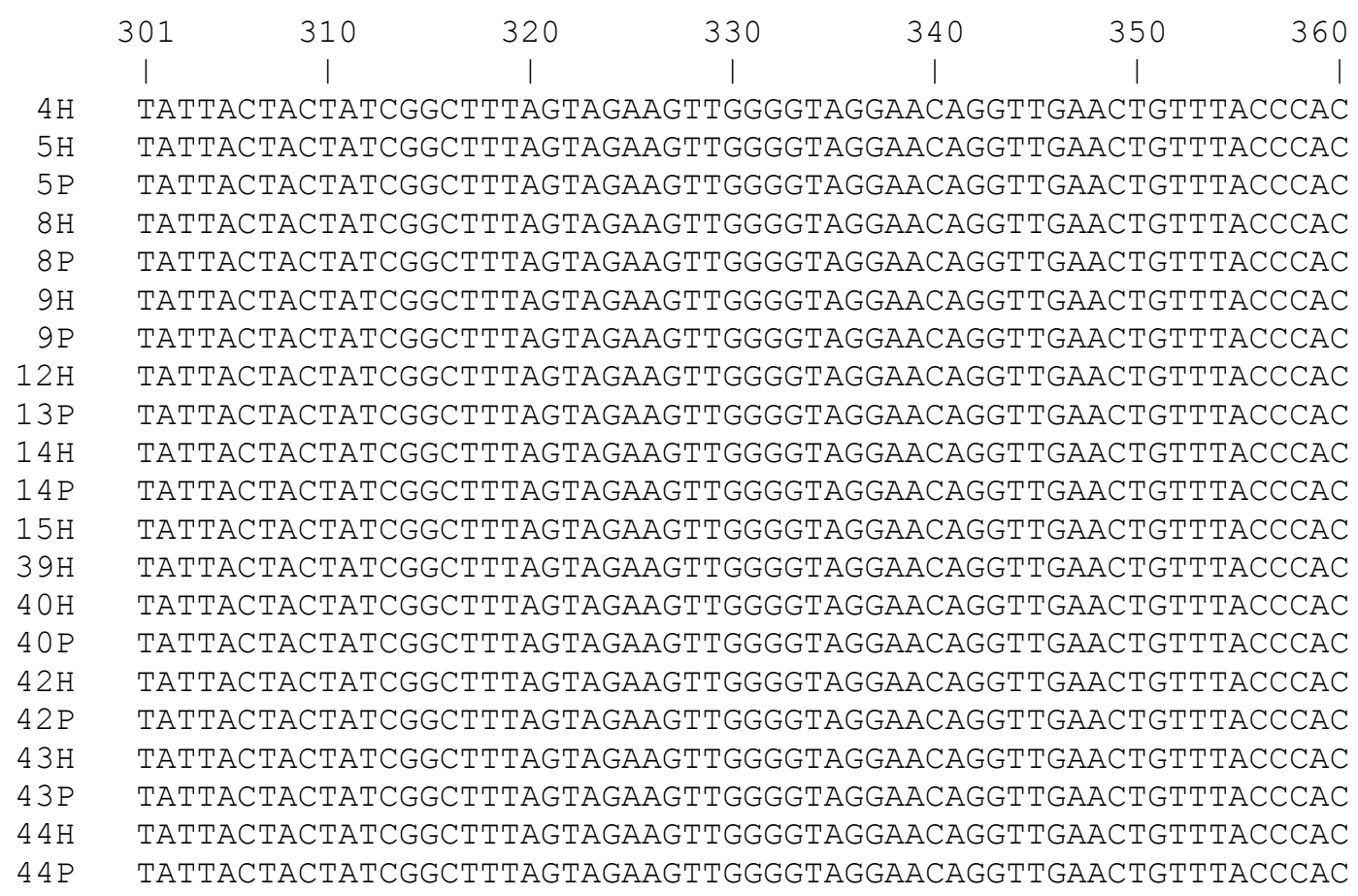

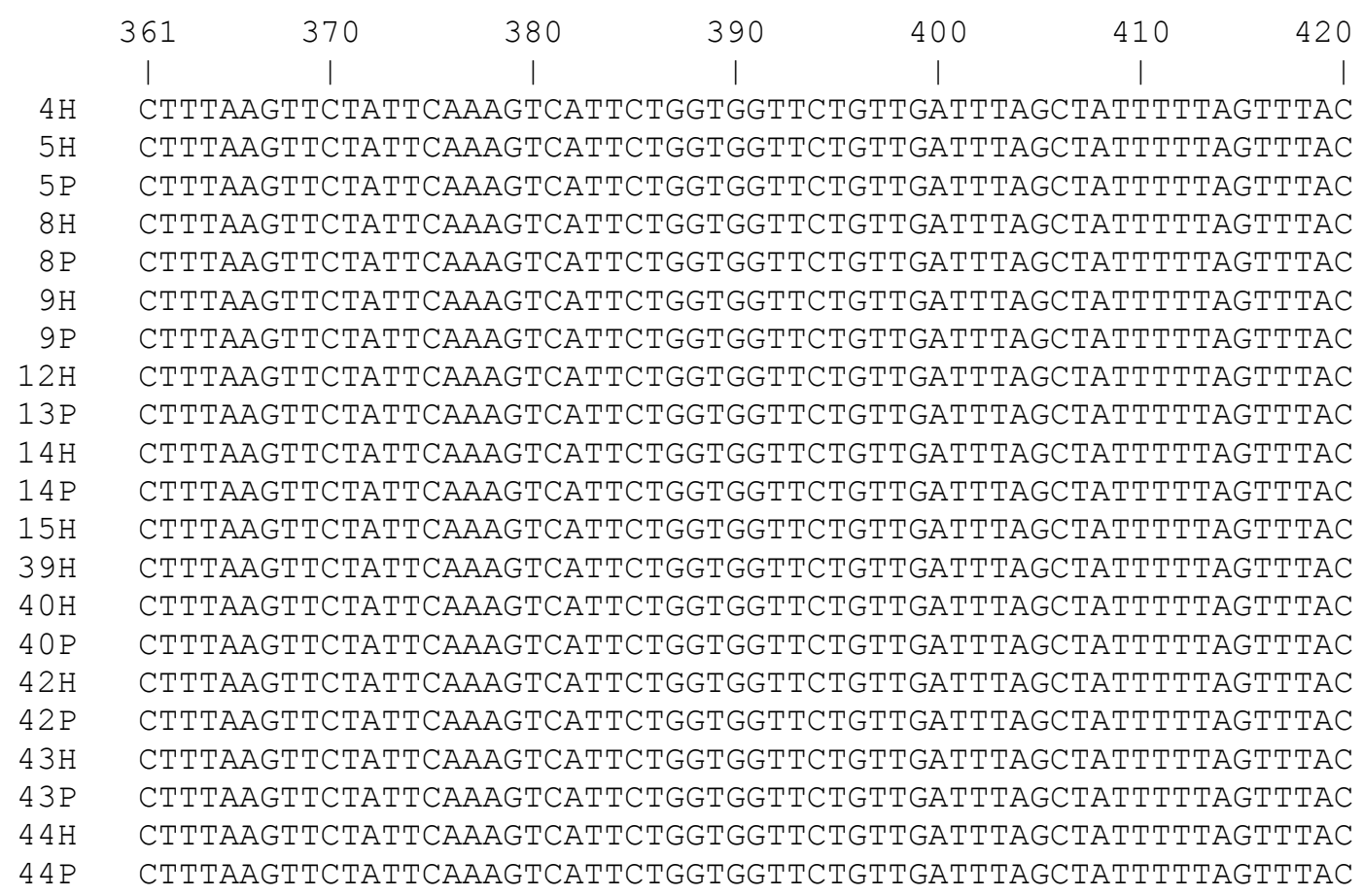




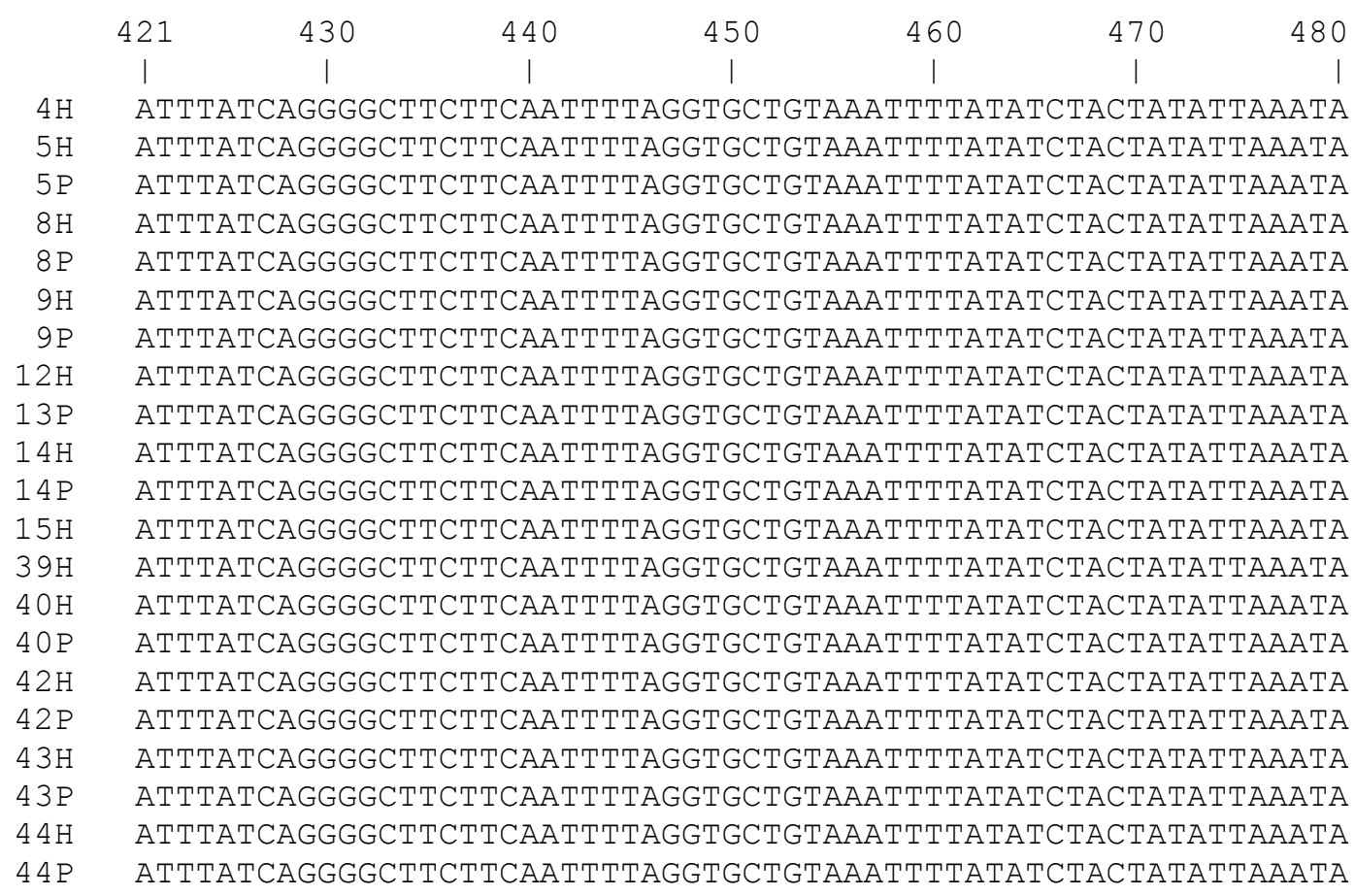

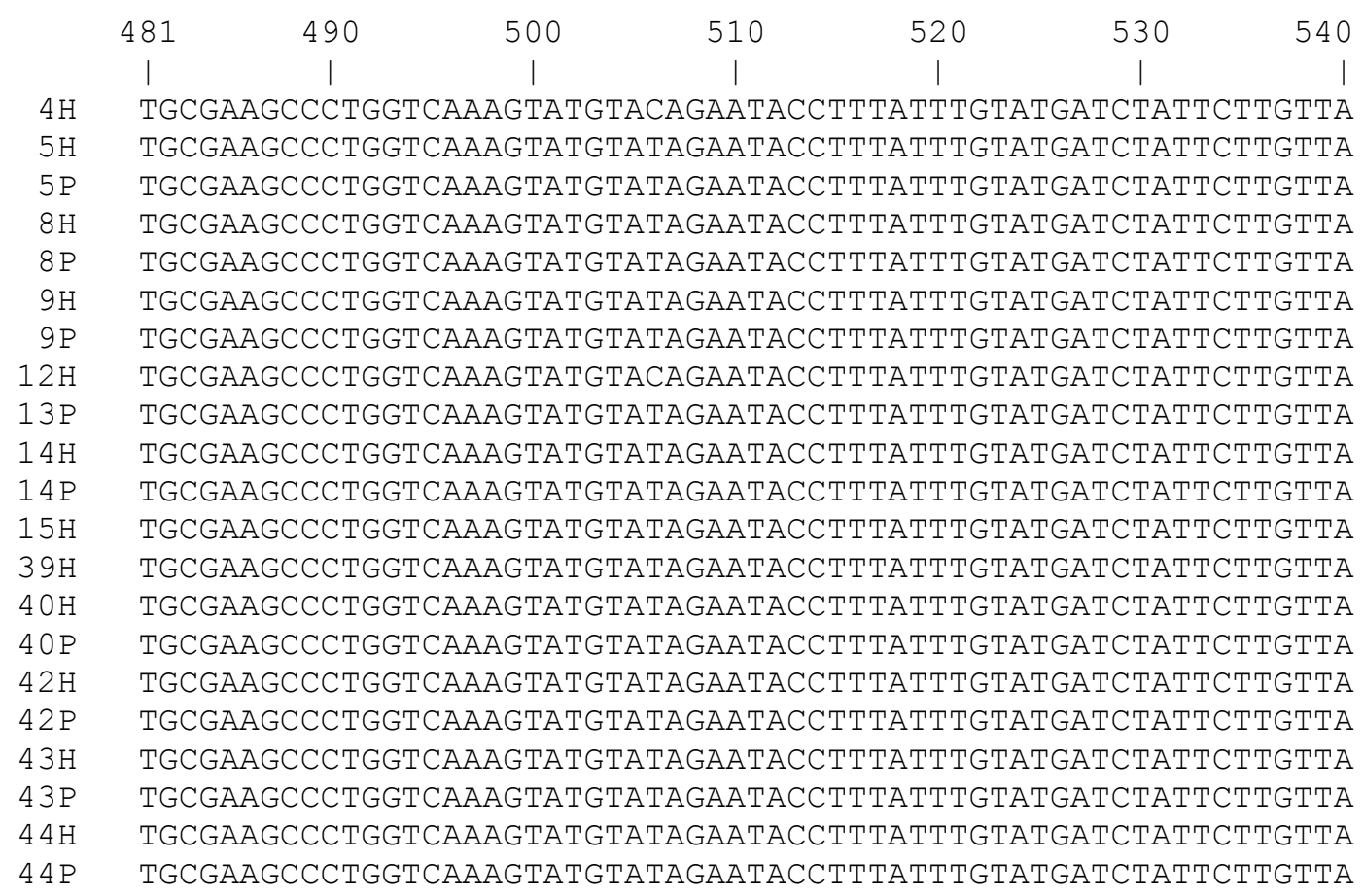




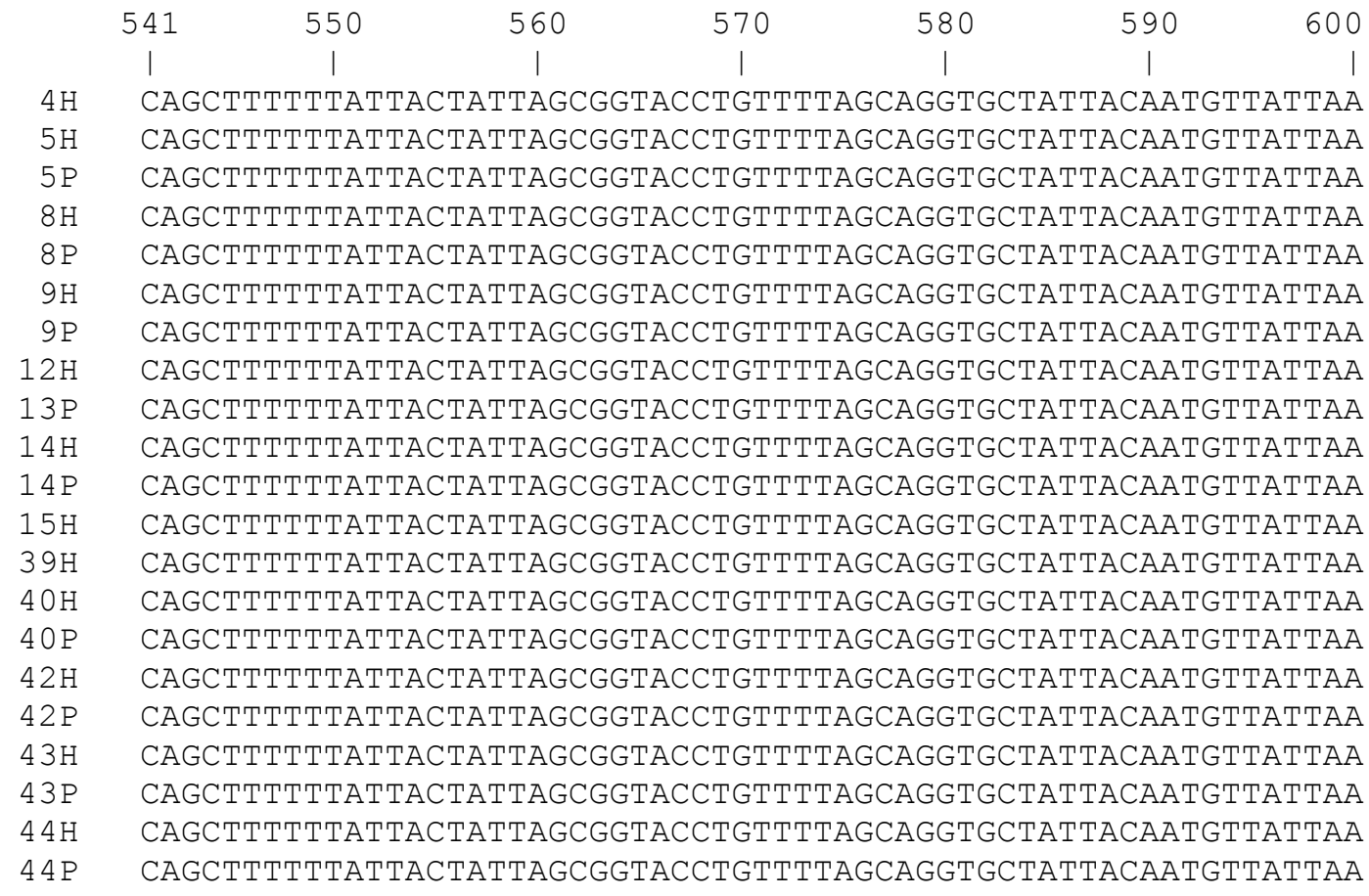

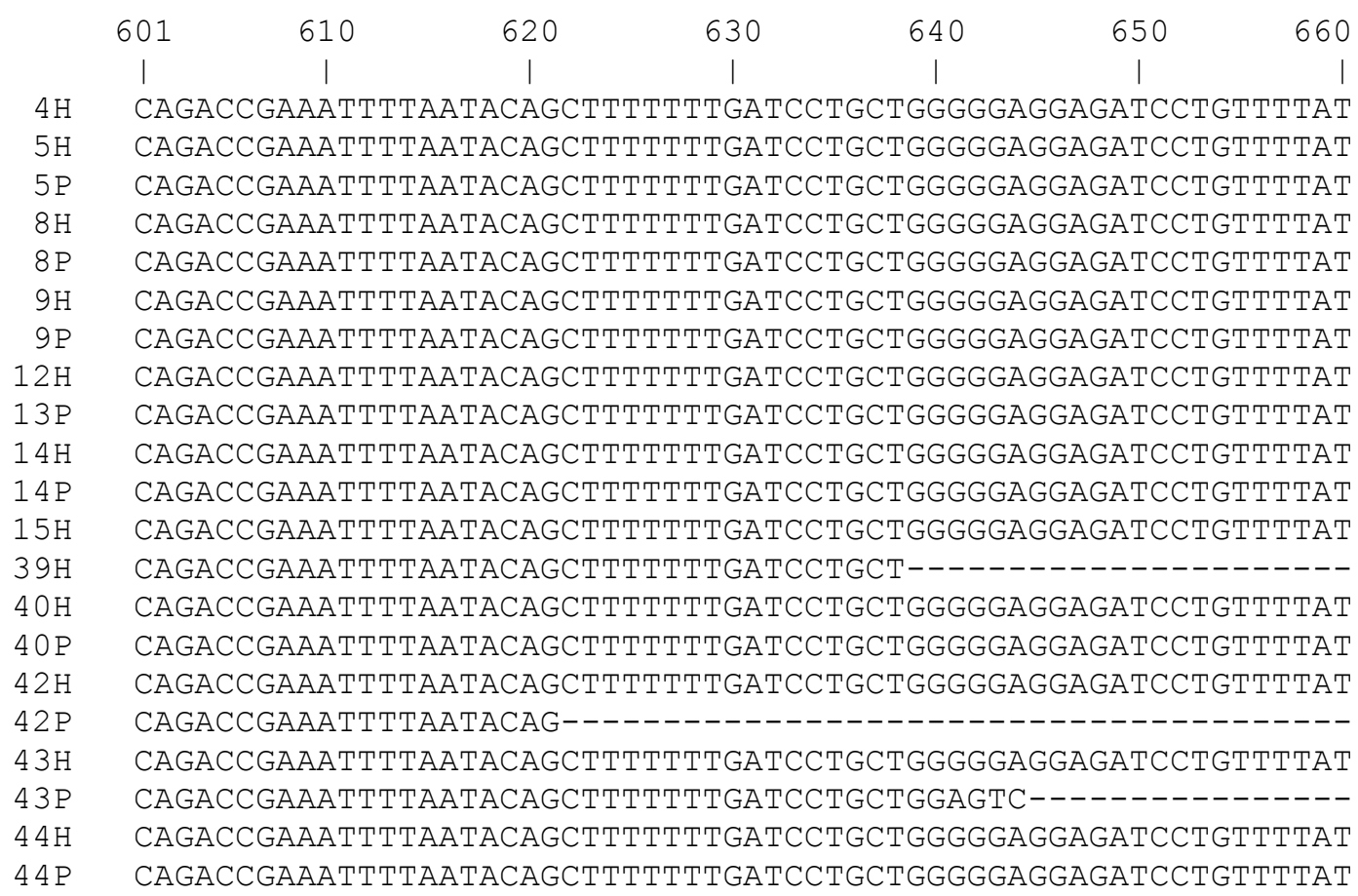




\begin{tabular}{|c|c|}
\hline & 670 \\
\hline & I \\
\hline $4 \mathrm{H}$ & ATCAACATTTATTTTG \\
\hline $5 \mathrm{H}$ & АTCAACATTTATTTTG \\
\hline $5 \mathrm{P}$ & ATCAACATTTATTTTG \\
\hline $8 \mathrm{H}$ & АTCAACATTTATTTTG \\
\hline $8 \mathrm{P}$ & АTCAACATTTATTTTG \\
\hline $9 \mathrm{H}$ & АTCAACATTTATTTTG \\
\hline 9P & АTCAACATTTATTTTG \\
\hline $12 \mathrm{H}$ & АTCAACATTTATTTTG \\
\hline $13 \mathrm{P}$ & АTCAАCATTTATTTTG \\
\hline $14 \mathrm{H}$ & АTCAACATTTATTTTG \\
\hline $14 \mathrm{P}$ & АTCAACATTTATTTTG \\
\hline $15 \mathrm{H}$ & ATCAACATTTATTTTG \\
\hline $39 \mathrm{H}$ & ---------------- \\
\hline $40 \mathrm{H}$ & АTCAACATTTATTTTG \\
\hline $40 \mathrm{P}$ & АTCAACATTTATTTTG \\
\hline $42 \mathrm{H}$ & AтCAACATTTATTTTG \\
\hline $42 \mathrm{P}$ & \\
\hline $43 \mathrm{H}$ & ATCAACATTTATTTTG \\
\hline 43 & \\
\hline 44 & АTCAACATTTATTTT \\
\hline 4 & ATCAACATTTATTTTG \\
\hline
\end{tabular}




\section{Appendix 3}

Cox2-3 alignment of Rhodophyllis membranacea $(2 \mathrm{H}, 3 \mathrm{H}, 4 \mathrm{H}, 5 \mathrm{H}, 6 \mathrm{H}, 8 \mathrm{H}, 9 \mathrm{H}$,

$13 \mathrm{H}, 14 \mathrm{H}, 15 \mathrm{H})$ and its parasite $(5 \mathrm{P}, 6 \mathrm{P}, 8 \mathrm{P}, 10 \mathrm{P}, 13 \mathrm{P})$

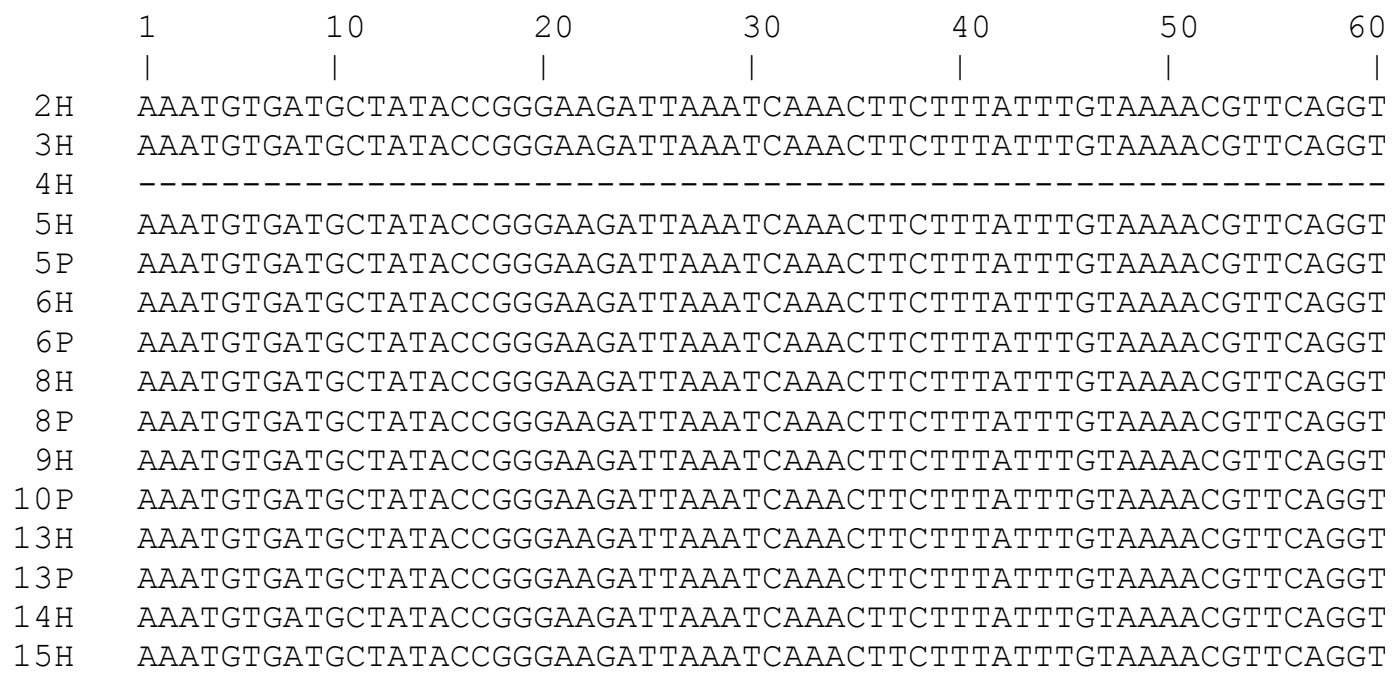

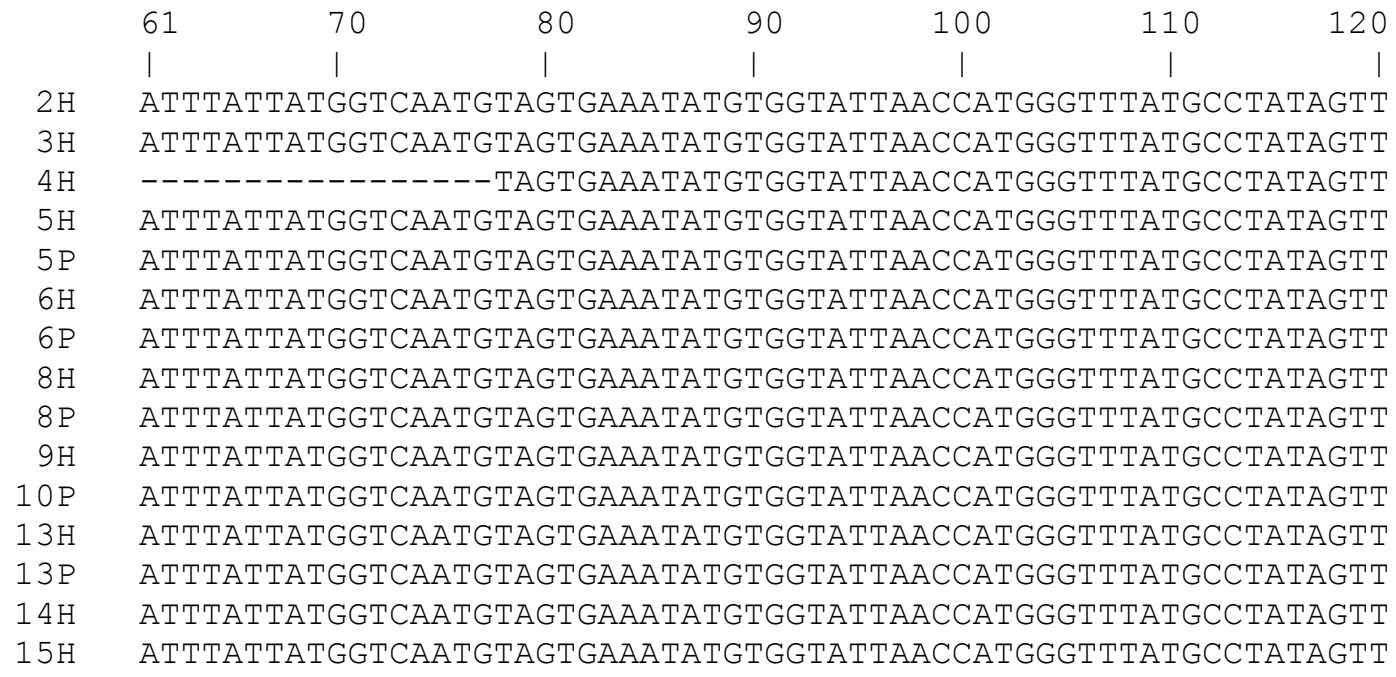




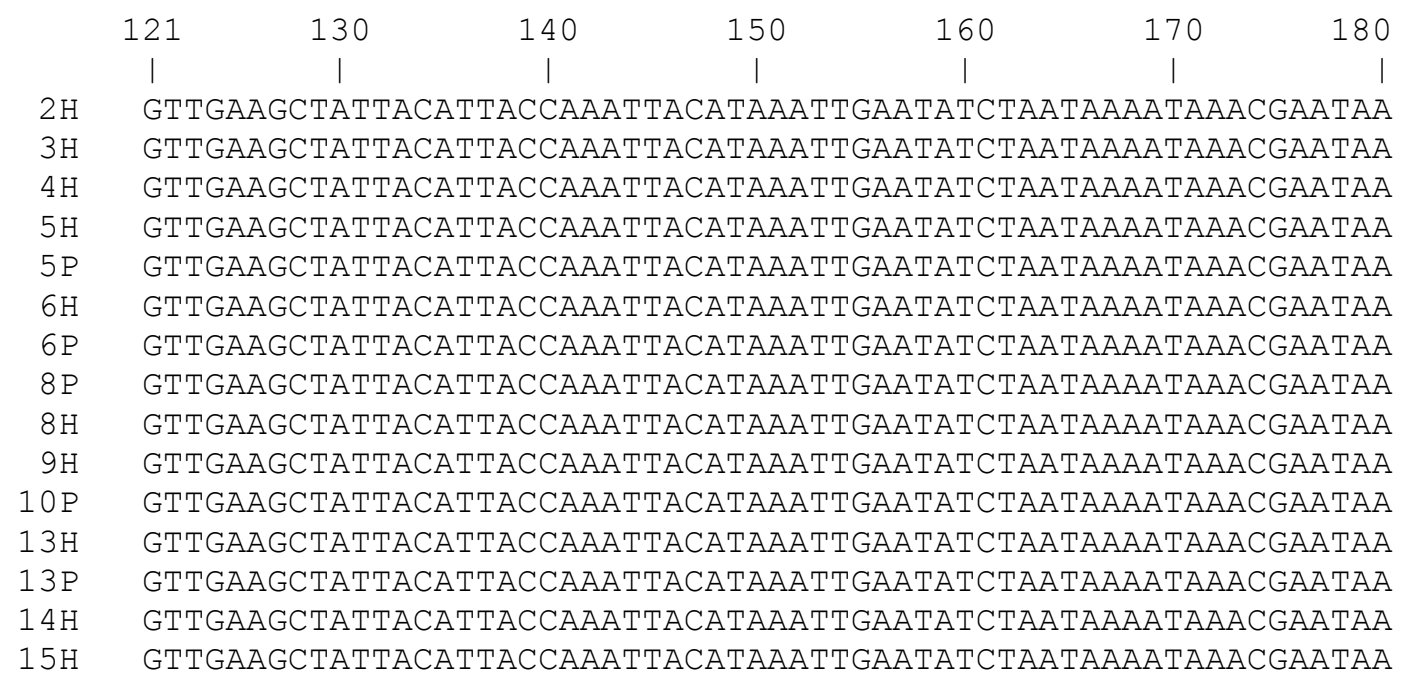

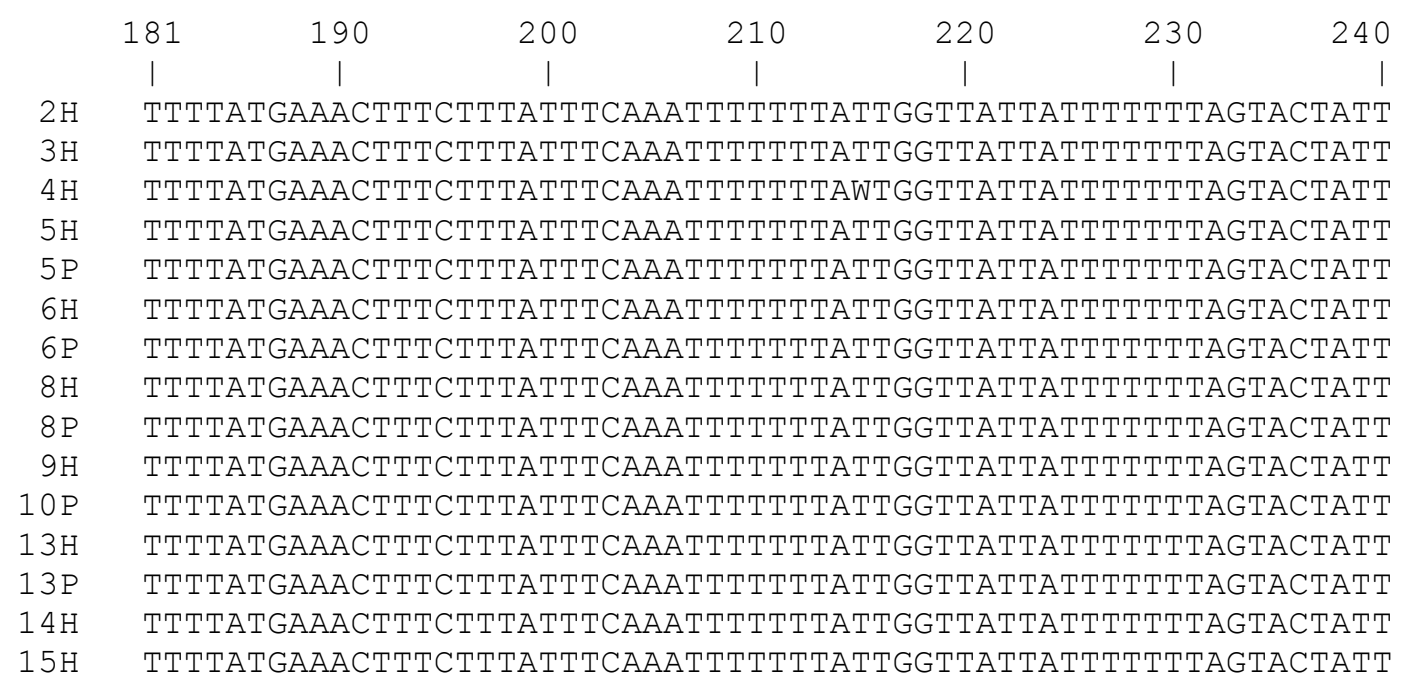




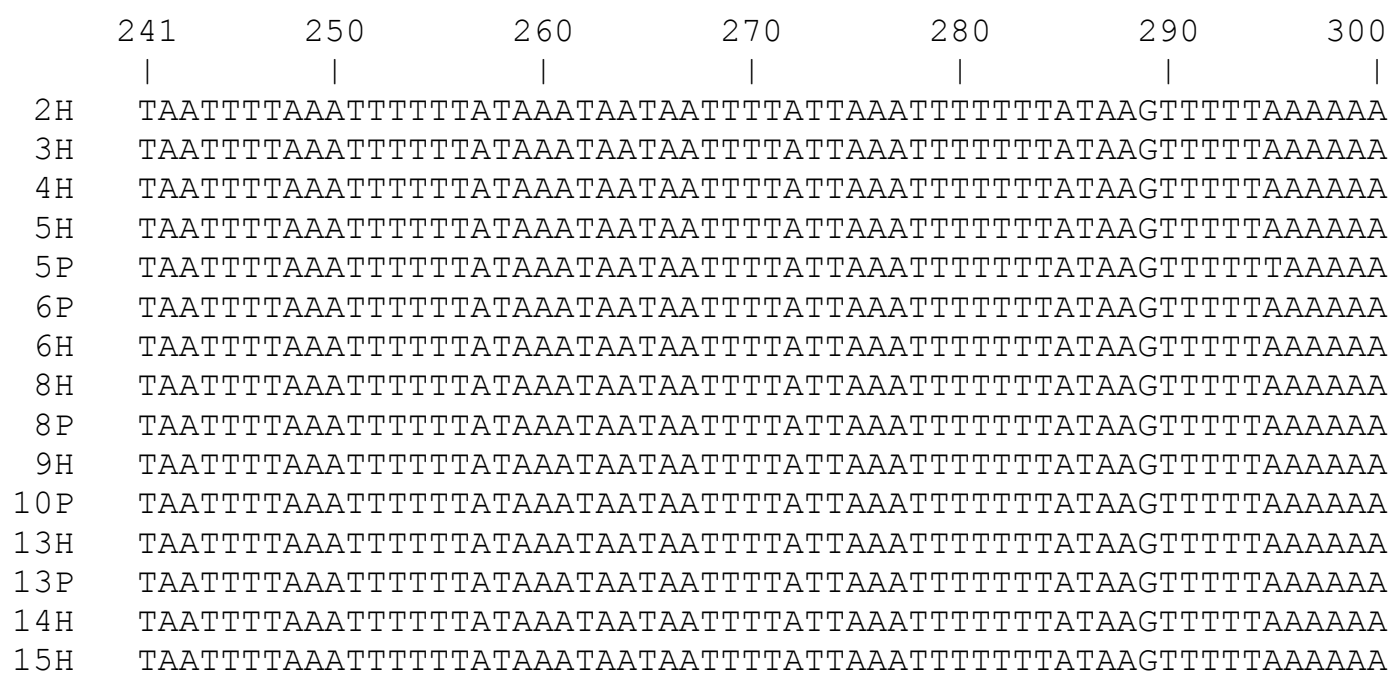

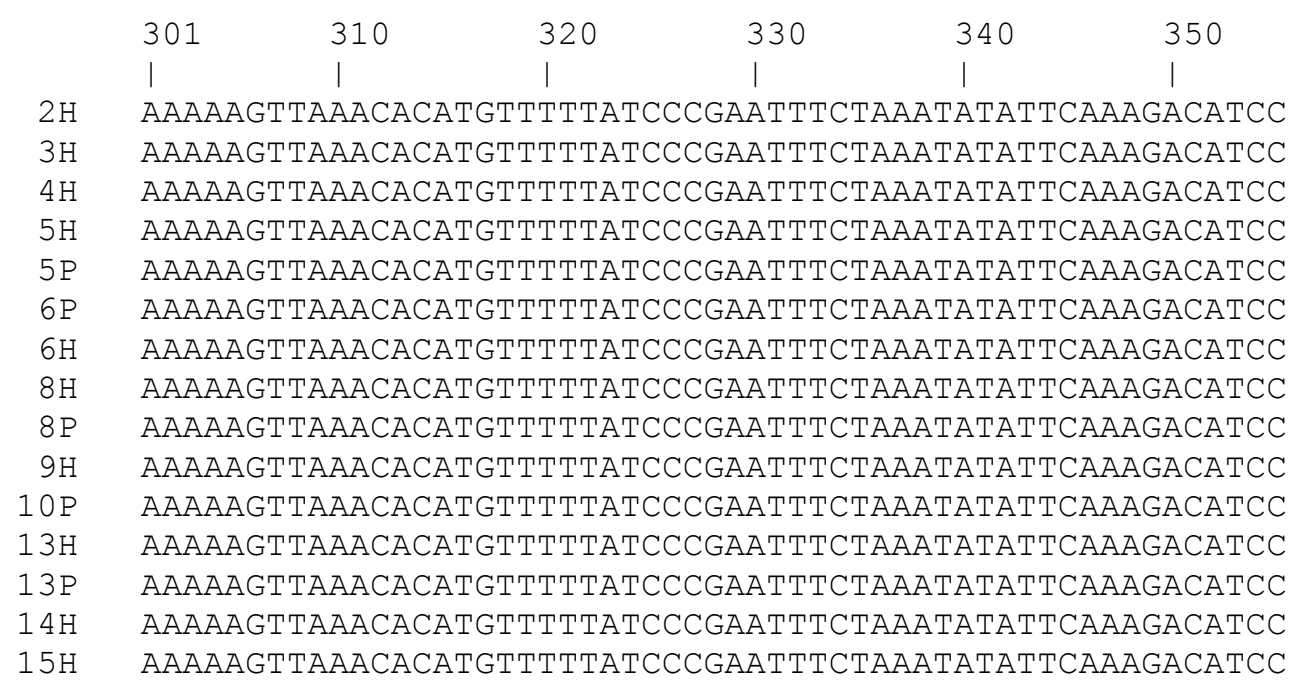




\section{Appendix 4}

Table A4.1. Downloaded sequences from Genbank used in all phylogenetic analysis. Species

name and Genbank Accession Number is also shown.

\begin{tabular}{|c|c|}
\hline Species & Genbank Accession No. \\
\hline Acanthopeltis longiramulosa Lee et Kim & HM629884 \\
\hline Adelophycus corneus (J. Agardh) Kraft & AF515285 \\
\hline Ahnfeltia fastigiata (Endlicher) Makienko & DQ343668 \\
\hline Asteromenia peltata Huisman et Millar & AY437710 \\
\hline Asparagopsis taxiformis (Delile) Trevisan de Saint-Léon & AY772727 \\
\hline Atractophora hypnoides Crouan et Crouan & AY772728 \\
\hline Audouinella asparagopsis (Chemin) Dixon & AF079795 \\
\hline Audouinella caespitosa (J. Agardh) Dixon & AF079787 \\
\hline Audouinella dasyae (Collins) Woelkerling & L26181 \\
\hline Balbiania investiens (Lenormand) Sirodot & AF132294 \\
\hline Ballia callitricha (C. Agardh) Kützing & AF236791 \\
\hline Balliopsis prieurii (Kützing) Saunders et Necchi & AF419245 \\
\hline Batrachospermum brasiliense Necchi & FJ386470 \\
\hline Callophyllis rangiferina (Brown) Womersley & U33123 \\
\hline Caloglossa stipitata Post & AF522247 \\
\hline Capreolia implexa Guiry et Womersley & U60344 \\
\hline Champia parvula (C. Agardh) Harvey & EF613310 \\
\hline Chondrus yendoi Yamada et Mikami & DQ316988 \\
\hline Crassitegula walsinghamii Schneider, Lane et Saunders & AY964057 \\
\hline Cumagloia andersonii (Farlow) Setchell et Gardner & DQ343669 \\
\hline Curdiea flabellata Chapman & L26207 \\
\hline Dilsea californica (J. Agardh) Kuntze & U33126 \\
\hline Dilsea integra (Kjellman) Rosenvinge & FJ848966 \\
\hline Endocladia muricata (Endlichter) J. Agardh & U33127 \\
\hline Erythrymenia minuta Kylin & AF085272 \\
\hline Farlowia mollis (Harvey et Bailey) Farlow et Setchell & GU176299 \\
\hline Farlowia mollis & U33129 \\
\hline $\begin{array}{l}\text { Fauchea repens (C. Agardh) Montagne et Bory de Saint- } \\
\text { Vincent }\end{array}$ & AF085267 \\
\hline Furcellaria lumbricalis (Hudson) Lamouroux & GQ406350 \\
\hline Galaxaura marginata (Ellis et Solander) Lamouroux & AF006090 \\
\hline Gainia mollis Moe & GQ406351 \\
\hline Gelidiella acerosa (Forsskål) Feldmann et Hamel & AF039551 \\
\hline Gelidiopsis intricata (C. Agardh) Vickers & EF033594 \\
\hline Gelidium caulacantheum J. Agardh & AF039544 \\
\hline Gelidium latifolium Bornet & Y11953 \\
\hline Gelidium pusillum (Stackhouse) Le Jolis & AF039542 \\
\hline Gloiopeltis capillaris Suringar & AY437680 \\
\hline
\end{tabular}




\begin{tabular}{|c|c|}
\hline Gloiopeltis furcata (Postels et Ruprecht) J. Agardh & $\mathrm{U} 33130$ \\
\hline Gracilaria cliftonii Withel, Millar et Kraft & AY617146 \\
\hline Gracilaria gracilis (Stackhouse) Steentoft & EU937742 \\
\hline $\begin{array}{l}\text { Gracilaria lemaneiformis (Bory de Saint-Vincent) } \\
\text { Greville }\end{array}$ & JN609255 \\
\hline Gracilaria salicornia (C. Agardh) Dawson & EF033615 \\
\hline Gracilaria verrucosa (Hudson) Papenfuss & Y11508 \\
\hline $\begin{array}{l}\text { Gracilariopsis lemaneiformis (Bory de Saint-Vincent) } \\
\text { Dawson, Acleto et Foldvik }\end{array}$ & L26214 \\
\hline Grateloupia intestinalis (Harvey) Setchell et Parkinson & AY437702 \\
\hline Haliptilon roseum (Lamarck) Garbary et Johansen & EF628229 \\
\hline Hildenbrandia angolensis Welwitsch et West & AF207833 \\
\hline Hildenbrandia rubra (Somerfelt) Meneghini & L19345 \\
\hline Hyalosiphonia caespitosa Okamura & JN403057 \\
\hline $\begin{array}{l}\text { Hydrolithon pachydermum (Foslie) Bailey, Gabel et } \\
\text { Freshwater }\end{array}$ & AY234235 \\
\hline Hypnea sp. & EU240869 \\
\hline Inkyuleea mariana (Harvey) Choi, Kraft et Saunders & AF236792 \\
\hline Isabbottia ovalifolia (Kylin) Balakrishnan & EF033590 \\
\hline Kumanoa ambigua (Montagne) Entwisle & FJ386481 \\
\hline Lesleigha sp. & AY437707 \\
\hline Lesleigha sp. & JN602193 \\
\hline Lithophyllum sp. & AY083172 \\
\hline Lithothamnion glaciale Kjellman & U60738 \\
\hline Mastophoropsis canalicutata (Harvey) Woelkerling & U62118 \\
\hline $\begin{array}{l}\text { Meiodiscus spetsbergensis (Kjellman) Saunders et } \\
\text { McLachlan }\end{array}$ & $\mathrm{U} 23814$ \\
\hline Melanthalia obtusata (Labillardière) J. Agardh & DQ343692 \\
\hline Melanthalia obtusata & L26215 \\
\hline Nemalionopsis shawii Howard et Parker & AF506272 \\
\hline Neodilsea borealis (Abbott) Lindstrom & EF033610 \\
\hline Neodilsea natashae Lindstrom & JF928825 \\
\hline Nizymenia australis Sonder & U09616 \\
\hline Palmaria palmata (Linnaeus) Weber et Mohr & Z14142 \\
\hline Peyssonnelia sp. & AY437688 \\
\hline Peyssonnelia rubra (Greville) J. Agardh & DQ629016 \\
\hline Pihiella liagoraciphila Huisman, Sherwood et Abbott & AY301992 \\
\hline Plocamium angustum (J. Agarth) Hooker et Harvey & U09620 \\
\hline Polyopes constrictus (Turner) J. Agardh & AY437705 \\
\hline Pyropia tenera Kjellman & AB101442 \\
\hline Predaea kraftiana Millar et Guiry & EF033618 \\
\hline Predaea kraftiana & AF515296 \\
\hline Pterocladia lucida (Brown) J. Agardh & AF419118 \\
\hline Pterocladia lucida & U60349 \\
\hline Pterocladiella bartlettii (Taylor) Santelices & EF191192 \\
\hline
\end{tabular}




\begin{tabular}{|l|c|}
\hline $\begin{array}{l}\text { Pterocladiella caerulescens (Kützing) Santelices et } \\
\text { Hommersand }\end{array}$ & HQ412472 \\
\hline Pterocladiella caerulescens & HQ412473 \\
\hline Pterocladiella caerulescens & HQ412476 \\
\hline Pterocladiella caerulescens & HQ412477 \\
\hline Pterocladiella caerulescens & HQ412482 \\
\hline $\begin{array}{l}\text { Pterocladiella capillacea (Gmelin) Santelices et } \\
\text { Hommersand }\end{array}$ & HM629885 \\
\hline Pterocladiella capillacea & HQ422696 \\
\hline Pterocladiella capillacea & AF039549 \\
\hline Pterocladiella psammophila Tronchin et Freshwater & HQ412486 \\
\hline Ptilonia australasica Harvey & AY437646 \\
\hline Ptilophora pinnatifida J. Agardh & U60345 \\
\hline Renouxia sp. & EF033584 \\
\hline $\begin{array}{l}\text { Rhodachlya } \text { madagascarensis West, Scott, West, Karsten, } \\
\text { Clayden et Saunders }\end{array}$ & EU262260 \\
\hline Rhodymenia stenoglossa J. Agardh & AF515303 \\
\hline Sphaerococcus coronopifolius Stackhouse & FJ848974 \\
\hline Thorea sp. & AF42053 \\
\hline Thorea violacea Bory de Saint-Vincent & AF342744 \\
\hline Titanophora weberae Børgesen & AF515301 \\
\hline Trematocarpus fragilis (C. Agardh) De Toni & AY437696 \\
\hline Tsengia comosa (Harvey) Womersley et Kraft & AF515303 \\
\hline $\begin{array}{l}\text { Wetherbeella australica } \text { (Womersley et Kraft) Saunders et } \\
\text { Kraft }\end{array}$ & AF515290 \\
\hline & \\
\hline
\end{tabular}




\section{Appendix 5}

RuBisCO spacer alignment of Pterocladia lucida $(45 \mathrm{H}, 6214)$ and

\section{Pterocladiophila hemisphaerica (45P, G215)}

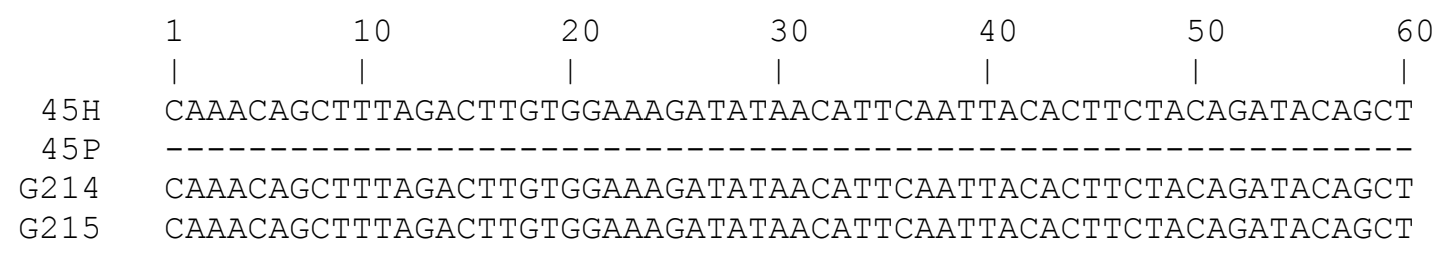

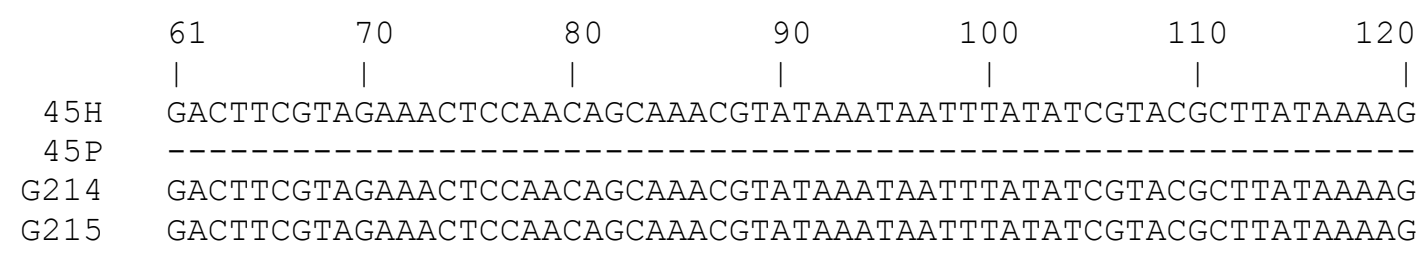

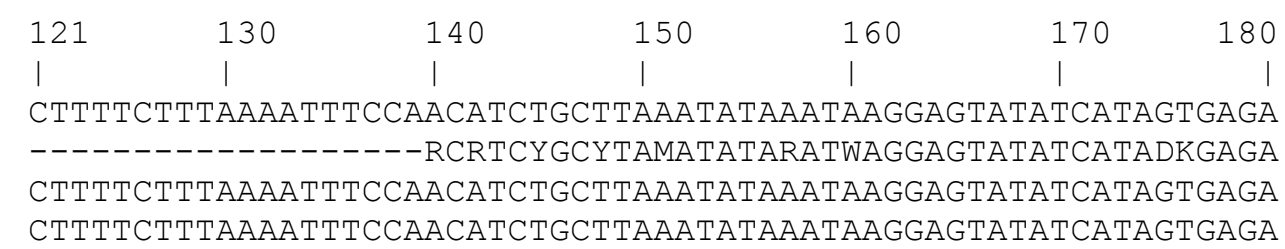

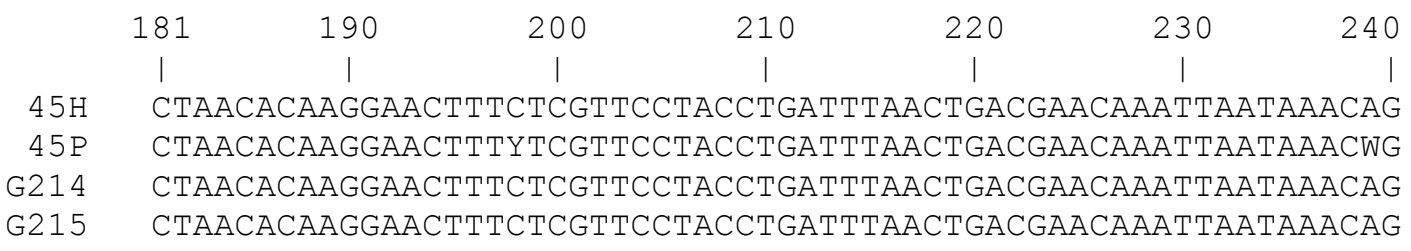
ATTGCATACGCAGTATCTCAAAATTGGTCAATTAATATAGAACATACAGAAGATCCTCAT ATTGCATACGCAGNATCTCAAAATTGGYCAATTAATATAGAACATACAGAAGATCCTCAT ATTGCATACGCAGTATCTCAAAATTGGTCAATTAATATAGAACATACAGAAGATCCTCAT ATTGCATACGCAGTATCTCAAAATTGGTCAATTAATATAGAACATACAGAAGATCCTCAT

241

250

260

270

280

290

300 


$\begin{array}{rlc} & 301 & 310 \\ & \text { I } & \text { | } \\ 45 \mathrm{H} & \text { CCACGTAATAATTATT } \\ \text { 45P } & \text { CCACGTAATAATATT } \\ \text { G214 } & \text { CCACGCAATAATTATT } \\ \text { G215 } & \text { CCACGCAATAATTATT }\end{array}$




\section{Appendix 6}

Cox1 alignment of Acanthopeltis longiramulosa (HM629884), Pterocladiella

caerulescens (HQ412472, HQ412473, HQ412476, HQ412477, HQ412482),

Pterocladiella capillacea (HM629885, HQ422696), Pterocladiella psammophila

(HQ412486), Pterocladia lucida (45H, 6214) and Pterocladiophila hemisphaerica (45P, 45P.2, G215, G215.2)

$\begin{array}{rrrrrr}10 & 20 & 30 & 40 & 50 & 60 \\ 1 & 1 & \mid & \mid & \mid\end{array}$

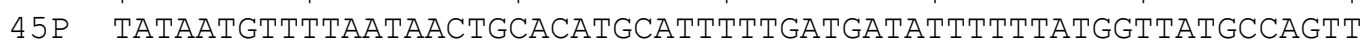

45P.2 TATAATGTTTTAATAACTGCACATGCATTTTTGATGATATTTTTTATGGTTATGCCAGTT

46H TACAATGTCTTGATTACTGCCCATGCATTTTTAATGATTTTTTTATGGTTATGCCTGTT

G214 TACAATGTCTTGATTACCGCTCATGCATTTTTAATGATTTTTTTTATGGTTATGCCTGTT

G215 TATAATGTTTTAATAACTGCACATGCATTTTTGATGATATTTTTTATGGTTATGCCAGTT

G215.2 TATAATGTTTAATAACTGCACATGCATTTTTGATGATATTTTTTATGGTTATGCCAGTT HM629884 TACAATGTATTAATTACAGCTCACGCTTTTTTGATGATTTTTTTTATGGTAATGCCGGTT HM629885 TATAATGTTTTAATTACTGCTCATGCATTTTTAATGATATTTTTCATGGTGATGCCTGTA HQ412472 TATAATGTCTTGATTACTGCACATGCATTTTTGATGATATTTTTTATGGTTATGCCTGTT HQ412473 TATAATGTCTTGATTACTGCACATGCATTTTTGATGATATTTTTTATGGTTATGCCTGTT HQ 412476 TATAATGTTTTGATTACTGCACATGCATTTTTAATGATATTTTTTATGGTTATGCCTGTT HQ 412477 TATAATGTTTTAATTACTGCACATGCATTTTTAATGATATTTTTTATGGTTATGCCTGTT HQ412482 TATAATGTTTTGATTACTGCACATGCATTTTTAATGATATTTTTTATGGTTATGCCTGTT HQ412486 TATAACGTTTTAATTACTGCACACGCATTTTTAATGATATTTTTCATGGTGATGCCAGTT HQ422696 TATAATGTTTTAATTACAGCCCACGCATTTTTAATGATTTTTTTTATGGTTATGCCCGTT

\begin{tabular}{rrrrrrr}
61 & 70 & 80 & 90 & 100 & 110 & 120 \\
\hline & $\mid$ & $\mid$ & $\mid$ & $\mid$ & $\mid$
\end{tabular}

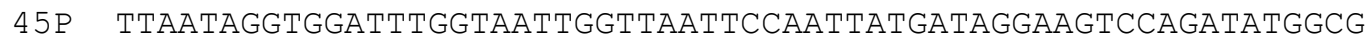

45P.2 TTAATAGGTGGATTTGGTAATTGGTTAATCCAATTATGATAGGAAGTCCAGATATGGCG

46H TTAATTGgTGGTTTTGgTAATTGgTtAgTACCCATAATGATTGGTAGTCCTGATATGGCT

G214 TTAATTGGTGGTTTTGGTAATTGGTTAGTACCCATAATGATCGGTAGCCCTGATATGGCT

G215 TTAATAGGTGGATTGGTAATTGTTAATTCCAATTATGATAGGAAGTCCAGATATGGCG

G215.2 TTAATAGGTGGATTTGGTAATTGGTTAATTCCAATTATGATAGGAAGTCCAGATATGGCG HM629884 TTAATAGGAGGTTTTGGAAATTGGTTGGTACCAATAATGATAGGTAGTCCGGATATGGCT HM629885 TTAATTGGGGGATTTGGAAATTGATTAGTACCCATAATGATAGGTAGTCCTGATATGGCA HQ412472 CTTATAGGGGGCTTTGGAAATTGATTAGTTCCTATTATGATAGGTAGCCCTGATATGGCA HQ412473 CTTATAGGAGGCTTTGGAAATTGATTAGTTCCTATTATGATAGGTAGTCCTGATATGGCA HQ412476 CTTATAGGAGGTTTCGGAAATTGATTAGTTCCCATTATGATAGGTAGTCCTGATATGGCA HQ412477 CTTATAGGAGGTTTTGGAAATTGATTAGTTCCTATTATGATAGGTAGTCCTGATATGGCA HQ412482 CTTATAGGAGGTTTTGGAAATTGATTAGTTCCTATTATGATAGGTAGTCCTGATATGGCA HQ412486 CTTATAGGTGGTTTTGGAAATTGATTGGTTCCTATTATGATTGGTAGTCCTGATATGGCG HQ422696 ATGATTGGGGGTTTCGGCAATTGATTAGTTCCTATTATGATAGGTAGCCCTGATATGGCT 
121

।

(1)

$45 \mathrm{P} .2$ TTTCCACGACTAAATAATATTTCATTTTGATTATTGCCTCCTTCTTTAGGATTATTATTA TTCCCTCGTTTAAATAACATCTCATTTTGATTACTTCCACCTTCTCTCTGTCTTTTATTA TTTCCTCGTTTAAATAACGTTTCATTTTGATTACTTCCACCTTCTCTCTGTCTTTTATTA TTTCCACGACTAAATAATATTTCATTTTGATTATTGCCTCCTTCTTTAGGATTATTATTA TTTCCACGACTAAATAATATTTCATTTTGATTATTGCCTCCTTCTTTAGGATTATTATTA TTTCCTCGTTTGAATAACATCTCCTTTTGATTACTTCCCCCTTCTTTATGTTTACTTTTA TTCCCCCGTCTAAATAATATTTCGTTTTGGTTATTACCTCCATCGTTATGTTTATTGTTA TTTCCTCGTTTGAATAATATTTCATTTTGATTACTGCCACCATCATTATGTTTACTATTG TTTCCTCGTTTGAATAATATTTCATTTTGATTACTGCCACCATCATTATGTTTACTATTG TTTCCTCGTTTGAATAATATTTCATTTTGATTACTGCCACCATCATTATGTTTACTATTG TTTCCTCGTTTAAATAATATTTCATTTTGATTATTGCCGCCATCATTATGTTTACTATTA TTTCCTCGTTTAAATAATATTTCATTTTGATTATTGCCGCCATCATTATGTTTACTATTA TTTCCTCGTTTGAATAACATTTCATTTTGATTACTGCCACCATCATTATGTTTATTACTG

TTTCCAAGACTAAATAATATTTCTTTTTGATTATTACCTCCATCATTGTGTTTATTATTA

HQ412486

HQ 422696

18

190

200

210

220

230

240

$45 \mathrm{P}$

CTTTCCGCATTTATTGAAGTAGGAGTAGGGACCGGATGAACTGTATATCCGCCATTAAGT

$45 \mathrm{P} .2$ CTTTCCGCATTTATTGAAGTAGGAGTAGGGACCGGATGAACTGTATATCCGCCATTAAGT ACTTCTGCATTAGTAGAAGTTGGGGTAGGAACAGGTTGAACAGTTTATCCTCCTTTAAGT

G214 ACTTCTGCGTTAGTAGAAGTTGGGGTAGGGACAGGTTGAACAGTTTACCCTCCTTTAAGT

G215 CTTTCCGCATTTATTGAAGTAGGAGTAGGGACCGGATGAACTGTATATCCGCCATTAAGT CTTTCCGCATTTATTGAAGTAGGAGTAGGGACCGGATGAACTGTATATCCGCCATTAAGT ACTTCGGCAATTGTAGAAGTAGGTGTGGGTACTGGTTGAACTGTGTATCCACCTCTAAGT ACATCTGCGTTGGTTGAAGTAGGTGTTGGAACTGGTTGAACAGTTTATCCACCCTTAAGT ACATCTGCATTGGTTGAAGTAGGTGTGGGAACGGGTTGAACTGTCTACCCCCCCTTAAGC ACATCTGCATTAGTTGAAGTAGGTGTGGGAACGGGTTGAACTGTTTACCCCCCCTTAAGC ACATCTGCATTAGTTGAAGTAGGTGTAGGAACGGGTTGAACTGTCTACCCCCCCTTAAGC ACATCTGCATTAGTTGAAGTAGGTGTAGGAACGGGTTGAACTGTTTATCCTCCTTTAAGC ACATCTGCGTTAGTTGAAGTAGGTGTAGGAACGGGTTGAACTGTTTATCCTCCTTTAAGC HQ412486 ACATCTGCACTAGTTGAAGTAGGTGTAGGAACTGGTTGAACTGTTTATCCCCCTTTAAGC
HQ422696 GCTTCTGCTGTAGTAGAAGTTGGTGTAGGTACAGGATGAACTGTATACCCACCATTGAGT

241

$$
\text { । }
$$

260

250

$$
\text { । }
$$

270

280

290

$$
\text { | }
$$

300

GCTATTCAAAGTCATTCAGGCGGATCAGTCGATTTAGCTATATTTAGTTTGCATTTATCA GCTATTCAAAGTCATTCAGGCGGATCAGTCGATTTAGCTATATTTAGTTTGCATTTATCA TCAATTCAAAGCCATTCTGGAGGAGCCGTTGATTTAGCTATATTTAGTTTACACATCTCA TCAATTCAAAGTCATTCTGGAGGAGCTATTGATTTAGCTATATTTAGCTTACACATCTCA GCTATTCAAAGTCATTCAGGCGGATCAGTCGATTTAGCTATATTTAGTTTGCATTTATCA GCTATTCAAAGTCATTCAGGCGGATCAGTCGATTTAGCTATATTTAGTTTGCATTTATCA TCGATTCAAAGTCATTCAGGAGGTGCTGTGGATCTAGCTATTTTTAGCCTACATATTTCA TCAATTCAAAGCCATTCTGGGGGCGCTGTTGATCTTGCTATATTTAGTTTGCATATTTCG TCGATTCAAAGTCATTCAGGAGGAGCTGTGGATTTGGCTATATTTAGTTTGCATATCTCA TCAATTCAAAGTCATTCAGGAGGAGCTGTGGATTTGGCTATATTTAGTTTGCATATCTCA TCAATCCAAAGTCATTCAGGTGCTGCTGTAGATTTAGCTATATTTAGTTTACATATCTCA TCAATTCAAAGTCATTCAGGCGGTGCTGTGGATTTGGCTATATTTAGTTTACATATCTCA TCAATTCAAAGTCATTCAGGCGGTGCTGTGGATTTGGCTATATTTAGTTTACATATCTCA TCAATTCAAAGCCACTCAGGTGGTGCCGTTGATTTAGCTATATTTAGCTTACATATATCA TCAATACAAAGTCATTCTGGAGGTGCCGTAGATTTAGCTATTTTTAGTTTACATTTAGCA 
$\begin{array}{rrrrrrr}301 & 310 & 320 & 330 & 340 & 350 & 360 \\ \mid & \mid & \mid & \mid & \mid & \mid\end{array}$

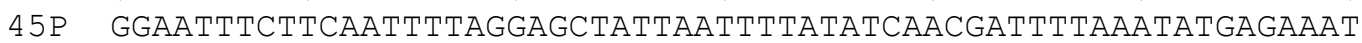

45P.2 GGAATTCTTCAATTTTAGGAGCTATTAATTTTATATCAACGATTTTAAATATGAGAAAT

46H GGAGCGTCATCAATTCTAGGTGCAGTTAATTTTATATCAACAATTTTAAATATGCGTAAT

G214 GGAGCGTCATCAATTCTAGGCGCAGTTAACTTTATATCAACAATTTTAAATATGCGTAAT

G215 GGAATTCTTCAATTTTAGGAGCTATTAATTTTATATCAACGATTTTAAATATGAGAAAT

G215.2 GGAATTTCTTCAATTTTAGGAGCTATTAATTTTATATCAACGATTTTAAATATGAGAAAT HM629884 GGGGCTTCCTCAATCCTTGGTGCAATTAATTTTATTTCAACTATTTTGAATATGCGCAAC HM629885 GGAGCTTCATCAATTTTAGGTGCCGTAAATTTTATTTCAACTATTCTAAACATGCGTAAT HQ 412472 GGTGCTTCATCTATTTTAGGTGCTGTTAATTTTATCTCTACTATTTTGAATATGCGTAAT HQ412473 GGTGCTTCATCTATTTTAGGTGCTGTTAATTTTATCTCTACTATTTTGAATATGCGTAAT HQ412476 GGTGCTTCATCTATTTTAGGAGCTGTTAATTTTATTTCTACTATTTTGAATATGCGTAAT HQ 412477 GGTGCTTCATCTATTTTAGGTGCTGTTAATTTTATTTCTACTATTTTGAATATGCGTAAT HQ412482 GGTGCTTCATCTATTTTAGGTGCTGTTAATTTTATTTCTACTATTTTGAATATGCGTAAT HQ412486 GGTGCTTCATCTATTTTAGGTGCCGTTAATTTTATTTCTACTATCTTAAATATGCGTAAT HQ422696 GGTGCTTCTTCTATTTTAGGTGCCATCAATTTTATATCAACTATATTAAATATGCGTAAT

$\begin{array}{rrrrrrr}361 & 370 & 380 & 390 & 400 & 410 & 420 \\ \mid & \mid & \mid & \mid & \mid & \mid\end{array}$

45P CCAGGACAAACAATGTATCGAATCCCTTATTTGTTTGATCAATTTTTGTAACAGCATTT 45P.2 CCAGGACAAACAATGTATCGAATTCCCTTATTTGTTTGATCAATTTTTGTAACAGCATTT

46H CCAGGACAGACAATGTACAGGATGCCTCTTTTTGTCTGATCAATTTTTGTGACTGCTTTT

G214 CCAGGACAGACAATGTATAGGATGCCTCTTTTTGTTTGATCGATTTTTGTGACTGCTTTT

G215 CCAGGACAAACAATGTATCGAATTCCCTTATTTGTTTGATCAATTTTTGTAACAGCATTT G215.2 CCAGGACAAACAATGTATCGAATTCCCTTATTTGTTTGATCAATTTTTGTAACAGCATTT HM629884 CCTGGGCAAACAATGTACCGAATGCCATTATTTGTTTGATCAATATTTGTAACAGCGTTT HM629885 CCTGGGCAAACAATGTATAGAATGCCTTTATTTGTTTGATCAATTTTCGTAACAGCTTTT HQ412472 CCGGGTCAAACCATGTACAGAATGCCATTATTTGTTTGATCGATTTTTGTAACAGCTTTT HQ412473 CCGGGTCAAACCATGTACAGAATGCCATTATTTGTTTGATCGATTTTTGTAACAGCTTTT HQ 412476 CCAGGTCAAACCATGTATAGAATGCCGTTATTTGTTTGATCAATTTTTGTAACGGCTTTT HQ412477 CCAGGTCAAACTATGTACAGAATGCCATTATTTGTTTGATCAATTTTTGTAACAGCTTTT HQ 412482 CCAGGTCAAACTATGTACAGAATGCCATTATTTGTTTGATCAATTTTTGTAACAGCTTTT HQ412486 CCCGGTCAAACTATGTACAGAATGCCACTATTTGTTTGATCAATTTTTGTGACAGCTTTT HQ422696 CCAGGCCAAAATATGTACCAAATGCCACTATTTGTTTGGTCAATATTTGTAACAGCATTT

\begin{tabular}{rrrrrrr}
421 & 430 & 440 & 450 & 460 & 470 & 480 \\
\hline & I & $\mid$ & $\mid$ & $\mid$ & $\mid$
\end{tabular}

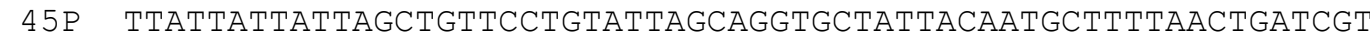
45P.2 TTATTATTATTAGCTGTTCCTGTATTAGCAGGTGCTATTACAATGCTTTTAACTGATCGT

46H TTACTTTTATTAGCGGTCCCCGTTTTAGCAGGAGCTATCACAATGTTACTAACAGATCGA G214 TTACTCTTATTAGCGGTCCCCGTTTTAGCAGGAGCTATCACAATGTTATTAACAGATCGA

G215 TTATTATTATTAGCTGTTCCTGTATTAGCAGGTGCTATTACAATGCTTTTAACTGATCGT

G215.2 TTATTATTATTAGCTGTTCCTGTATTAGCAGGTGCTATTACAATGCTTTTAACTGATCGT HM629884 TTGTTATTATTAGCTGTACCAGTTTTAGCTGGAGCTATTACAATGTTATTAACAGATCGT HM629885 TTACTACTATTAGCAGTACCAGTTTTAGCTGGTGCTATTACTATGTTATTAACTGATAGA HQ412472 CTGCTATTATTAGCAGTACCGGTTTTGGCTGGTGCAATCACTATGTTACTAACTGATAGG HQ412473 CTGCTATTATTAGCAGTACCAGTTTTAGCTGGTGCAATCACTATGTTACTAACTGATAGA HQ412476 TTATTATTATTAGCAGTACCAGTTTTAGCTGGTGCAATTACTATGTTACTAACTGATAGG HQ412477 CTATTATTATTAGCGGTACCAGTTTTAGCTGGTGCAATTACTATGTTACTAACTGATAGG HQ412482 CTATTATTATTAGCGGTACCAGTTTTAGCTGGTGCAATTACTATGTTACTAACTGATAGG HQ 412486 TTACTACTATTGGCGGTACCAGTTCTAGCTGGCGCAATTACTATGTTGTTAACTGATAGA HQ422696 TTATTACTATTAGCTGTACCAGTATTAGCAGGTGCTATTACAATGCTTTTAACAGATCGT 


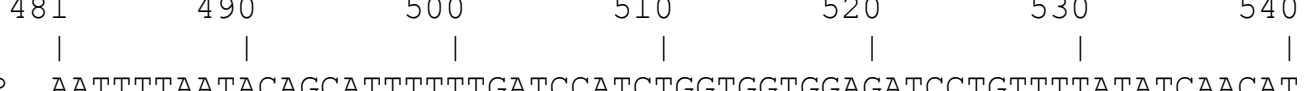

45P AАTTTTAATACAGCATTTTTTGATCCATCTGGTGGTGGAGATCCTGTTTTATATCAACAT

45P.2 AATTTTAATACAGCATTTTTTGATCCATCTGGTGGTGGAGATCCTGTTTTATATCAACAT

46H AATTTTAATACTTCATTCTTTGATCCTGCGGGAGGGGGAGATCCTGTACTTTATCAACAT

G214 AATTTTAATACTTCATTCTTTGATCCTGCGGGAGGAGGAGATCCTGTACTTTACCAACAT

G215 AATTTTAATACAGCATTTTTTGATCCATCTGGTGGTGGAGATCCTGTTTTATATCAACAT

G215.2 AATTTTAATACAGCATTTTTTGATCCATCTGGTGGTGGAGATCCTGTTTTATATCAACAT HM629884 AATTTTAATACATCATTTTTCGACCCAGCTGGTGGAGGTGATCCCGTACTGTATCAGCAT HM629885 AATTTTAATACATCGTTCTTTGACCCCGCAGGTGGAGGTGATCCAGTACTATATCAGCAT HQ 412472 AATTTTAATACATCATTTTTTGATCAGCAGGAGGTGGTGATCCTGTACTTTATCAACAC HQ 412473 AATTTTAATACATCATTTTTTGATCCAGCAGGAGGTGGTGATCCTGTACTTTATCAACAC HQ 412476 AATTTTAATACATCATTTTTTGATCCAGCAGGAGGTGGTGATCCGGTACTTTATCAACAC HQ 412477 AАTTTTAATACATCATTTTTTGATCCAGCAGGAGGTGGTGATCCGGTACTTTACCAACAC HQ412482 AATTTTAATACATCATTTTTTGATCCAGCAGGAGGTGGTGATCCGGTACTTTACCAACAC HQ 412486 AATTTTAATACATCATTCTTTGATCCAGCAGGAGGAGGTGATCCGGTACTTTATCAACAT HQ422696 AATTTTAATACATCTTTTT--_-_-_-_-_-_-_-_-_-_-_-_-_-_-_-_-_-_-_- 


\section{Appendix 7}

LSU alignment of Pterocladia lucida (45H), Pterocladiophila hemisphaerica (45P) and downloaded Genbank sequences: Caloglossa stipitata (AF522247), Dilsea integra (FJ848966), Farlowia mollis (GU176299), Furcellaria lumbricalis (GQ406350), Gainia mollis (GQ406351), Gelidiella acerosa (AF039551), Gelidium caulacantheum (AF039544), Gelidium pusillum (AF039542), Gracilaria lemaneiformis (JN609255), Gracilaria salicornia (EF033615), Gracilaria verrucosa (Y11508), Lesleigha sp. (JN602193), Hyalosiphonia caespitosa (JN403057), Melanthalia obtusata (DQ343692), Neodilsea borealis (EF033610), Neodilsea natashae (JF928825), Predaea kraftiana (EF033618), Pterocladia lucida (AF419118), Pterocladiella capillacea (AF039549), Sphaerococcus coronopifolius (FJ848974).

$45 \mathrm{H}$

$45 \mathrm{P}$

AF039542

AF039544

AF039549

AF039551

AF 419118

AF522247

DQ343692

EF033610

EF033615

EF033618

FJ848966

FJ848974

GQ 406350

GQ 406351

GU176299

JF928825

JN 403057

JN609255

JN602193

Y11508

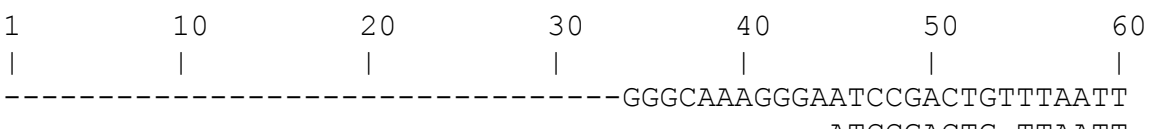

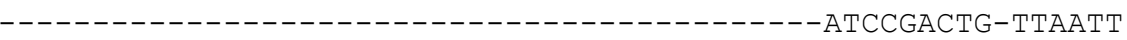

CGCCCACAGCATGCAGCAAACTAGAACTGCAACGGGCAAAGGGAATCCGACTGTTTAATT CGCCCACAGCATGCAGCAAACTAGAACTGCAACGGGCAAAGGGAATCCGACTGTTTAATT CGCCCACAGCATGCAGCAAACTAGAACTGCAACGGGCAAAGGGAATCCGACTGTTTAATT CGCCCACAGCATGCAGCAAACTAGAACTGCAACGGGCAAAGGGAATCCGACTGTTTAATT CGCCCACAGCATGCAGCAAACTAGAACTGCAACGGGCAAAGGGAATCCGACTGTTTAATT CGCCCACAACATGCAGCAAACTAGAACTGCAACGGGCAAAGGGAATCCGACTGTTTAATT CGCCCACAGAATGCAGCGAACTAGAACTGCAACGGGCAAAGGGAATCCGACTGTTTAATT CGCCCACAGCATGCAGCAGACTAGAACTGCAACGGGCAAAGGGAATCCGACTGTTTAATT CGCTCACAGCATGCAGCGAACTAGAACTGCAACGGGCAAAGGGAATCCGACTGTTTAATT CGCCCACAGCATGCAGCAAACTAGAACTGCAACGGGCAAAGGGAATCCGACTGTTTAATT CGCCCACAGCATGCAGCAGACTAGAACTGCAACGGGCAAAGGGAATCCGACTGTTTAATT CGCCCACAGCATGCAGCAGACTAGAACTGCAACGGGCAAAGGGAATCCGACTGTTTAATT CGCCCACAGCATGCAGCAGACTAGAACTGCAACGGGCAAAGGGAATCCGACTGTTTAATT CGCCCACAGCATGCAGCAGACTAGAACTGCAACGGGCAAAGGGAATCCGACTGTTTAATT CGCCCACAGCATGCAGCAGACTAGAACTGCAACGGGCAAAGGGAATCCGACTGTTTAATT CGCCCACAGCATGCAGCAGACTAGAACTGCAACGGGCAAAGGGAATCCGACTGTTTAATT CGCCCACAGCATGCAGCAGACTAGAACTGCAACGGGCAAAGGGAATCCGACTGTTTAATT CGCTCACAGCATGCAGCAAACTAGAACTGCAACGGGCAAGGGGAATCCGACTGTTTAATT CGCCCACAGCATGCAGCAGACTAGAACTGCAACGGGCAAAGGGAATCCGACTGTTTAATT CGCTCACAGCATGCAGCGAACTAGAACTGCAACGGGCAAAGGGAATCCGACTGTTTAATT 
AAAACAAAGCATTGCGAGGGCCGTGGCCGGTGATGACGCAATGTGATTTCTGCTCAGTGC

45P AAAACAAAGCATTGCGAAGGCCGTGGCCGGTGATGACGCAATGTGATTTCTGCTCAGTGC AF039542 $\mathrm{AF} 039544$ AF039549 AF039551 AF 419118 AF522247 DQ343692 EF033610 EF033615 EF033618 FJ848966 FJ848974 GQ406350 GQ406351 GU176299 JF 928825 JN403057 JN609255 AAAACAAAGCATTGCGAGGGCCGTGGCCGGTGATGACGCAATGTGATTTCTGCTCAGTGC AAAACAAAGCATTGCGAGGGCCGTGGCCGGTGATGACGCAATGTGATTTCTGCTCAGTGC AAAACAAAGCATTGCGAGGGCCGTGGCCGGTGATGACGCAATGTGATTTCTGCTCAGTGC AAAACAAAGCAACGCGAGGGCCGTGGCCGGTGATGACGCGTTGTGATTTCTGCTCAGTGC AAAACAAAGCATTGCGAGGGCCGTGGCCGGTGATGACGCAATGTGATTTCTGCTCAGTGC AAAACAAAGCATTGCGACGGCCGTGGCCGGTGTTGACGCAATGTGATTTCTGCTCAGTGC AAAACAAAGCATTGCGAGGGCCGGGGACGGTGATTACGCAATGTGATTTCTGCTCAGTGC AAAACAAAGCATTGCGAAGGCCGTGGCCGGTGATGACGCAATGTGATTTCTGCTCAGTGC AAAACAAAGCATTGCGAGGGCCGGGGACGGTGATTACGCAATGTGATTTCTGCTCAGTGC AAAACAAAGCATTGCGAGGGCCGTGGCCGGTGATGACGCAATGTGATTTCTGCTCAGTGC AAAACAAAGCATTGCGAAGGCCGTGGCCGGTGATGACGCAATGTGATTTCTGCTCAGTGC AAAACAAAGCATTGCGAAGGCCGTGGCCGGTGATGACGCAATGTGATTTCTGCTCAGTGC AAAACAAAGCATTGCGAAGGCCGTGGCCGGTGATGACGCAATGTGATTTCTGCTCAGTGC AAAACAAAGCATTGCGAAGGCCGTGGCCGGTGATGACGCAATGTGATTTCTGCTCAGTGC AAAACAAAGCATTGCGAAGGCCGTGGCCGGTGATGACGCAATGTGATTTCTGCTCAGTGC AAAACAAAGCATTGCGAAGGCCGTGGCCGGTGATGACGCAATGTGATTTCTGCTCAGTGC AAAACAAAGCATTGCGAAGGCCGTGGCCGGTGATGACGCAATGTGATTTCTGCTCAGTGC AAAAC-AAGCATTGCGA-GGCCGGGGACGGTGATTACGCAATGTGATTTCTGCTCAGTGC AAAACAAAGCATTGCGAGGGCCGTGGCCGGTGATGACGCAATGTGATTTCTGCTCAGTGC AAAACAAAGCATTGCGAGGGCCGGGGACGGTGATTACGCAATGTGATTTCTGCTCAGTGC TCTGAATGTCAAAGTGAAGAAATTCAACC SAGCGCGGGTMAACAGCGGGAGTAACTATGA TCTGAATGTCAAAGTGAAGAGATTCAATCAAGCGCGGGTAAACAGCGGGAGTAACTATGA TCTGAATGTCAAAGTGAAGAGATTCAATCAAGCGCGGGTAAACAGCGGGAGTAACTATGA TCTGAATGTCAAAGTGAAGAGATTCAATCAAGCGCGGGTAAACAGCGGGAGTAACTATGA TCTGAATGTCAAAGTGAAGAGATTCAATCAAGCGCGGGTAAACAGCGGGAGTAACTATGA TCTGAATGTCAAAGTGAAGAGATTCAATCAAGCGCGGGTAAACAGCGGGAGTAACTATGA TCTGAATGTCAAAGTGAAGAGATTCAAATAAGCGCGGGTAAACAGCGGGAGTAACTATGA TCTGAATGTCAAAGTGAAGAGATTCAATCAAGCGCGGGTAAACAGCGGGAGTAACTATGA TCTGAATGTCAAAGTGAAGAGATTCAATCAAGCGCGGGTAAACAGCGGGAGTAACTATGA TCTGAATGTCAAAGTGAAGAGATTCAATCAAGCGCGGGTAAACAGCGGGAGTAACTATGA TCTGAATGTCAAAGTGAAGAGATTCAATCAAGCGCGGGTAAACAGCGGGAGTAACTATGA TCTGAATGTCAAAGTGAAGAGATTCAATCAAGCGCGGGTAAACAGCGGGAGTAACTATGA TCTGAATGTCAAAGTGAAGAGATTCAATCAAGCGCGGGTAAACAGCGGGAGTAACTATGA TCTGAATGTCAAAGTGAAGAGATTCAATCAAGCGCGGGTAAACAGCGGGAGTAACTATGA TCTGAATGTCAAAGTGAAGAGATTCAATCAAGCGCGGGTAAACAGCGGGAGTAACTATGA TCTGAATGTCAAAGTGAAGAGATTCAATCAAGCGCGGGTAAACAGCGGGAGTAACTATGA TCTGAATGTCAAAGTGAAGAGATTCAATCAAGCGCGGGTAAACAGCGGGAGTAACTATGA TCTGAATGTCAAAGTGAAGAGATTCAATCAAGCGCGGGTAAACAGCGGGAGTAACTATGA TCTGAATGTCAAAGTGAAGAGATTCAATCAAGCGCGGGTAAACAGCGGGAGTAACTATGA TCTGAATGTCAAAGTGAAGAGATTCAATCAAGCGCGGGTAAACAGCGGGAGTAACTATGA TCTGAATGTCAAAGTGAAGAGATTCAATCAAGCGCGGGTAAACAGCGGGAGTAACTATGA 

AF039542 CTCTCTTAAGGTAGCCAAATGCCTCGTCATCTAATTAGTGACGCGCATGAATGGATTAAC CTCTCTTAAGGTAGCCAAATGCCTCGTCATCTAATTAGTGACGCGCATGAATGGATTAAC CTCTCTTAAGGTAGCCAAATGCCTCGTCATCTAATTAGTGACGCGCATGAATGGATTAAC CTCTCTTAAGGTAGCCAAATGCCTCGTCATCTAATTAGTGACGCGCATGAATGGATTAAC СTCTCTTAAGGTAGCCAAATGCCTCGTCATCTAATTAGTGACGCGCATGAATGGATTAAC СTCTCTTAAGGTAGCCAAATGCCTCGTCATCTAATTAGTGACGCGCATGAATGGATTAAC СTCTCTTAAGGTAGCCAAATGCCTCGTCATCTAATTAGTGACGCGCATGAATGGATTAAC CTCTCTTAAGGTAGCCAAATGCCTCGTCATCTAATTAGTGACGCGCATGAATGGATTAAC CTCTCTTAAGGTAGCCAAATGCCTCGTCATCTAATTAGTGACGCGCATGAATGGATTAAC CTCTCTTAAGGTAGCCAAATGCCTCGTCATCTAATTAGTGACGCGCATGAATGGATTAAC CTCTCTTAAGGTAGCCAAATGCCTCGTCATCTAATTAGTGACGCGCATGAATGGATTAAC CTCTCTTAAGGTAGCCAAATGCCTCGTCATCTAATTAGTGACGCGCATGAATGGATTAAC CTCTCTTAAGGTAGCCAAATGCCTCGTCATCTAATTAGTGACGCGCATGAATGGATTAAC CTCTCTTAAGGTAGCCAAATGCCTCGTCATCTAATTAGTGACGCGCATGAATGGATTAAC CTCTCTTAAGGTAGCCAAATGCCTCGTCATCTAATTAGTGACGCGCATGAATGGATTAAC СTCTCTTAAGGTAGCCAAATGCCTCGTCATCTAATTAGTGACGCGCATGAATGGATTAAC СTCTCTTAAGGTAGCCAAATGCCTCGTCATCTAATTAGTGACGCGCATGAATGGATTAAC СTCTCTTAAGGTAGCCAAATGCCTCGTCATCTAATTAGTGACGCGCATGAATGGATTAAC CTCTCTTAAGGTAGCCAAATGCCTCGTCATCTAATTAGTGACGCGCATGAATGGATTAAC CTCTCTTAAGGTAGCCAAATGCCTCGTCATCTAATTAGTGACGCGCATGAATGGATTAAC CTCTCTTAAGGTAGCCAAATGCCTCGTCATCTAATTAGTGACGCGCATGAATGGATTAAC

Y11508

\begin{tabular}{l|c|c|c|} 
| & $\mid$ & $\mid$ & $\mid$
\end{tabular} \mid

$\begin{array}{ll}\text { 45H } & \text { GAGATTCCTACTGTCCCTATCTGCTTCTAGCGAAACCACAGCCGAGGGAACGGGCTCGGC } \\ \text { 45P }\end{array}$ AF039542 GAGATTCCTACTGTCCCTATCTGCTTCTAGCGAAACCACAGCCGAGGGAACGGGCTCGGC AF039544 GAGATTCCTACTGTCCCTATCTGCTTCTAGCGAAACCACAGCCGAGGGAACGGGCTCGGC AF039549 GAGATTCCTACTGTCCCTATCTGCTTCTAGCGAAACCACAGCCGAGGGAACGGGCTCGGC AF039551 GAGATTCCTACTGTCCCTATCTGCTTCTAGCGAAACCACAGCCGAGGGAACGGGCTCGGC AF419118 GAGATTCCTACTGTCCCTATCTGCTTCTAGCGAAACCACAGCCGAGGGAACGGGCTCGGC AF522247 DQ343692 EF033610 $\mathrm{EF} 033615$ $\mathrm{EF} 033618$ FJ848966 FJ848974 GO 406350 GQ 406351 GU176299 JF928825 JN403057 JN609255 JN602193

Y11508 GAGATTCCTACTGTCCCTATCTGCTTCTAGCGAAAACCCAGCCGGGGGAACGGGCTCGGC GAGATTCCTACTGTCCCTATCTGCTTCTAGCGAAACCACAGCCGGGGGAACGGGCCCGGC GAGATTCCTACTGTCCCTATCTGCTTCTAGCGAAACCACAGCCGAGGGAACGGGCTCGGC GAGATTCCTACTGTCCCTATCTGCTTCTAGCGAAACCACAGCCGGGGGAACGGGCCCGGC GAGATTCCTACTGTCCCTATCTGCTTCTAGCGAAACCACAGCCGAGGGAACGGGCTCGGC GAGATTCCTACTGTCCCTATCTGCTTCTAGCGAAACCACAGCCGAGGGAACGGGCTCGGC GAGATTCCTACTGTCCCTATCTGCTTCTAGCGAAACCACAGCCGAGGGAACGGGCTCGGC GAGATTCCTACTGTCCCTATCTGCTTCTAGCGAAACCACAGCCGAGGGAACGGGCTCGGC GAGATTCCTACTGTCCCTATCTGCTTCTAGCGAAACCACAGCCGAGGGAACGGGCTCGGC GAGATTCCTACTGTCCCTATCTGCTTCTAGCGAAACCACAGCCGAGGGAACGGGCTCGGC GAGATTCCTACTGTCCCTATCTGCTTCTAGCGAAACCACAGCCGAGGGAACGGGCTCGGC GAGATTCCTACTGTCCCTATCTGCTTCTAGCGAAACCACAGCCGAGGGAACGGGCTCGGC GAGATTCCTACTGTCCCTATCTGCTTCTAGCGAAACCACAGCCAGGGGAACGGGCCTGGA GAGATTCCTACTGTCCCTATCTGCTTCTAGCGAAACCACAGCCGAGGGAACGGGCTCGGC GAGATTCCTACTGTCCCTATCTGCTTCTAGCGAAACCACAGCCGGGGGAACGGGCCCGGC 


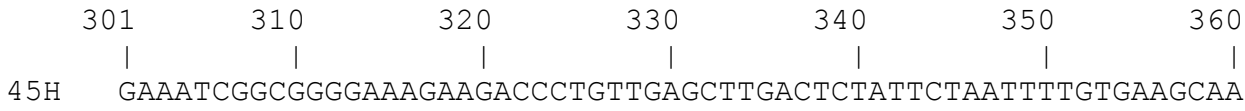

45P GAAATCGGCGGGGAAAGAAGACCCTGTTGAGCTTGACTCTATTCTAATTTTGTGAAGCAA AF039542 GAAATCGGCGGGGAAAGAAGACCCTGTTGAGCTTGACTCTATTCTAATTTTGTGAAGCAA AF039544 GAAATCGGCGGGGAAAGAAGACCCTGTTGAGCTTGACTCTATTCTAATTTTGTGAAGCAA AF039549 GAAATCGGCGGGGAAAGAAGACCCTGTTGAGCTTGACTCTATTCTAATTTTGTGAAGCAA AF039551 GAAATCGGCGGGGAAAGAAGACCCTGTTGAGCTTGACTCTATTCTAATTTTGTGAAGCAA AF419118 GAAATCGGCGGGGAAAGAAGACCCTGTTGAGCTTGACTCTATTCTAATTTTGTGAAGCAA AF522247 AAAAATGGCGGGGAAAGAAGACCCTGTTGAGCTTGACTCTATTCTAGAACTGTGAAACGA DQ343692 GAAATCGGCGGGGAAAGAAGACCCTGTTGAGCTTGACTCTATTCTAATTTTGTGGAGCAA EF033610 GAAATCGGCGGGGAAAGAAGACCCTGTTGAGCTTGACTCTATTCTAATTTTGTGAAGCAA EF033615 AAAATCGGCGGGGAAAGAAGACCCTGTTGAGCTTGACTCTATTCTAATTTTGTGGAGCAA EF033618 AAAATCGGCGGGGAAAGAAGACCCTGTTGAGCTTGACTCTATTCTAATTTTGTGAAGCAA FJ848966 GAAATCGGCGGGGAAAGAAGACCCTGTTGAGCTTGACTCTATTCTAATTTTGTGAAGCAA FJ848974 GAAATCGGCGGGGAAAGAAGACCCTGTTGAGCTTGACTCTATTCTAATTTTGTGAAGCAA GQ406350 GAAATCGGCGGGGAAAGAAGACCCTGTTGAGCTTGACTCTATTCTAATTTTGTGAAGCAA GQ406351 GU176299 JF928825 JN403057 JN609255 JN602193 GAAATCGGCGGGGAAAGAAGACCCTGTTGAGCTTGACTCTATTCTAATTTTGTGAAGCAA GAAATCGGCGGGGAAAGAAGACCCTGTTGAGCTTGACTCTATTCTAATTTTGTGAAGCAA GAAATCGGCGGGGAAAGAAGACCCTGTTGAGCTTGACTCTATTCTAATTTTGTGAAGCAA GAAATCGGCGGGGAAAGAAGACCCTGTTGAGCTTGACTCTATTCTAATTTTGTGAAGCAA AAAATCGGCGGGGAAAGAAGACCCTGTTGAGCTTGACTCTATTCTAATTTTGTGGAGCAA CAAATCGGCGGGGAAAGAAGACCCTGTTGAGCTTGACTCTATTCTAATTTTGTGAAGCAA GAAATCGGCGGGGAAAGAAGACCCTGTTGAGCTTGACTCTATTCTAATTTTGTGGAGCAA

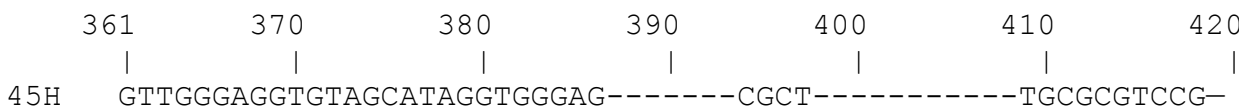

45P GTTGGGAGGTGTAGCATAGGTGGGAGCT-----AGTTT---------TAACCGTAAGGT AF039542 GTTGGGAGGTGTAGCATAGGTGGGAG-------CGCT----------TGCGCGTCCG-AF039544 GTTGGGAGGTGTAGCATAGGTGGGAG-------CGCT-----------TGCGCGTCCG-AF039549 GTTGGGAGGTGTAGCATAGGTGGGAG-------CGCT----------TGCGCGTCCGAF039551 GTTGGGAGGTGTAGCATAGGTGGGAG-------CGCT-----------TGCGCGTCCGAF419118 GTTGGGAGGTGTAGCATAGGTGGGAG-------CGCT----------TGCGCGTCCG-AF522247 GTTAGGAGGTGTAGAATAGGTGGGAG-------AGCTT----------TGCTCGTCAGDQ343692 GTTGGGAGGTGTAGCATAGGTGGGAGACCAA--TTTT-----------TGGTCAAAAGEF033610 GTTGGGAGGTGTAGCATAGGTGGGAG-------CGCT----------TGCGCGTCCGEF033615 GTTGGGAGGTGTAGCATAGGTGGGAG-------ACTTTA---------TTGTCGTCAGEF033618 GTTGGGAGGTGTAGCATAGGTGGGAG-------TGTTTCGCTTCGGCGTGCACGGCCGFJ848966 GTTGGGAGGTGTAGCATAGGTGGGAG-------CGCT-----------TGCGCGTCCG--

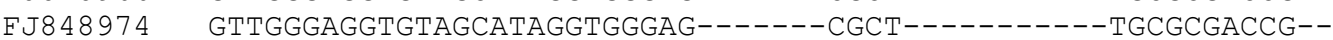
GQ 406350 GTTGGGAGGTGTAGCATAGGTGGGAG-------CGCT-----------TGCGCAACCG--

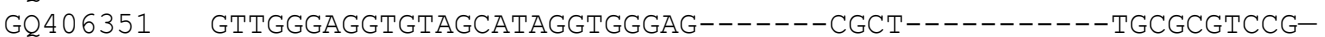
GU176299 GTTGGGAGGTGTAGCATAGGTGGGAG-------CGCT-----------TGCGCGTCCGJF928825 GTTGGGAGGTGTAGCATAGGTGGGAG-------CGCT-----------TGCGCGTCCGJN403057 GTTGGGAGGTGTAGCATAGGTGGGAG-------CGCT----------TGCGCGTCCG-JN602193 GCTGGGAGGTGTAGCATAGGTGGGAGACTCTTCTGCTTTCGGGGGGATTTGTCGAACGJN609255 GTTGGGAGGTGTAGCATAGGTGGGAG------ACTTT---------ACGTCGCCAG-Y11508 GTTGGGAGGTGTAGCATAGGTGGGAG-------ACCT----------CGGTCGTCAG-- 


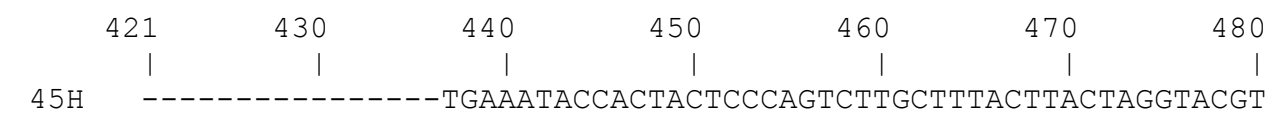

45P ATGATATTAGCAAACTTGAAATACCACTACTCCCAATCTTGCTTTACTTACTGGATAAGT AF039542 --------------TGAAATACCACTACTCCCAGTCTTGCTTTACTTACTAGGTAAGC AF039544 -------------TGAAATACCACTACTCCCAGTCTTGCTTTACTTACTAGGTAAGC AF039549 -------------tTGAAATACCACTACTCCCAGTCTTGCTTTACTTACTAGGTTAGT AF039551 --------------TGAAATACCACTACTCCCAGTCTTGCTTTACTTACTAGGTAATT AF419118 -------------TGAAATACCACTACTCCCAGTCTTGCTTTACTTACTAGGTACGT AF522247 -------------TGAAATACCACTACTCCTAATCTCGTTTTACTTACCACGTGCGT DQ343692 --------------TGAAATACCACTACTCCCAATCTTGCTTTACTTACTAGGCTGGT EF033610 ------------TGAAATACCACTACTCCCAGTCTTGCTTTACTTACTGGGTTGGT EF033615 -------------TGAAATACCACTACTCCCAATCTTGCTTTACTTACTAGGCAGGG EF033618 ------------TGAAATACCACTACTCCCAGTCTTGCTTTACTTACGGGGTGAGT FJ848966 --------------TGAAATACCACTACTCCCAGTCTTGCTTTACTTACTGGGTTGGT FJ848974 ------------TGAAATACCACTACTCCCAGTCTTGCTTTACTTACTGGGTTGGT GQ 406350 GQ 406351 GU176299 JF928825 JN403057 JN602193 JN609255

Y11508 -------------TGAAATACCACTACTCCCAGTCTTGCTTTACTTACTGGGTTGGT -------------TGAAATACCACTACTCCCAGTCTTGCTTTACTTACTGGGTTGGT -------------TGAAATACCACTACTCCCAGTCTTGCTTTACTTACTGGGTTGGT -------------TGAAATACCACTACTCCCAGTCTTGCTTTACTTACTGGGTTGGT -------------TGAAATACCACTACTCCCAGTCTTGCTTTACTTACTGGGTTGGT --------------TGAAATACCACTACTCCCAGTCTTGCTTTACTTACTGGGTGGGT -------------TGAAATACCACTACTCCCAATCTTGCTTTACTTACTAGGCAGGT

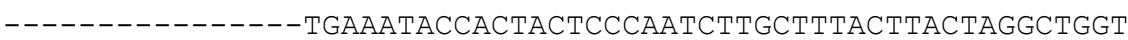

\begin{tabular}{|c|c|c|c|c|c|c|}
\hline 481 & 490 & 500 & 510 & 520 & 530 & 540 \\
\hline I & | & I & 1 & I & 1 & 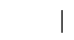 \\
\hline
\end{tabular}

45P GTGGAATGGGCAGCACGTGGCGGCCGTTAAAAGCCACGCGTGTGCGCCTTTATATTTTAA AF039542 GTGGATGAGTC---------------------------TTACGAC-TTCATTTTAG AF039544 GTGGATGAGTC---------------------------TTACGAC-TTCATTTTAG

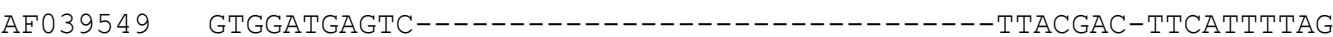
AF039551 GTGGATGAGTT-----------------------TTACGAC-TTGATTTTAG AF419118 GTGGATGAGTC--------------------------TTACGAC-TTCATTTTAG AF522247 GTGGATGAATT----------------------------GAACCTCATTTTTCAG DQ343692 GTGGATGGGTT-------------------GTAGCATTTGTTGCAAT-CTTGTTTTTG

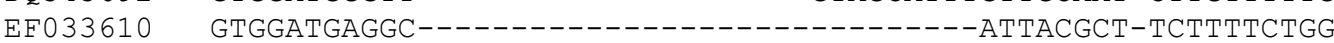
EF033615 GTGGATGGGTT--------------------GTCAAATCTTTGGCAAT-CTTTTTTTGG EF033618 GTGGATGGGAT--------------------------TTACGTC-CCTTTTTTGG FJ848966 GTGGATGAAGC--------------------------ATTACGCT-TCTTTTTTGG FJ848974 GTGGATGAGTC--------------------------TTACGAC-TCTATTCTAG GQ406350 GTGGATGAGCC---------------------------TTACGGC-TCTATTCTGG GQ406351 GTGGATCAGCC----------------------------TTACGGCTTTTATTCTGG GU176299 GTGGATGAGCC----------------------------TTACGGC-TCTATTCTGG JF928825 GTGGATGAGGC--------------------------ATTACGCT-TCTTTTCTGG JN403057 GTGGATGAGGC-----------------------TATTTTACGCC-TCTTTTCTGG

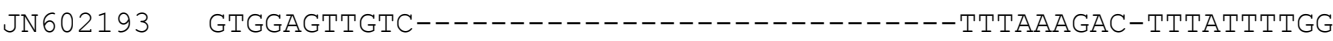

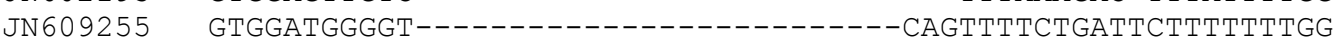

Y11508 GTGGGTGGATT------------------GTT--ATTTTTGGCAAT-CTTTTTTTTG 


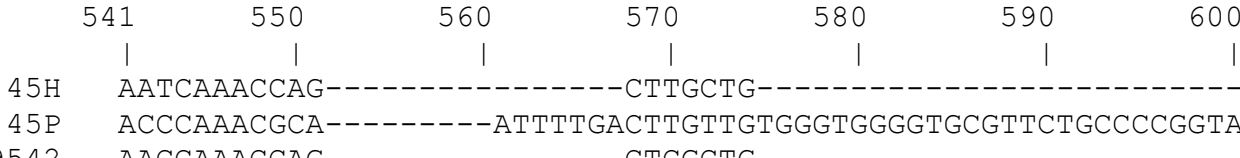

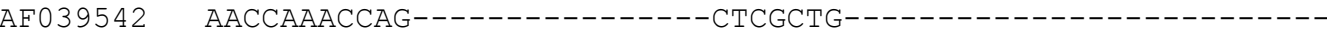

AF039544 AACCAAACCAG---------------CTTGCTG------------------------

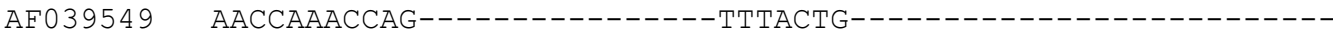

AF039551 AACCAAACCAG--------------CTTGCTG-----------------------

AF419118 AATCAAACCAG---------------CTTGCTG-------------------------

AF522247 AACCTAACACA---------CCTGTAAACCG-TG-------------------------

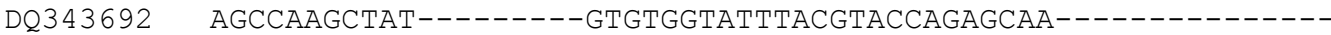

EF033610 AACCAATGTGA-_-_-_-_-_GATTTATTTTTCG-_-_-_-_-_-_-_-_-_-_-_-_-

EF033615 AGCCAAGCCAT---------GTCGGAATCCTCGGATTCGGAGTAG--------------

EF033618 AACCAAATTTG-------------TGACTTGTTACAA-----------------------

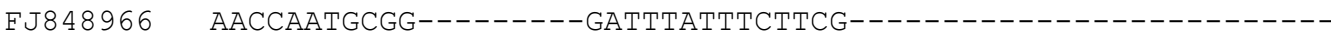

FJ848974

GQ 406350

GQ 406351

GU176299

JF928825

JN403057

JN602193

JN609255

Y11508

AACCAATGCAA-------------TTTTTTG-

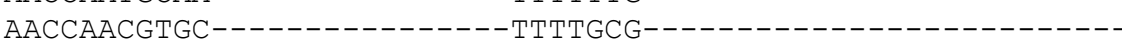

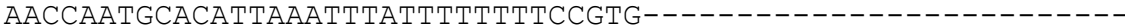

AACCAATGCAA--------AATTGTTTTTTTTTG-----------------------

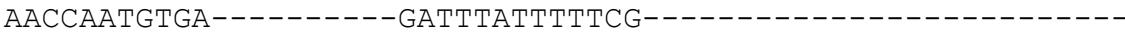

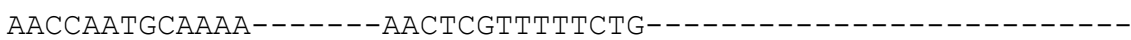

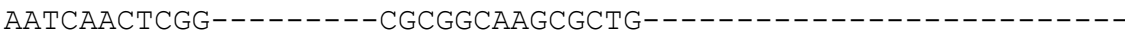

AGCCAAGCCGG---------TTTTTTCTTCGGGAAAGACC-ATAG--------------

AGCCAAGCCAT--------GTCAGAATCCTCGGATACTGAGTAG--------------

\begin{tabular}{rrrrrrr} 
& 610 & 620 & 630 & 640 & 650 & 660 \\
\hline & 1 & $\mid$ & $\mid$ & $\mid$ & $\mid$
\end{tabular}

45H - $\mathrm{H}$

45P GAATGTCCCGATCCATGACGACGATGCCGTGACCACGGTCCAGAACACATTTAGGAGGGG AF039542 ----------------------GTGACCACAGCCTAGCACACATTTAGGAGGGG

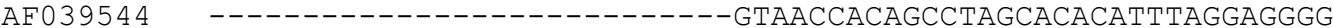
AF039549 -----------------------GTAACCACAGCCTAGCACACATTTAGGAGGGG AF039551 -----------------------GTGACCACAGCCTAGCACACATTTAGGAGGGG AF 419118 -----------------------GTGACCACAGCCTAGCACACATTTAGGAGGGG AF522247 ----------------------TGGATCTCGGCGTGGGACACTTTTAGGAGGGG

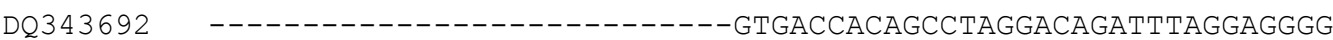
EF033610 -----------------------CAGACCACAGCCCAGCACACATTTAGGAGGGG EF033615 ------------------------GTGACCACAGCCTAGGACAGACTTAGGAGGGG EF033618 -----------------------ATGACCACAGCCCCGTACACATTTAGGAGGGG FJ848966 ----------------------CAGACCACAGCCCAGCACACATTTAGGAGGGG FJ848974 ------------------------CAGACCACAGCCCAGCACACATTTAGGAGGGG GQ 406350 -----------------------CGGACCACAGCCCAGCACACATTTAGGAGGGG GQ 406351 ------------------------CAGACCACAGCCCAGCACACATTTAGGAGGGG

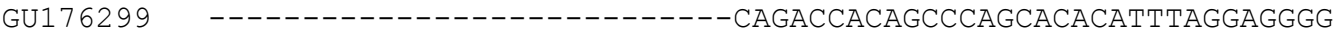
JF928825 ------------------------CAGACCACAGCCCAGCACACATTTAGGAGGGG JN403057 -----------------------CAGACCACAGCCCAGTACACATTTAGGAGGGG JN602193 ------------------------ACGACCACAGCCCAGTACACATTTAGGAGGGG JN609255 --------------------------GTGACCACCGCCTAGGACAGATTTAGGAGGGG Y11508 -----------------------GTGACCACAGCCTAGGACAGATTTAGGAGGGG 
45P AGTTTGGCTGGGGCGGTACATCTTCTACAAAACAACGAAGGTGTCCAAAGATAAGCTCAG AF039542 AGTTTGGCTGGGGCGGCACATCTTCTACAAGACAACGAAGGTGTCCAAAGATAAGCTCAG AF039544 AGTTTGGCTGGGGCGGCACATCTTCTACAAGACAACGAAGGTGTCCAAAGATAAGCTCAG AF039549 AF039551 AF 419118 AF522247 DQ343692 $\mathrm{EF} 033610$ EF033615 $\mathrm{EF} 033618$ FJ848966 FJ848974 GQ 406350 GQ 406351 GU176299 JF928825 JN403057 JN602193 JN609255 AGTTTGGCTGGGGCGGCACATCTTCTACAAGACAACGAAGGTGTCCAAAGATAAGCTCAG AGTTTGGCTGGGGCGGCACATCTTCTACAAGACAACGAAGGTGTCCAAAGATAAGCTCAG AGTTTGGCTGGGGCGGCACATCTTCTACAAGACAACGAAGGTGTCCAAAGATAAGCTCAG AGTTTGGCTGGGGCGGCACATTTTCTACAAGACAACGAAGGTGTCCAAAGATAAGCTCAG AGTTTGGCTGGGGCGGTACATCTTCTACAAGACAACGAAGGTGTCCAAAGATCAGCTCAG AGTTTGGCTGGGGCGGCACATCTTCTACAAGACAACGAAGGTGTCCAAAGATAAGCTCAG AGTTTGGCTGGGGCGGTACATCTTCTACAAGACAACGAAGGTGTCCAAAGATCAGCTCAG AGTTTGGCTGGGGCGGTACATCTTCTACAAGACAACGAAGGTGTCCAAAGATAAGCTCAG AGTTTGGCTGGGGCGGCACATCTTCTACAAGACAACGAAGGTGTCCAAAGATAAGCTCAG AGTTTGGCTGGGGCGGCACATCTTCTACAAGACAACGAAGGTGTCCAAAGATAAGCTCAG AGTTTGGCTGGGGCGGCACATCTTCTACAAGACAACGAAGGTGTCCAAAGATGAGCTCAG AGTTTGGCTGGGGCGGCACATCTTCTACAAGACAACGAAGGTGTCCAAAGATAAGCTCAG AGTTTGGCTGGGGCGGCACATCTTCTACAAGACAACGAAGGTGTCCAAAGATAAGCTCAG AGTTTGGCTGGGGCGGCACATCTTCTACAAGACAACGAAGGTGTCCAAAGATAAGCTCAG AGTTTGGCTGGGGCGGCACATCTTCTACAAGACAACGAAGGTGTCCAAAGATAAGCTCAG AGTTTGGCTGGGGCGGTACATCTTCTACAAGACAACGAAGGTGTCCAAAGATAAGCTCAG AGTTTGGCTGGGGCGGTACATCTTCTACAAGACAACGAAGGTGTCCTAAGATCAGCTCAG AGTTTGGCTGGGGCGGTACATCTTCTACAAGACAACGAAGGTGTCCAAAGATCAGCTCAG TGAGAACAGAAATCTCATGTAGCGCAAAAGGGTAAAAGCTTGTTTGATTTCGATTTTCAG AF039542 AF039544 AF039549 AF039551 AF 419118 AF522247 DQ343692 EF033610 EF033615 EF033618 FJ848966 FJ84 8974 GQ 406350 GQ 406351 GU176299 JF928825 JN 403057 JN602193 TGAGAACAGAAATCTCACGTAGCGCAAAAGGGTAAAAGCTTGTTTTATTTTGATTTTCAG TGAGAACAGAAATCTCACGTAGCGCAAAAGGGTAAAAGCTTGTTTTATTTTGATTTTCAG TGAGAACAGAAATCTCACGTAGCGCAAAAGGGTAAAAGCTTGTTTTATTTTGATTTTCAG TGAGAACAGAAATCTCACGTAGCGCAAAAGGGTAAAAGCTTGTTTTATTTTGATTTTCAG TGAGAACAGAAATCTCACGTAGCGCAAAAGGGTAAAAGCTTGTTTTATTTTGATTTTCAG TGAGAACAGAAATCTCACGTAGCGCAAAAGGGTAAAAGCTTGTTTGATTTTGATTTCCAG TGAGAACAGAAATCTCACGTAGCGTAAAAGGGTAAAAGCTGGTTTGATTTTGATTTTCAG TGAGAACAGAAATCTCACGTAGCGGAAAAGGCTAAAAGCTTGTTTGATTTTGATTTTCAG TGAGAACAGAAATCTCACGTAGCGCAAAAGGGTAAAAGCTGGTTTGATTTCGATTTTCAG TGAGAACAGAAATCTCACGTAGCGCAAAAGGGTAAAAGCTTGTTTGATTTTGATTTTCAG TGAGAACAGAAATCTCACGTAGCGGAAAAGGCTAAAAGCTTGTTTGATTTTGATTTTCAG TGAGAACAGAAATCTCACGTAGCGCAAAAGGGTAAAAGCTTGTTTGATTTTGATTTTCAG TGAGAACAGAAATCTCACGTAGCGCAAAAGGGTAAAAGCTCGTTTGATTTTGATTTTCAG TGAGAACAGAAATCTCACGTAGCGCAAAAGGGTAAAAGCTTGTTTGATTTTGATTTTCAG TGAGAACAGAAATCTCACGTAGCGGAAAAGGCTAAAAGCTTGTTTGATTTTGATTTTCAG TGAGAACAGAAATCTCACGTAGCGGAAAAGGCTAAAAGCTTGTTTGATTTTGATTTTCAG TGAGAACAGAAATCTCACGTAGCGGAAAAGGCTAAAAGCTTGTTTGATTTTGATTTTCAG TGAGAACAGAAATCTCACGTAGCGCAAAAGGGTAAAAGCTTGTTTGATTTTGATTTTCAG TGAGAACAGAAATCTCACGTAGCGCAAAAGGGTAAAAGCTGGTTTGATTTCGATTTTCAG TGAGAACAGAAATCTCACGTAGCGCAAAAGGGTAAAAGCTGGTTTGATTTCGATTTTCAG 
AF039542

AF039544

AF039549

AF039551

AF 419118

AF 522247

DQ343692

EF033610

EF033615

EF033618

FJ848966

FJ848974

GQ 406350

GQ406351

GU176299

JF928825

JN 403057

JN602193

JN609255

Y11508 TGCGAGTCGAAAACGCGAAAGCGTGGCCTATCGATCTTTTCACGATTCGAGATTTGAAGC TGCGAGTCGAAAACGCGAAAGCGTGGCCTATCGATCCTTTCACGATTCGAGATTTGAAGC TGCGAGTCGAAAACGCGAAAGCGTGGCCTATCGATCCTTTCACGATTCGAGATTTGAAGC TGCGAGTCGAAAACGCGAAAGCGTGGCCTATCGATCCTTTCACGATTCGAGATTTGAAGC TGCGAGTCGAAAACGCGAAAGCGTGGCCTATCGATCCTTTCACGATTCGAGATTTGAAGC TGCGAGTCGAAAACGCGAAAGCGTGGCCTATCGATCCTTTCACGATTCGAGATTTGAAGC TGCGAGTCGAAAACGCGAAAGCGTGGCCTATCGATCCTTTTGAGTTTCGAGACTTGAAGC TGCGAGTCGAAAACGCGAAAGCGTGGCCTATCGATCCTTTCATGATTCGAGATTTGAAGC TGCGAGTCGAAAACGCGAAAGCGTGGCCTATCGATCCTTTCACGATTCGAGATTTGAAGC TGCGAGTCGAAAACGCGAAAGCGTGGCCTATCGATCCTTTCACGATTCGAGATTTGAAGC TGCGAGTCGAAAACGCGAAAGCGTGGCCTATCGATCCTTTCACTATTCGAGATTTGAAGC TGCGAGTCGAAAACGCGAAAGCGTGGCCTATCGATCCTTTCACGATTCGAGATTTGAAGC TGCGAGTCGAAAACGCGAAAGCGTGGCCTATCGATCCTTTCACGATTCGAGATTTGAAGC TGCGAGTCGAAAACGCGAAAGCGTGGCCTATCGATCCTTTCACTATTCGAGATTTGAAGC TGCGAGTCGAAAACGCGAAAGCGTGGCCTATCGATCCTTTCACGATTCGAGATTTGAAGC TGCGAGTCGAAAACGCGAAAGCGTGGCCTATCGATCCTTTCACGATTCGAGATTTGAAGC TGCGAGTCGAAAACGCGAAAGCGTGGCCTATCGATCCTTTCACGATTCGAGATTTGAAGC TGCGAGTCGAAAACGCGAAAGCGTGGCCTATCGATCCTTTCACGATTCGAGATTTGAAGC TGCGAGTCAAAAACGCGAAAGCGTGGCCTATCGATCCTTTCACATTTCGAGATTTGAAGC TGCGAGTCGAAAACGCGAAAGCGTGGCCTATCGATCCTTTCACGATTCGAGATTTGAAGC TGCGAGTCGAAAACGCGAAAGCGTGGCCTATCGATCCTTTCACGATTCGAGATTTGAAGC

GAGAGGTGTCAGAAAAGTTACCACAGGGATAACTGGCTTGTGGCGGCCAAGCGTTCATAG GAGAGGTGTCAGAAAAGTTACCACAGGGATAACTGGCTTGTGGCGGCCAAGCGTTCATAG AF039542 AF03954 AF039549 AF039551 AF419118 AF522247 DO343692 EF033610 EF033615 EF033618 FJ848966 FJ84 8974 GQ 406350 GQ 406351 GU176299 JF928825 JN 403057 JN602193

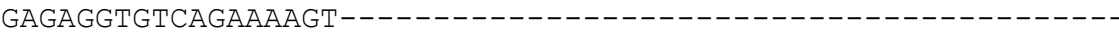

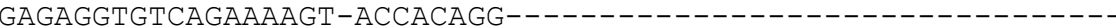

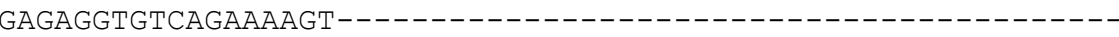
GAGAGGTGTCAGAAAAGTTACCACAGGGATAAC-

GAGAGGTGTCAGAAAAGTTACCACAGGGATAACTGGCTTGTGGCGGCCAAGCGTTCATAG AAGAGGTGTCAGAAAAGTTACCACAGGGATAACTGGCTTGTGGCGGCCAAGCGTTCATAG GAGAGGTGTCAGAAAAGTTACCACAGGGATAACTGGCTTGTGGCGGCCAAGCGTTCATAG GAGAGGTGTCAGAAAAGTTACCACAGGGATAACTGGCTTGTGGCGGCCAAGCGTTCATAG GAGAGGTGTCAGAAAAGTTACCACAGGGATAACTGGCTTGTGGCGGCCAAGCGTTCATAG GAGAGGTGTCAGAAAAGTTACCACAGGGATAACTGGCTTGTGGCGGCCAAGCGTTCATAG GAGAGGTGTCAGAAAAGTTACCACAGGGATAACTGGCTTGTGGCGGCCAAGCGTTCATAG GAGAGGTGTCAGAAAAGTTACCACAGGGATAACTGGCTTGTGGCGGCCAAGCGTTCATAG GAGAGGTGTCAGAAAAGTTACCACAGGGATAACTGGCTTGTGGCGGCCAAGCGTTCATAG GAGAGGTGTCAGAAAAGTTACCACAGGGATAACTGGCTTGTGGCGGCCAAGCGTTCATAG GAGAGGTGTCAGAAAAGTTACCACAGGGATAACTGGCTTGTGGCGGCCAAGCGTTCATAG GAGAGGTGTCAGAAAAGTTACCACAGGGATAACTGGCTTGTGGCGGCCAAGCGTTCATAG GAGAGGTGTCAGAAAAGTTACCACAGGGATAACTGGCTTGTGGCGGCCAAGCGTTCATAG GAGAGGTGTCAGAAAAGTTACCACAGGGATAACTGGCTTGTGGCGGCCAAGCGTTCATAG GAGAGGTGTCAGAAAAGTTACCACAGGGATAACTGGCTTGTGGCGGCCAAGCGTTCATAG GAGAGGTGTCAGAAAAGTTACCACAGGGATAACTGGCTTGTGGCGGCCAAGCGTTCATAG 


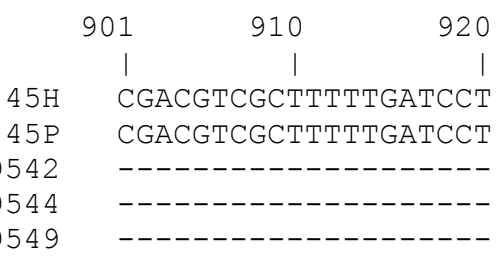

$\begin{array}{ll}\text { AF03954 } & ----------------- \\ \text { AF039549 -------------------- }\end{array}$

AF039551

AF 419118

AF 522247

CGACGTCGCTTTTTGATCCT

DQ343692

EF033610

CGACGTCGCTT---------

CGACGTCGCTTTTTGATCCT

CGACGTCGCTTTTTGATCCT

CGACGTCGCTTTTTGATCCT

CGACGTCGCTTTTTGATCCT

FJ848966 CGACGTCGCTTTTTGATCCT

FJ848974 CG06350 CGACGTCGCTTTTTGATCCT

GQ406351 CGACGTCGCTTTTTGATCCT

GU176299 CGACGTCGCTTTTTGATCCT

JF928825 CGACGTCGCTTTTTGATCCT

JN403057 CGACGTCGCTTTTTGATCCT

JN602193 CGACGTCGCTTTTTGATCCT

JN609255 CGACGTCGCTTTTTGATCCT

Y11508 CGACGTCGCTTTTTGATCCT 


\section{Appendix 8}

SSU alignment of Adelophycus corneus (AF515285), Ahnfeltia fastigiata (DQ343668), Asparagopsis taxiformis (AY772727), Asteromenia peltata (AY437710), Atractophora hypnoides (AY772728), Audouinella asparagopsis (AF079795), Audouinella caespitosa (AF079787), Audouinella dasyae (L26181), Balbiana investiens (AF132294), Ballia callitricha (AF236791), Balliopsis prieurii (AF419245), Batrachospermum brasiliense (FJ386470), Callophyllis rangiferina (U33123), Capreolia implexa (U60345), Champia parvula (EF613310), Chondrus yendoi (DQ316988), Crassitegula walsinghamia (AY964057), Cumagloia andersonii (DQ343669), Curdiea flabellata (L26207), Dilsea californica (U33126), Endocladia muricata (U33127), Erythrymenia minuta (AF085272), Farlowia mollis (U33129), Fauchea repens (AF085267), Galaxaura marginata (AF006090), Gelidium latifolium (Y11953), Gelidiopsis intricata (EF033594), Gloiopeltis furcata (U33130), Gloiosiphonia capillaris (AY437680), Gracilaria cliftonii (AY617146), Gracilaria gracilis (EU937742), Gracilariopsis lemaneinformis (L26214), Grateloupia intestinalis (AY437702), Haliptilon roseum (EF628229), Hildenbrandia angolensis (AF207833), Hildenbrandia rubra (L19345), Hydrolithon pachydermum (AY234235), Hypnea sp. (EU240869), Inkyuleea marina (AF236792), Isabbottia ovalifolia (EF033590), Kumanoa ambigua (FJ386481), Lesleigha sp. (AY437707), Lithophyllum sp. (AY083172), Lithothamnion glaciale (U60738), Mastophoropsis canaliculata (U62118), Meiodiscus spetsbergensis (U23814), Melanthalia obtusata (L26215), Nemalionopsis shawii (AF506272), Nizymenia australis (U09616), Palmaria palmata (Z14142), Peyssonnelia sp. (AY437688), Peyssonnelia rubra (DQ629016), Pihiella liagoraciphia (AY301992), Plocamium angustum (U09620), Polyopes constrictus 
(AY437705), Pyropia tenera (AB101442), Pterocladia lucida (G214, G214.2, U60349), Pterocladiella bartlettii (EF191192), Pterocladiophila hemisphaerica (45P, 45P.2, G215), Ptilonia australasica (AY437646), Ptilophora pinnatifida (U60345), Predaea sp. (AF515296), Renouxia sp. (EF033584), Rhodachlya madagascarensis (EU262260), Rhodymenia stenoglossa (AF515303), Thorea sp. (AF420253), Thorea violacea (AF342744), Titanophora weberae (AF515301), Trematocarpus fragilis (AY437696) and Wetherbeella australica (AF55290). Base pair differences are highlighted. 

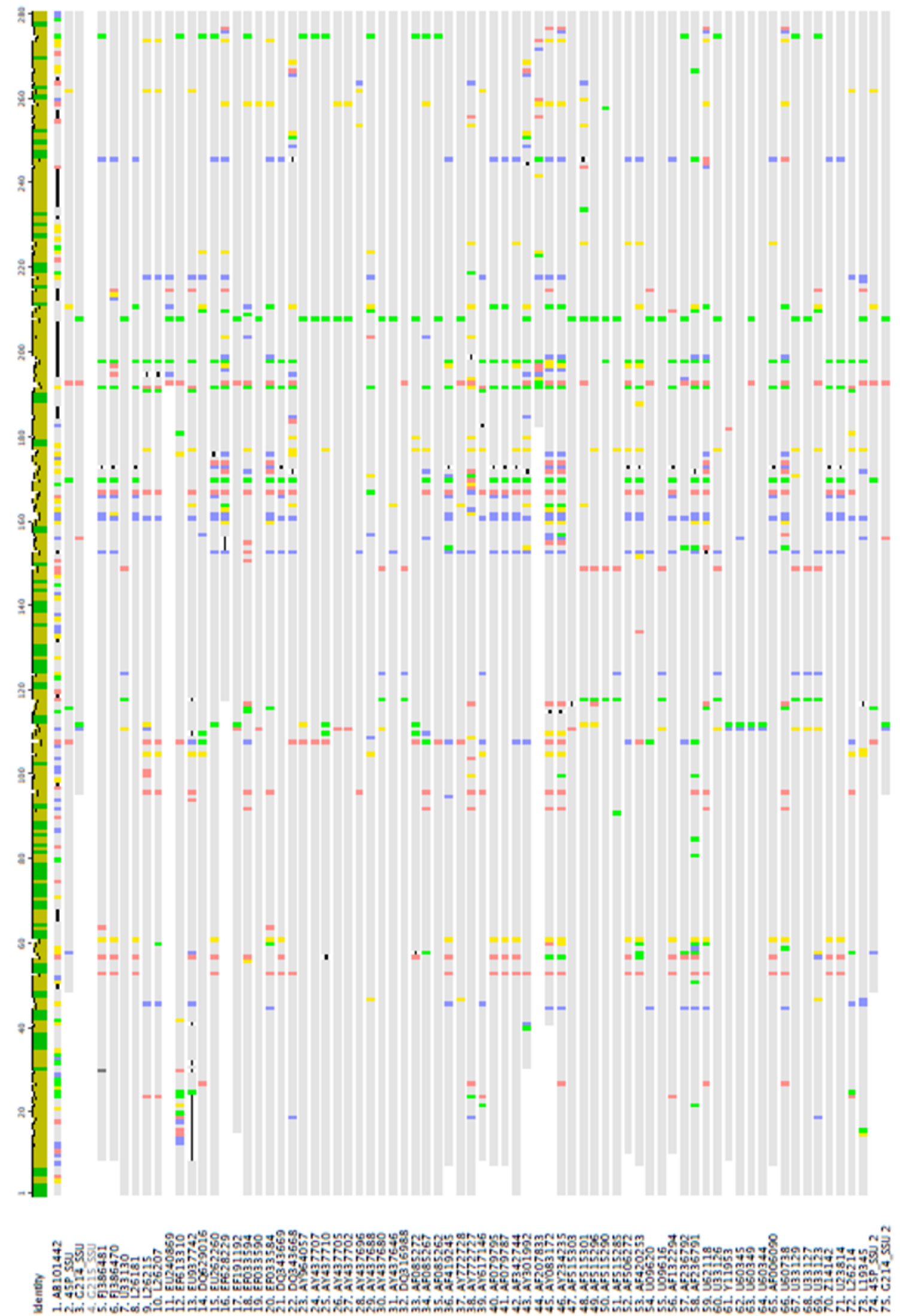


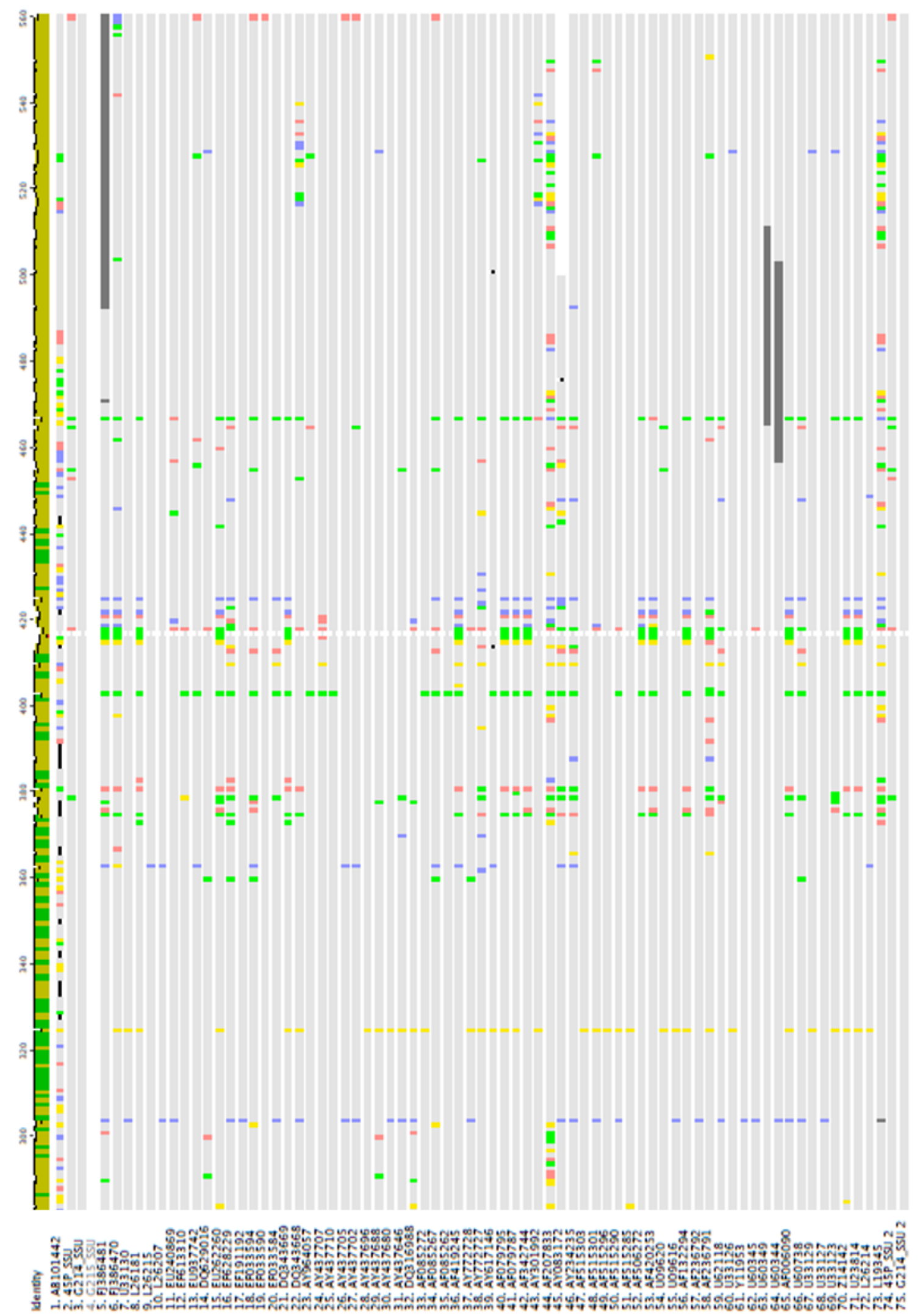



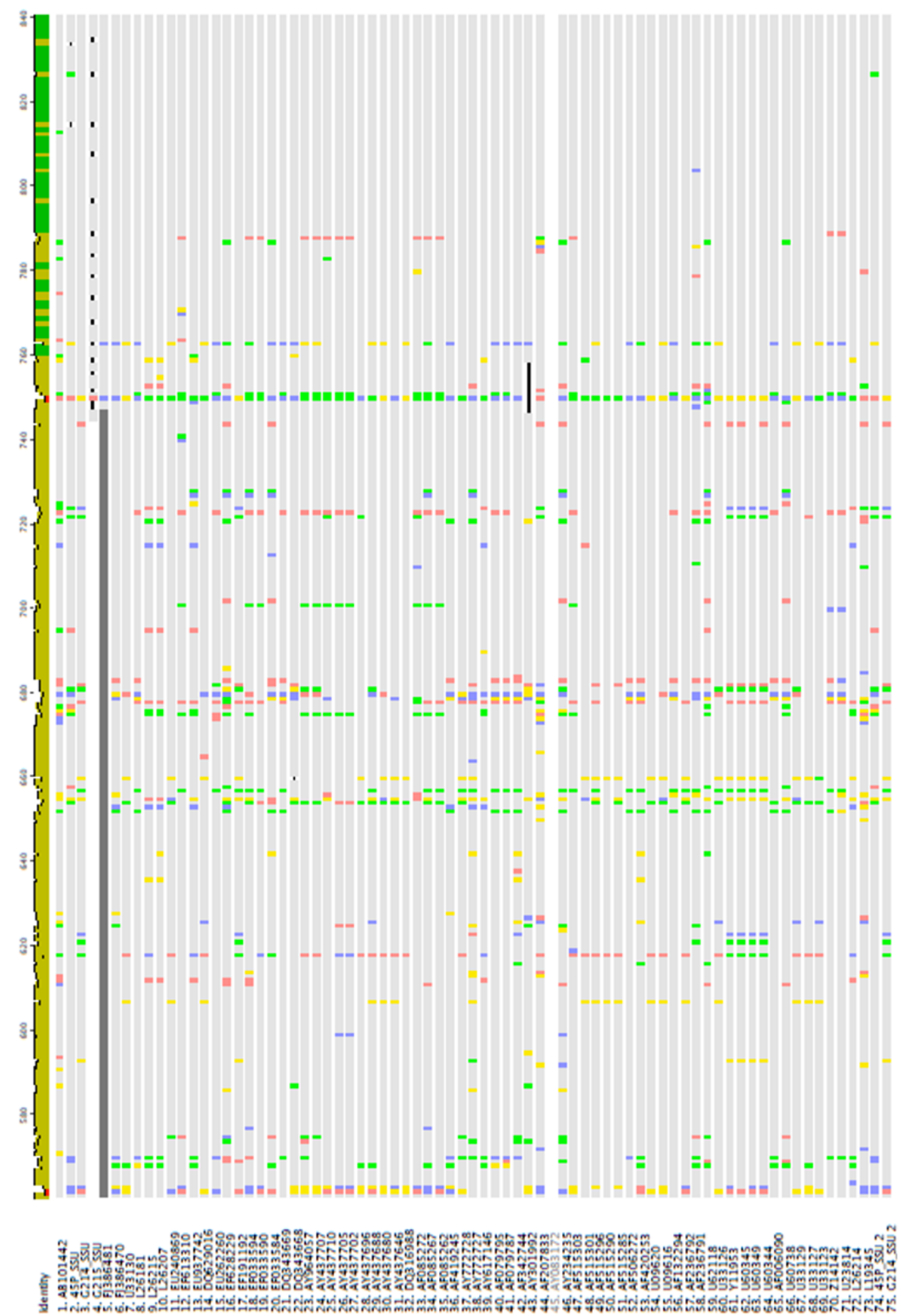

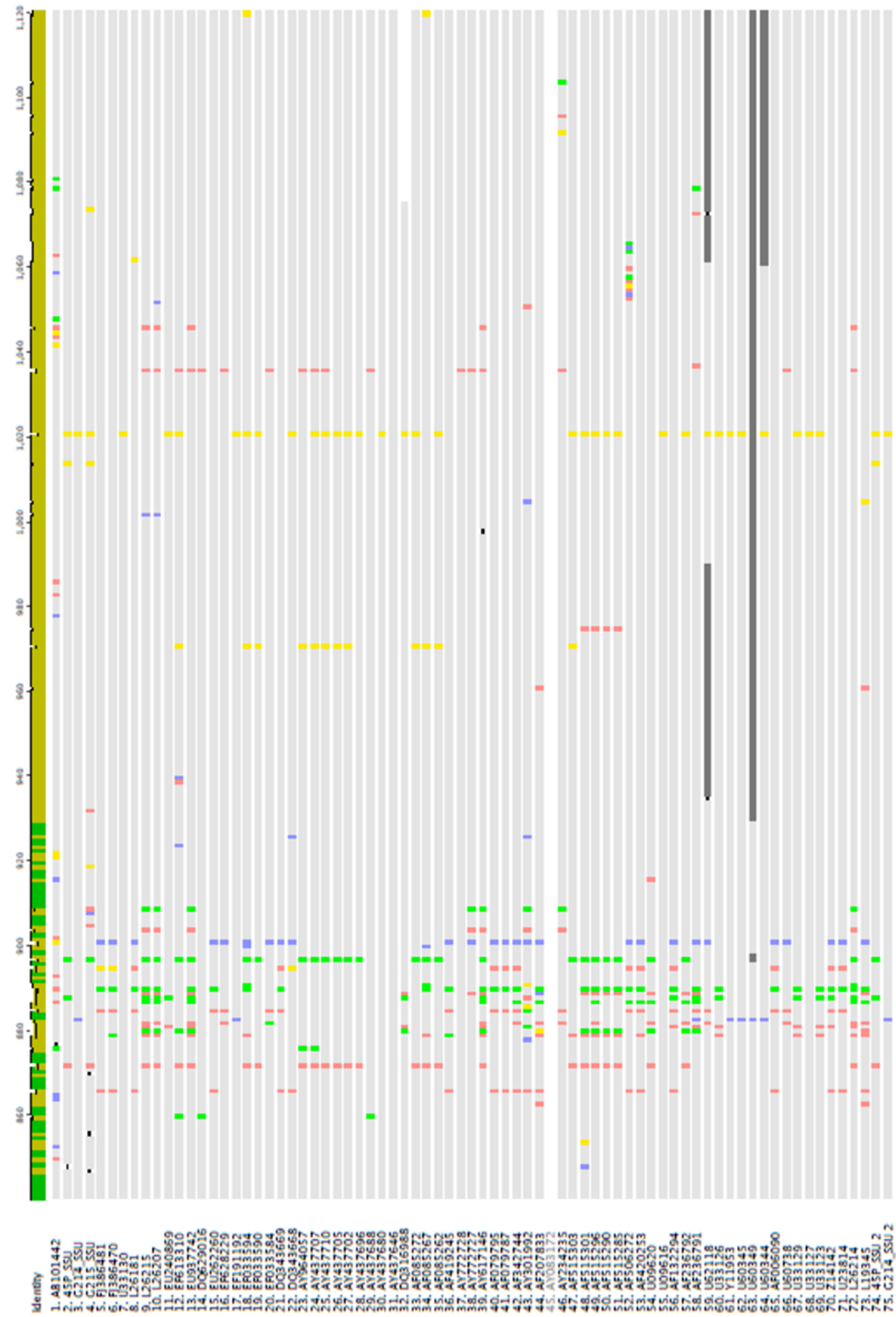


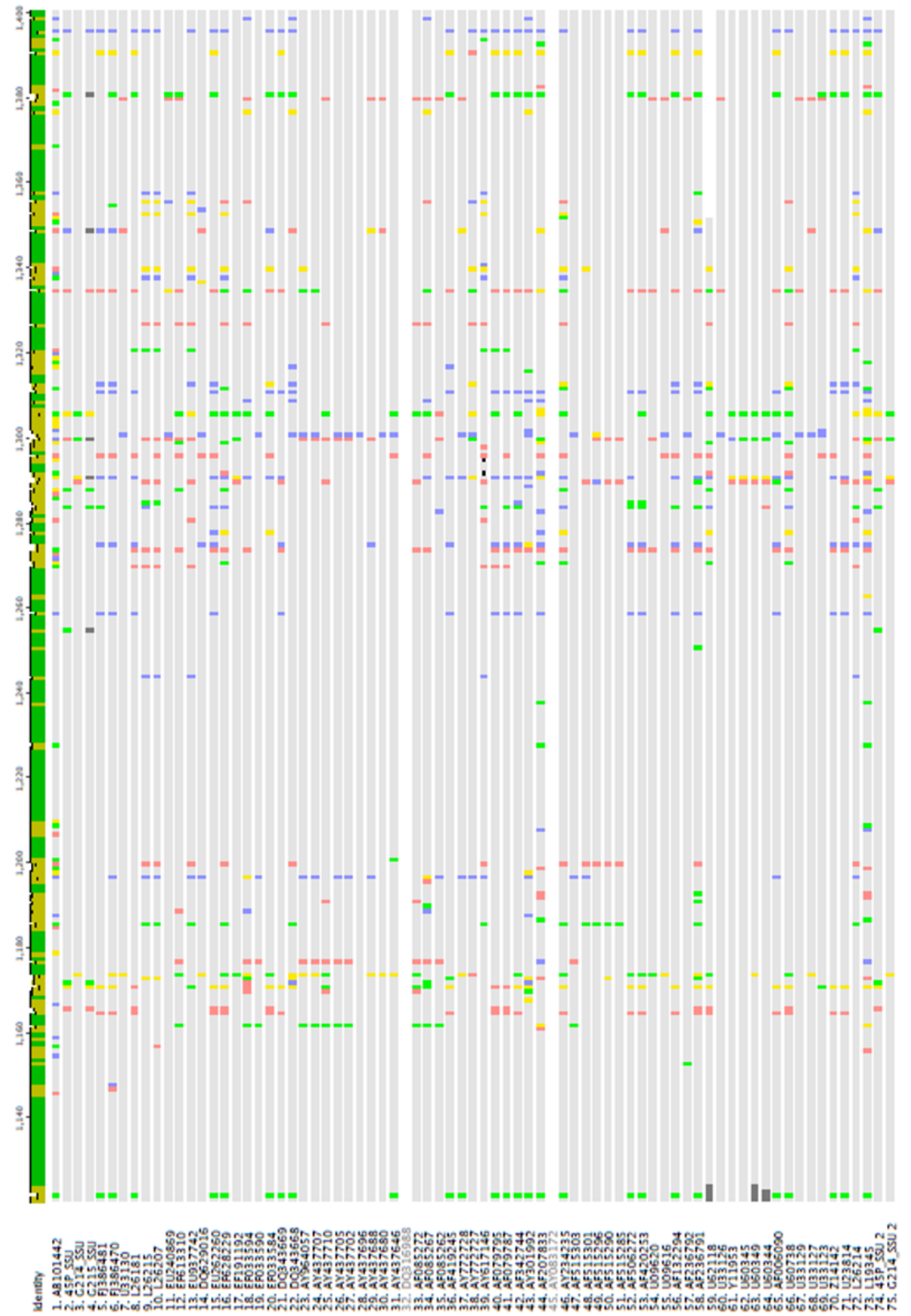



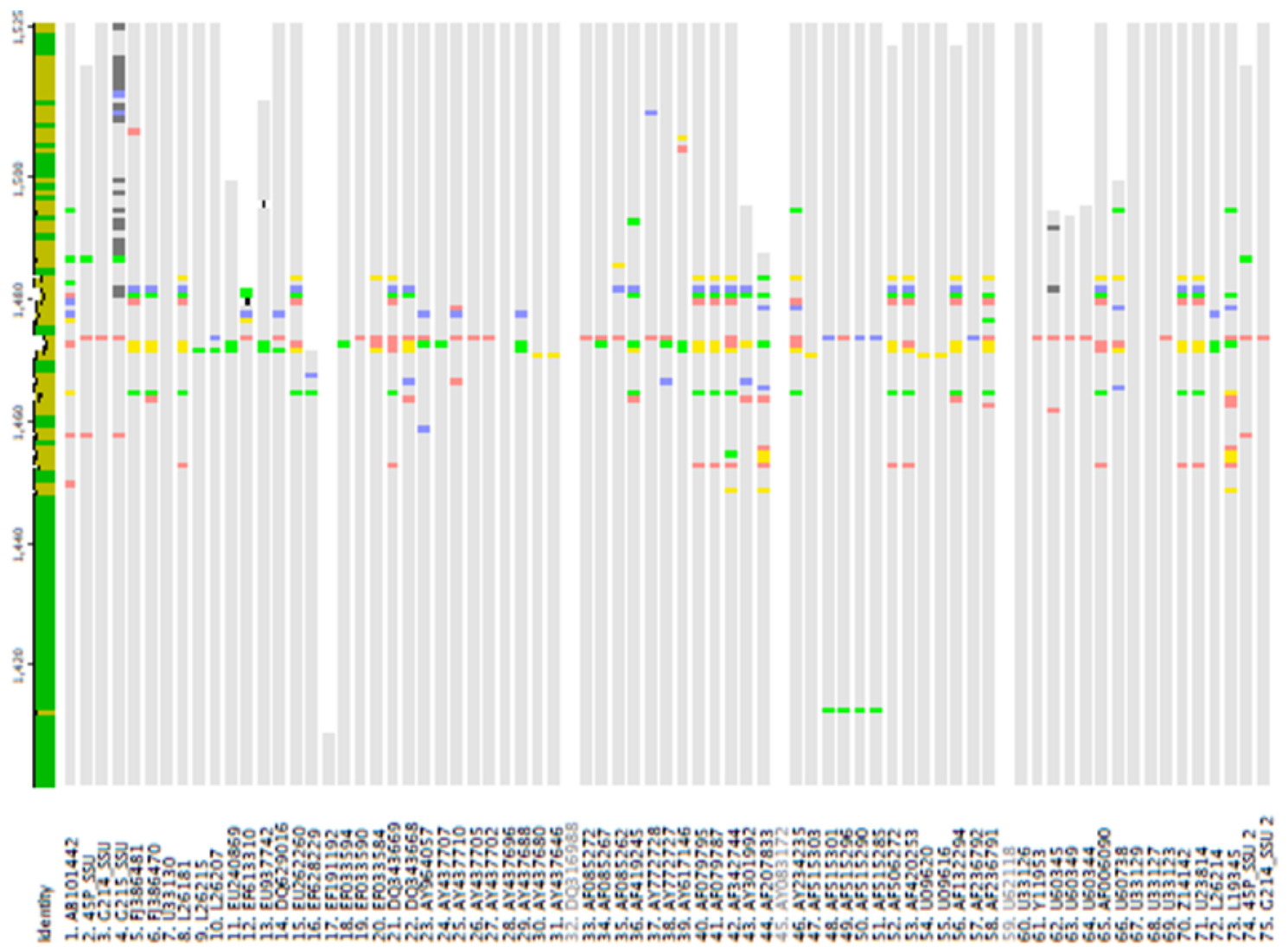


\section{Appendix 9}

Gene sequence for the atp 8 gene in Pterocladiophila hemisphaerica (45P). The open reading frame for the atp 6 gene is indicated in yellow and for the atp 8 gene in blue.

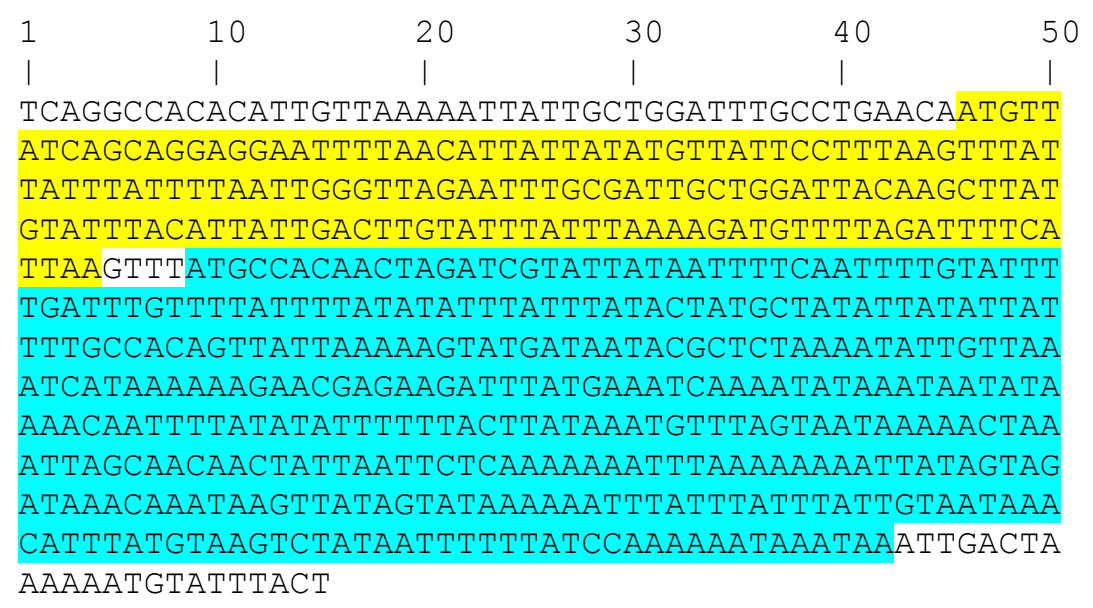




\section{Appendix 10}

Alignment of the gene sequence for the atp 8 gene in Pterocladia lucida $(45 \mathrm{H}$,

$46 \mathrm{H}, \mathrm{G} 214)$. The open reading frame for the atp 6 gene is indicated in yellow, for the atp 8 gene in blue and for the nad5 gene in green.
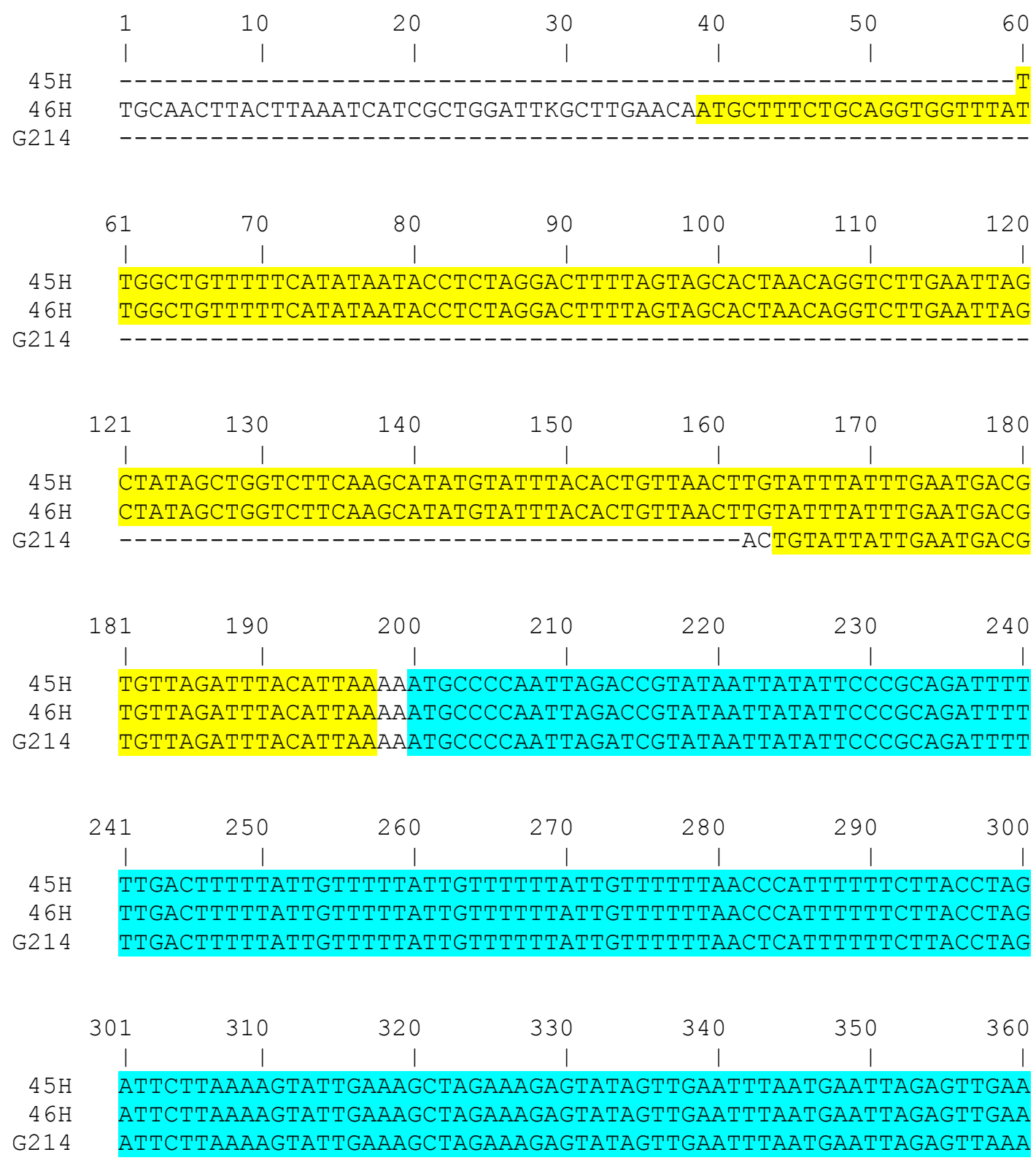


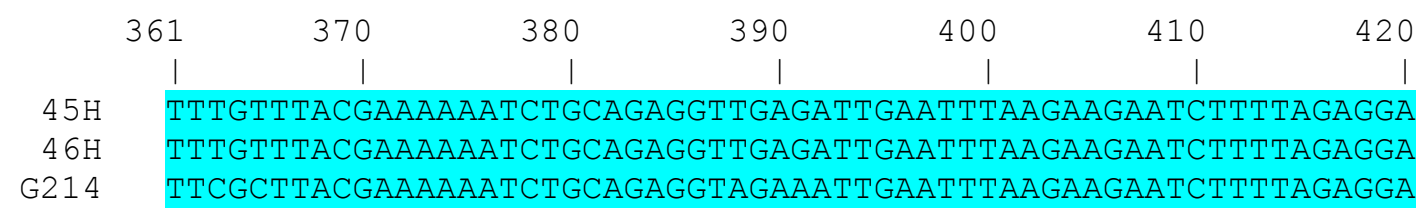

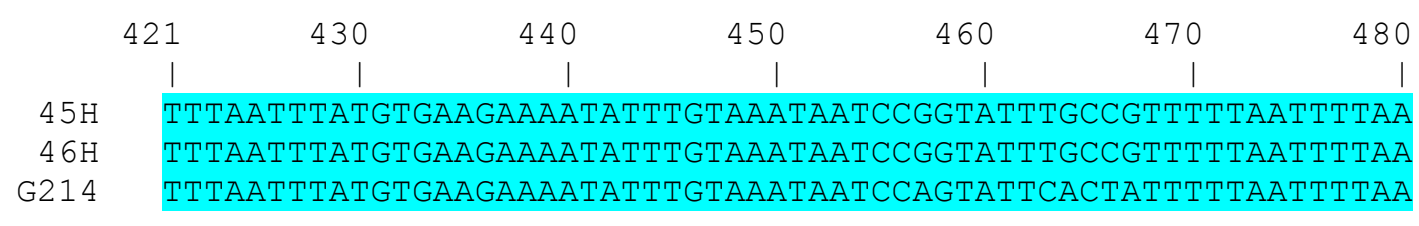

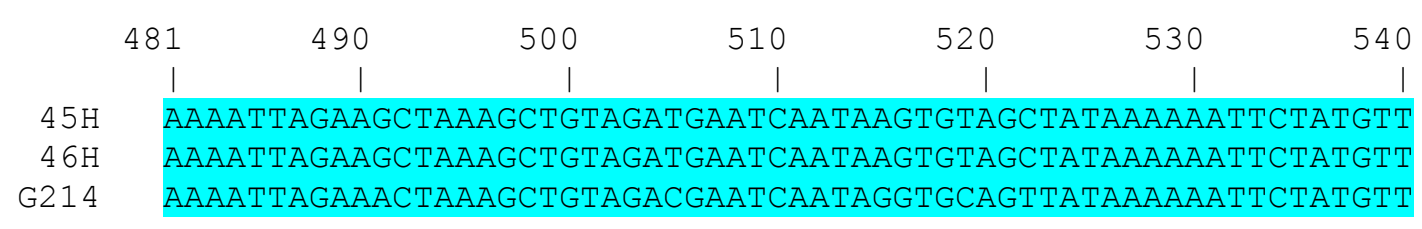

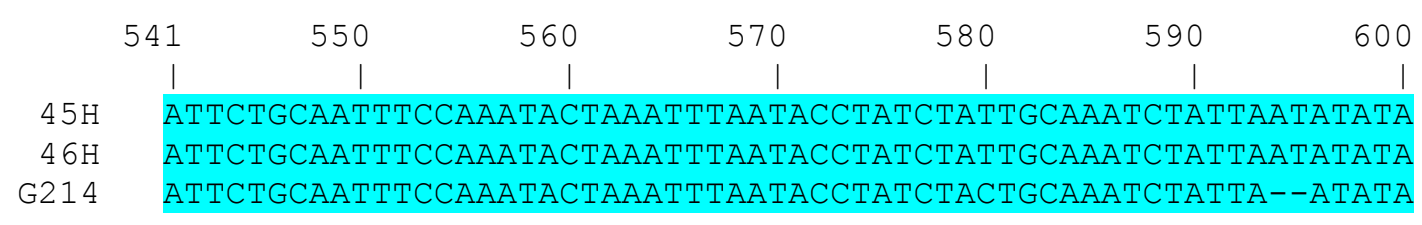

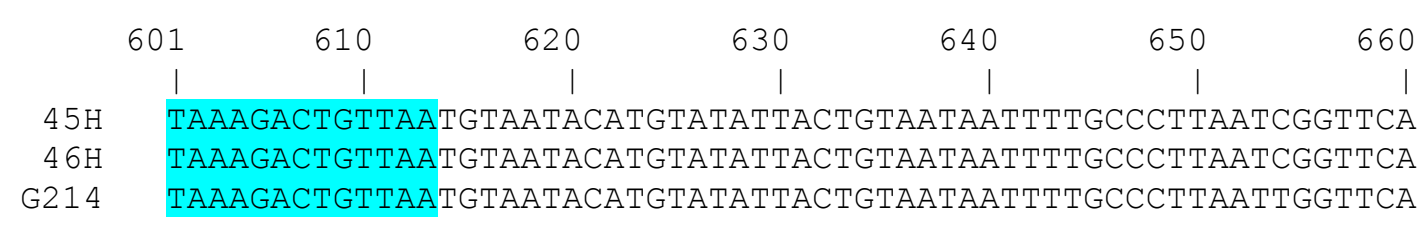

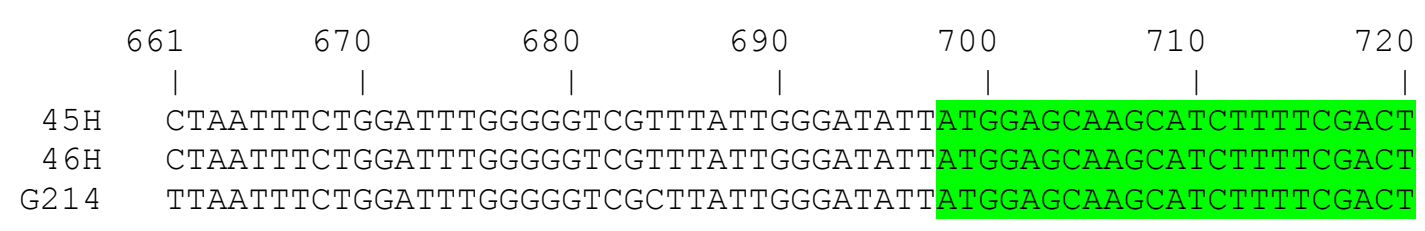

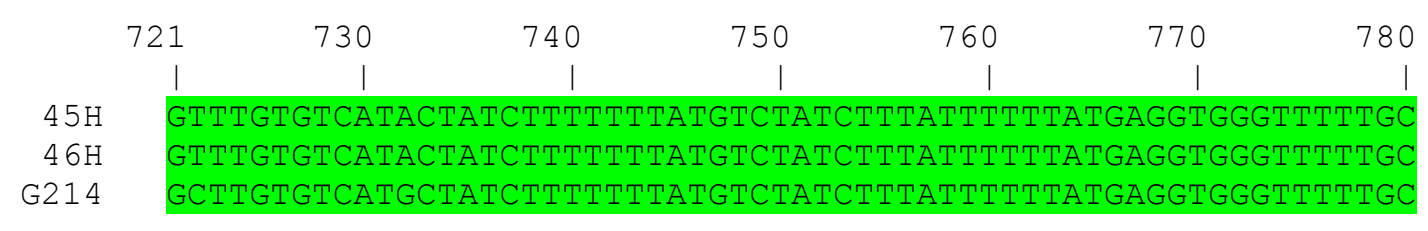

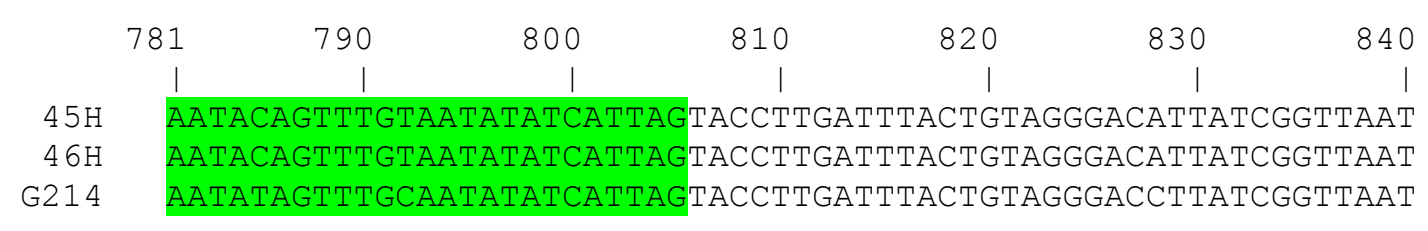




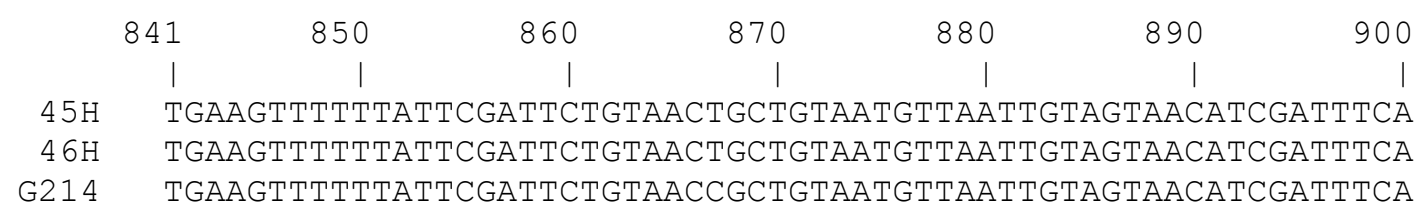

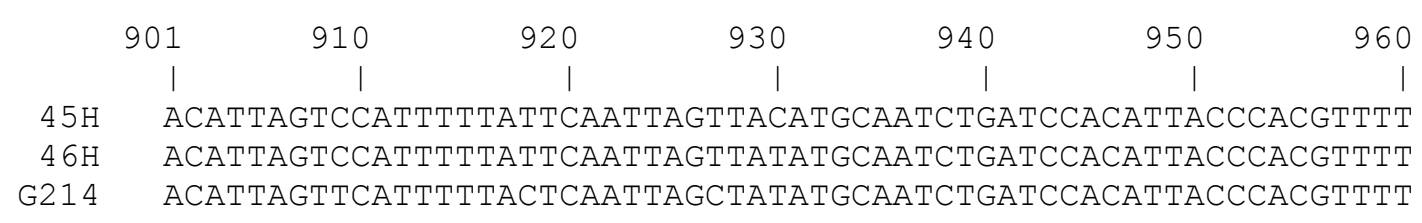

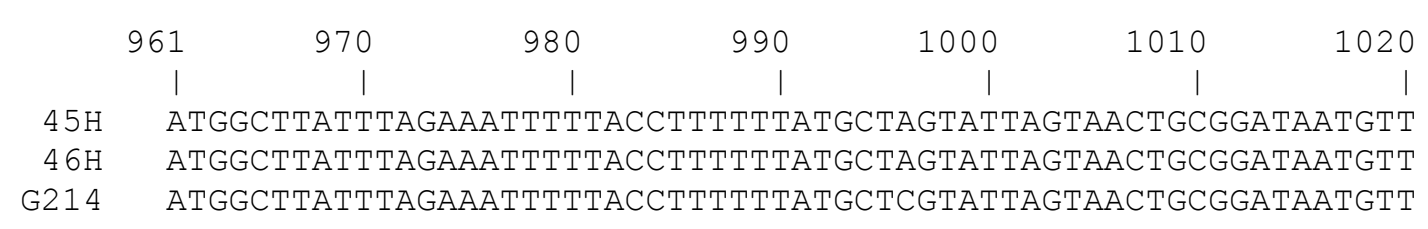

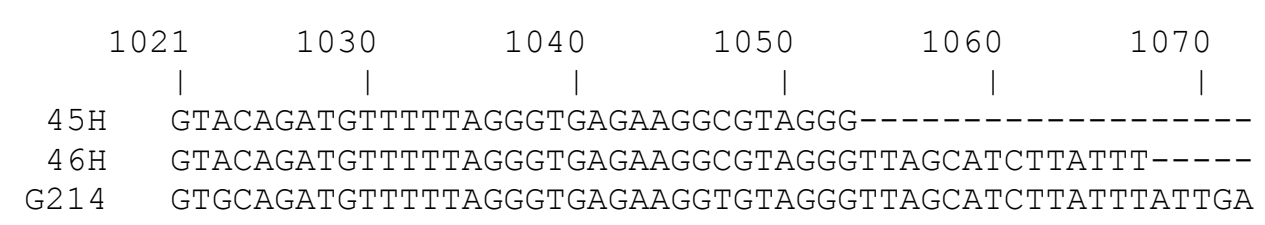

